\title{
Role of automated patch-clamp systems in drug research and development
}

Péter Orvos, M.Sc.

Ph.D. Thesis

Szeged, Hungary 


\title{
Role of automated patch-clamp systems in drug research and development
}

\author{
Péter Orvos, M.Sc.
}

Ph.D. Thesis

Doctoral School of Multidisciplinary Medical Science

Supervisor: László Virág, Ph.D.

Department of Pharmacology and Pharmacotherapy Faculty of Medicine, University of Szeged

Szeged, Hungary 


\section{LIST OF STUDIES RELATED TO THE SUBJECT OF THE DISSERTATION}

I. Effects of Chelidonium majus extracts and major alkaloids on hERG potassium channels and on dog cardiac action potential - a safety approach.

Orvos P, Virág L, Tálosi L, Hajdú Z, Csupor D, Jedlinszki N, Szél T, Varró A, Hohmann J.

Fitoterapia. 2015 Jan; 100:156-65.

IF: 2.345 [2014]

II. Inhibition of $\mathbf{G}$ protein-activated inwardly rectifying $\mathbf{K}^{+}$channels by extracts of Polygonum persicaria and isolation of new flavonoids from the chloroform extract of the herb.

Lajter I, Vasas A, Orvos P, Bánsághi S, Tálosi L, Jakab G, Béni Z, Háda V, Forgo P, Hohmann J.

Planta Med. 2013 Dec; 79(18):1736-41.

IF: 2.339

III. Identification of diterpene alkaloids from Aconitum napellus subsp. firmum and GIRK channel activities of some Aconitum alkaloids.

Kiss T, Orvos P, Bánsághi S, Forgo P, Jedlinszki N, Tálosi L, Hohmann J, Csupor D. Fitoterapia. 2013 Oct; 90:85-93.

IF: 2.216

\section{OTHER STUDIES}

I. Electrophysiological effects of ivabradine in dog and human cardiac preparations: potential antiarrhythmic actions.

Koncz I, Szél T, Bitay M, Cerbai E, Jaeger K, Fülöp F, Jost N, Virág L, Orvos P, Tálosi L, Kristóf A, Baczkó I, Papp JG, Varró A.

Eur J Pharmacol. 2011 Oct 15; 668(3):419-26.

IF: 2.516 


\section{TABLE OF CONTENTS}

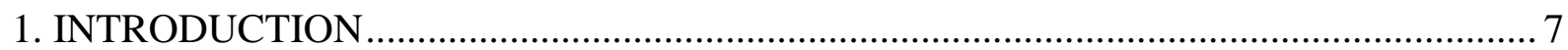

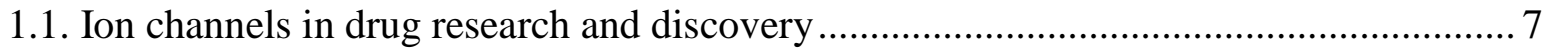

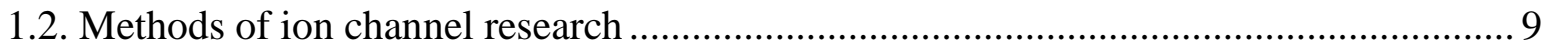

1.2.1. Conventional intracellular techniques ................................................................ 9

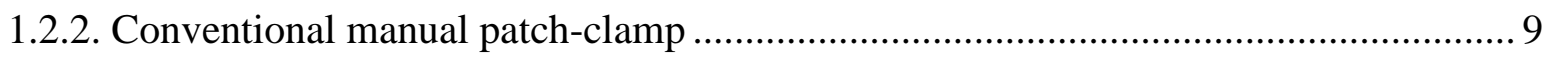

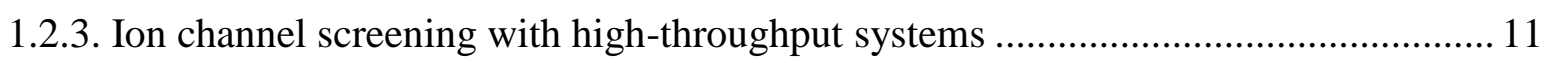

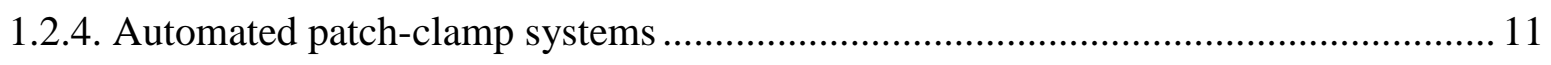

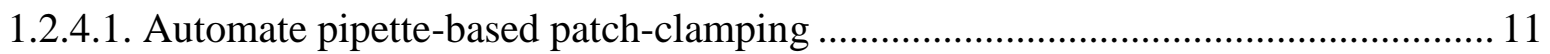

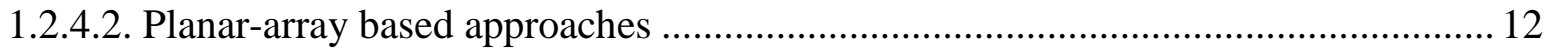

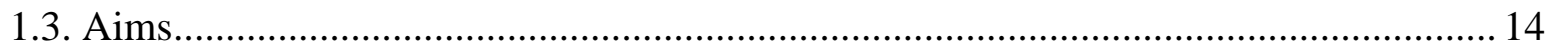

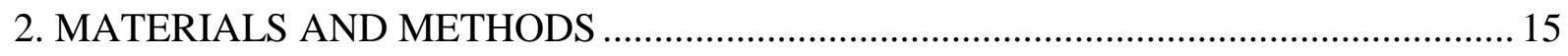

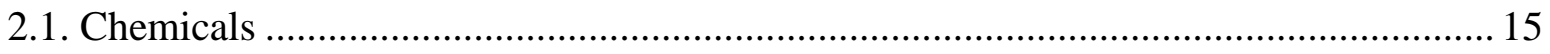

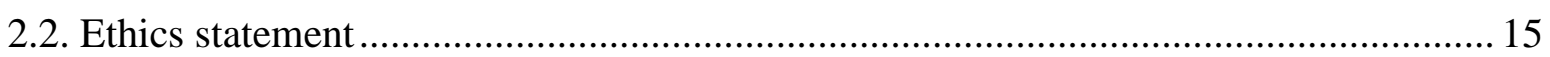

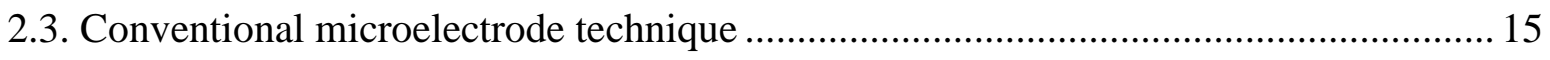

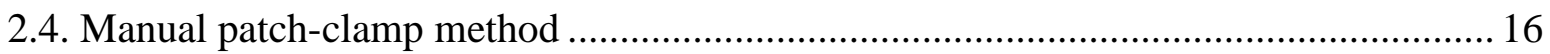

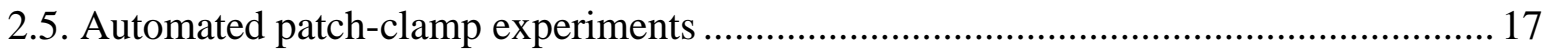

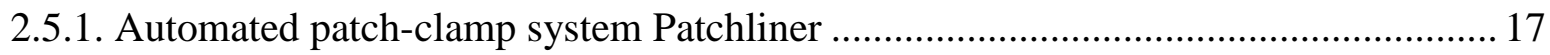

2.5.2. Cells and electrophysiology used for automated patch-clamp measurements ........... 17

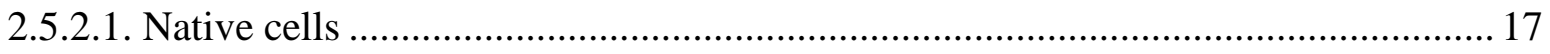

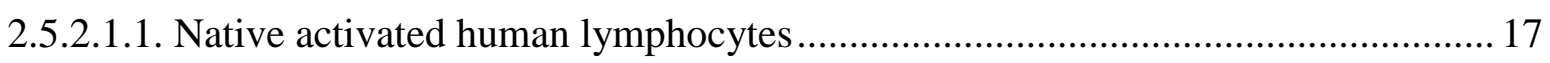

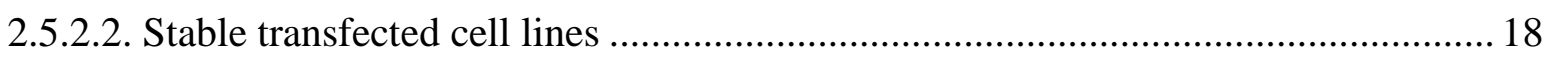

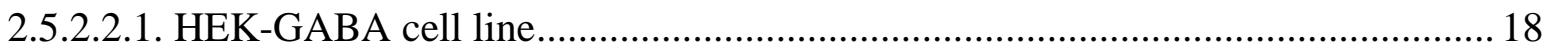

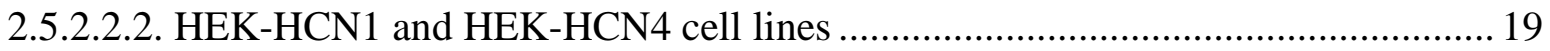

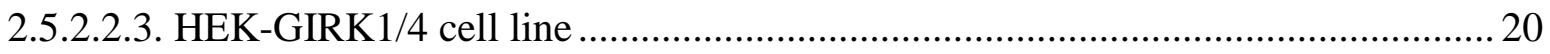

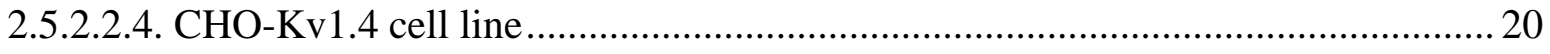

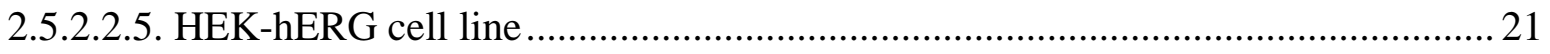

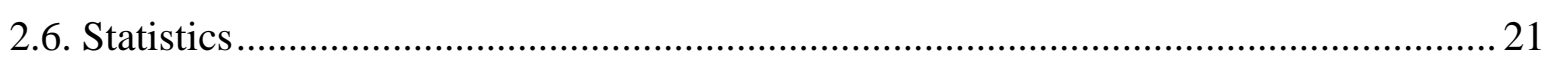

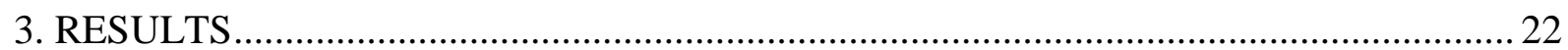

3.1. Evaluation and characterization of different cell lines with Patchliner........................ 22

3.1.1. Evaluation and characterization of $\mathrm{Kv} 1.3 \mathrm{~K}^{+}$channel in native activated human

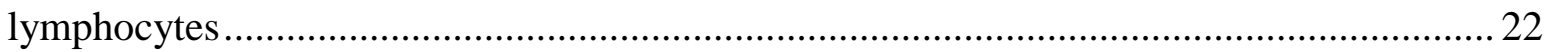

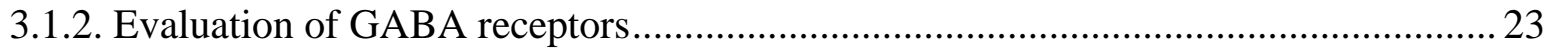

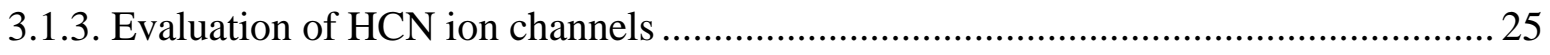

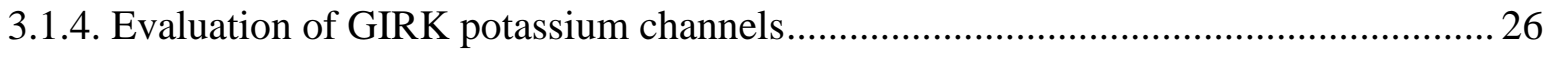

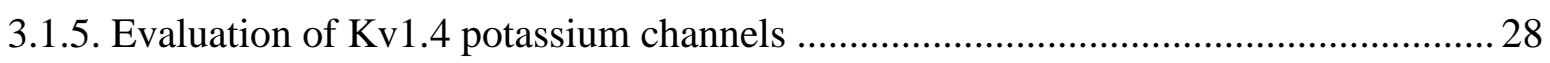


3.1.6. Evaluation of hERG potassium channels

3.2. Screening projects: Investigation of ion channel modulator capability of compounds with automated patch-clamp equipment

3.2.1. Screening of preselected chemical libraries on GIRK channel ................................ 29

3.2.2. Screening of different substrates originated from plants on GIRK channel............... 32

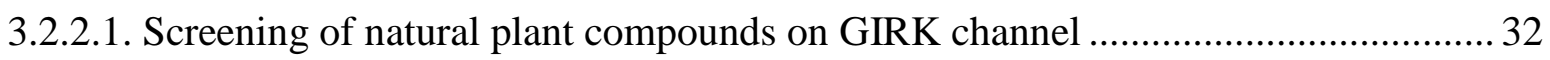

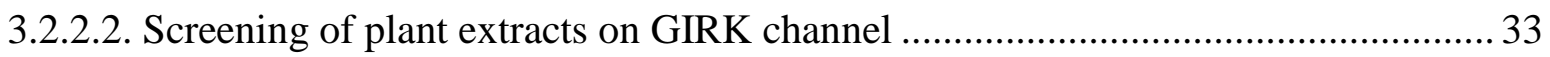

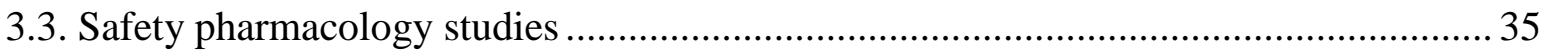

3.3.1. Assessment of hERG assay performed with automated patch-clamp system in the safety evaluation of investigational compounds....

3.3.2. Effects of Chelidonium majus extracts and major alkaloids on hERG ion channel and

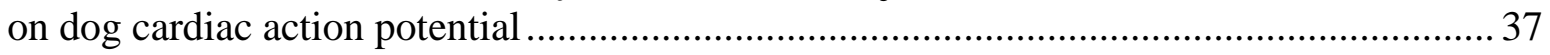

3.3.2.1. Effects of extracts and alkaloids of Chelidonium majus on hERG current ............. 38

3.3.2.2. Effects of extracts and alkaloids of Chelidonium majus on ventricular action

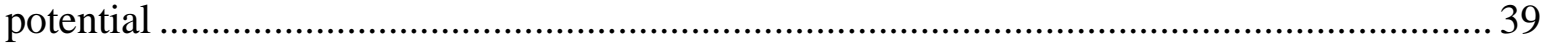

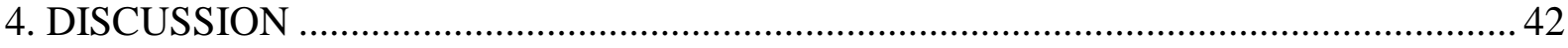

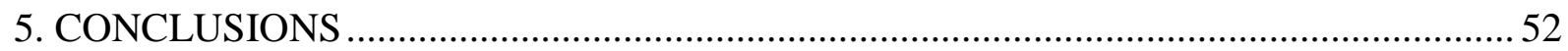

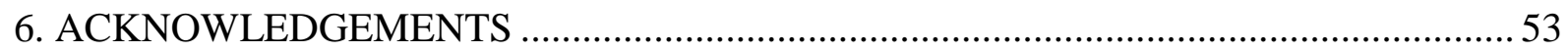

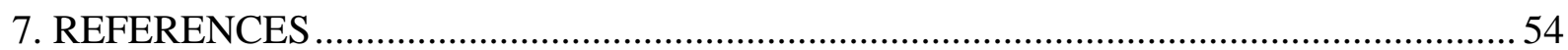




\section{ACRONYMS AND ABBREVIATIONS}

\begin{tabular}{|c|c|}
\hline AnTx & anuroctoxin \\
\hline APA & action potential amplitude \\
\hline $\mathbf{A P D}_{\mathbf{5 0}}$ & action potential duration measured at $50 \%$ of repolarization \\
\hline $\mathbf{A P D}_{90}$ & action potential duration measured at $90 \%$ of repolarization \\
\hline C. majus & Chelidonium majus \\
\hline CHO-K1 & Chinese hamster ovary $\mathrm{K} 1$ cell line \\
\hline DEA & desethylamiodarone \\
\hline DMEM & Dulbecco's modified Eagle's medium \\
\hline DMSO & dimethyl sulfoxide \\
\hline $\mathbf{E C}_{50}$ & half maximal effective concentration \\
\hline EDTA & ethylenediaminetetraacetic acid \\
\hline EGTA & ethylene glycol tetraacetic acid \\
\hline FBS & fetal bovine serum \\
\hline GABA & gamma-aminobutyric acid \\
\hline GIRK & G protein-coupled inwardly rectifying potassium channel \\
\hline GTP $\gamma \mathrm{S}$ & guanosine-5'-( $\gamma$-thio)-triphosphate \\
\hline HEK293 & human embryonic kidney 293 cell line \\
\hline HEPES & 4-(2-hydroxyethyl)-1-piperazineethanesulfonic acid \\
\hline HCN & hyperpolarization-activated cyclic nucleotide-gated channel \\
\hline hERG & human ether-a-go-go-related gene \\
\hline $\mathbf{I}_{\mathbf{C a}, \mathbf{L}}$ & L-type $\mathrm{Ca}^{2+}$ current \\
\hline $\mathbf{I}_{\mathbf{f}}$ & funny or pacemaker current \\
\hline $\mathbf{I}_{\text {KACh }}$ & acetylcholine receptor operated potassium current \\
\hline $\mathbf{I}_{\mathbf{K r}}$ & rapid delayed rectifier potassium current \\
\hline $\mathbf{I}_{\mathbf{K s}}$ & slow component of the delayed rectifier potassium current \\
\hline $\mathbf{I}_{\text {to }}$ & transient outward potassium current \\
\hline $\mathbf{I C}_{\mathbf{5 0}}$ & half maximal inhibitory concentration \\
\hline IMDM & Iscove's modified Dulbecco's medium \\
\hline MEM & minimum essential medium \\
\hline MgTx & margatoxin \\
\hline PBS & phosphate buffered saline \\
\hline TEA & tetraethylammonium \\
\hline $\mathbf{R P}$ & resting potential \\
\hline RPMI 1640 & Roswell Park Memorial Institute 1640 medium \\
\hline RP-silica gel & reversed-phase silica gel \\
\hline RP-HPLC & reversed-phase high-performance liquid chromatography \\
\hline RT & room temperature \\
\hline $\mathbf{V}_{\text {max }}$ & maximum upstroke velocity \\
\hline
\end{tabular}




\section{INTRODUCTION}

\subsection{Ion channels in drug research and discovery}

Ion channels are a large and diverse family of transmembrane pore-forming proteins present in a large variety of cell types [1][2][3][4][5][6][7]. They facilitate the rapid passive transport of specific inorganic ions (such as $\mathrm{Na}^{+}, \mathrm{K}^{+}, \mathrm{Ca}^{++}$and $\mathrm{Cl}^{-}$) through the lipid bilayers of plasma and organelle membranes down their electrochemical gradient that is established by the work of pumps and transporters [1][5][6][7][8][9].

Defined by the stimulus necessary to evoke activity, the majority of ion channels are commonly classified into two main subgroups: voltage-gated and ligand-gated channels. The most important difference is that voltage-gated ion channels are activated by changes in plasma membrane potential, while ligand-gated channels activated by endogenous ligands [3][4][5][10]. In addition, there are ion channels activated by mechanic force and hot or cold stimuli [3][4][5]. Ion channels are also grouped into various subclasses by another key functional characteristic, their selective permeability to different ions [7][8][11]. Voltagegated ion channels are rather specific for the various cations and anions. Therefore, these channels are typically named after the ion for which they are selective for. Ligand-gated ion channels are regularly named after the ligand essential for their activation [4].

A functional ion channel consists of one or more $\alpha$-subunits, forming an aqueous pore. Auxiliary $\beta$ and $\gamma$ subunits associate with the $\alpha$-subunits and modify their properties including gating, membrane surface expression, pharmacology and selectivity. The number of identified proteins that create the ion permeation pathways is around 300. The typical heteromultimeric assembly of the pore-forming subunits further elevates the number of possible combinations. In addition, more than 100 auxiliary proteins are known up to date. The heteromultimeric $\alpha$-subunits and their association with various auxiliary subunits together can give rise to a very large number of functional ion channel protein complexes [5][7][9][10][11].

Ion channels regulate a variety of physiological processes. They provide the base for membrane excitability thus they are prominent components of both the nervous and the cardiovascular system. Ion channels determine excitability of neurons and muscles by controlling the creation and propagation of action potentials, release of neurotransmitters, and setting up cardiac rhythm and muscle tone. In non-excitable cells, they play fundamental roles in hormone secretion, enzyme activation, gene expression, immune response and in cell replication, development and volume regulation [1][4][5][7][8][11][12]. 
Because of their pivotal role, ion channel dysfunction has adverse effects on physiology, and could lead to many severe chronic and acute diseases and disorders, so-called channelopathies. Since the diversity of ion channels is extremely high in excitable cells, including heart, skeletal, and smooth muscles as well as in the central and peripheral nervous system, most of channelopathies have been identified in these tissues. Functional abnormalities of ion channels are known to cause cardiovascular dysfunctions (such as lifethreatening cardiac arrhythmias and hypertension) and neurological disorders (multiple sclerosis, epilepsy, migraine, schizophrenia, depression, neuropathic pain and diabetic neuropathy). Additional examples of channelopathies are cystic fibrosis, kidney malfunction and type II diabetes [2][3][4][5][7][8][9][11]. Furthermore, each year more and more ion channels are identified and linked to diseases [10].

Most of these common diseases are primarily treated by drugs that pharmacological modulate ion channel functions, therefore ion channels represent a highly attractive class of molecular targets for both academic research and pharmaceutical industry [1][2][7][9]. As membranebound proteins they are accessible for small molecule treatment and are highly 'druggable' targets. This is primarily due to the various binding sites and many possible interactions that the ion channels offer. Ion channels currently represent the third largest target class of pharmaceutical agents (only overtaken by G-protein coupled and nuclear receptors). Approximately $13-15 \%$ of the top selling drugs on the market exert their effects through ion channels, reflecting their importance [1][3][4][5][9][10][11][12]. Within the pharmaceutical and biotechnology industry today, enormous efforts and resources are spent on ion channel drug screening, to discover and develop new and more effective medications [4].

Another important aspect of drug development programmes and ion channel drug screening is the safety evaluation of potential candidate molecules to assess possible adverse drug effects. Particularly important are the possibility of cardiovascular side effects, since several compounds exert their arrhythmogenic effects through the ion channel encoded by the human ether-a-go-go-related gene (hERG), expressed in cardiac ventricular myocytes, which has shown to be extremely promiscuous in its interactions with drugs. The inhibition of hERG channel may delay cardiac action potential repolarization, which can result in the prolongation of the QT interval on the ECG and increase the risk of potentially fatal ventricular arrhythmias, which had been the reason for the withdrawal of several would-be 'blockbuster' drugs from the market. At present, every new drug must go through preclinical safety testing determined by the U. S. Food and Drug Administration, the European Medicines Agency and other regulatory entities [1][2][4][7][12][13][14]. 


\subsection{Methods of ion channel research}

Despite their physiological importance and therapeutic relevance, ion channels remained an underexploited drug target class for a long time. Ion channels have historically been difficult to screen due to the limitations of methods. The available assay technologies cannot provide simultaneously the throughput and quality of data and put a trade-off between highthroughput and high-information content [1][5][10][11][12].

\subsubsection{Conventional intracellular techniques}

Conventional intracellular recordings involve a group of methods used to measure with accuracy the voltage across the cellular membranes by inserting an electrode inside the cell. Intracellular recordings can be performed with glass microelectrodes filled with conductive medium inserted through the membrane with negligible damage to the interior of the cell. This makes it possible to record the potential difference between the intracellular milieu and an extracellular reference point [15], presented on Figure 1A. However, electrophysiological techniques impaling a cell with a fine electrode can directly measure only the transmembrane voltage and its changes called action potential, but not the current flow through individual ion channels which serve as the basis of the transmembrane potential changes.

A

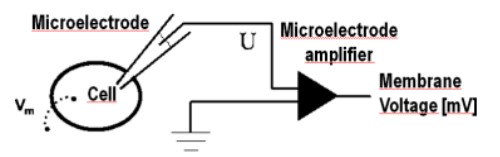

B

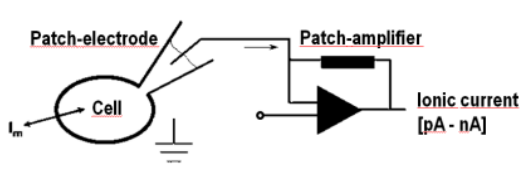

C

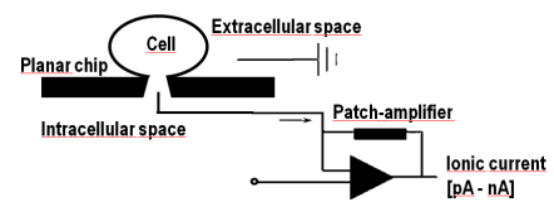

Figure 1. Schematic drawing of different electrophysiological techniques. Panel A shows the intracellular method which used to record the transmembrane potential by inserting a glass microelectrode into a cell and recording the potential changes with respect to an extracellular reference electrode. Panel B presents the classical patchclamp configuration uses a micropipette attached to the cell membrane. In whole-cell configuration, by applying brief suction, the patch of membrane covering the pipette tip can be ruptured and currents can be measured from the entire ion channel population. Planar patch-clamp (panel $\mathbf{C}$ ) is a novel method developed for high-throughput electrophysiology. Instead of positioning a pipette on an adherent cell, cell suspension is pipetted on a chip containing a microaperture where the cell is positioned by suction.

\subsubsection{Conventional manual patch-clamp}

Transmembrane ionic currents have been measured since 1952 after the pioneering work of Hodgkin and Huxley [16][17][18][19][20] who were awarded by Nobel Prize in 1963 [21]. 
However, it was not possible to use their methods for voltage-clamp experiments in most tissues because the cells are too small. Today, ion channels are most precisely studied using the conventional patch-clamp technique. By this method, measurement of the activity of individual channels or the entire ion channel population of the cell became possible. The wellestablished patch-clamp method developed by Erwin Neher and Bert Sakmann in the late 1970s [22][23] (Nobel prize in 1991 [24]). The patch-clamp technique has rapidly become the 'gold standard' in studying ion channel behaviour, function, kinetics and pharmacology in vitro, both in native or cultured mammalian cells [2][3][5][7][9][10][12][25].

A borosilicate glass microelectrode was patched onto the surface of a single cell and the ionic current passing through the enclosed ion channels in the plasma membrane was measured. The key requirement for performing such recordings is to form a 'gigaseal', where 'giga' denotes the extremely resistive tight interaction (several gigaohm) that is formed between the microelectrode and the lipid membrane, which enables fine quality recording of currents with high signal-to-noise ratio [1][2][3][4][12]. Neher and Sakmann accomplished their experiments in the cell-attached configuration in order to study the behaviour of single channels. However, by applying brief suction after the gigaohm seal is achieved, the patch of membrane covering the pipette tip can be ruptured, resulting in the most popular whole-cell configuration of patch-clamping. The direct access to the interior of the cell enables for voltage control of the cell membrane and allows modulating the intracellular environment. In this configuration, currents are measured from the entire ion channel population present in the cell membrane (Figure 1B). Voltage protocols and administration of drugs are tools used to analyse and characterize the ion channels expressed in a cell [2][4].

The patch-clamp is the only method which offers a direct, information-rich and real-time technology to study ion channel behaviour, function and regulation. Although providing excellent data quality, conventional patch-clamp also has disadvantages. Throughput in manual patch-clamp suffers severely from its laborious nature. It requires the continuous presence of a highly skilled, trained and patient operator. The fact that it takes years to acquire the soft skills necessary for operating the system also needs to be considered. These factors lead to the increase in price of data points. The typical throughput of conventional patchclamping is approximately five to ten data points per day allowing the characterization of only a limited number of compounds per week. This very low data throughput excludes manual patch-clamp as a screening tool in early drug development and optimization, since in these drug screening phases require a much greater throughput [1][2][3][4][7][9][10]. 


\subsubsection{Ion channel screening with high-throughput systems}

Due to the limitations in throughput of manual patch-clamp, high-throughput techniques are also required and become integral components for primary drug screening and ion channel drug discovery programmes. These methodologies are based on cell-free, non-functional ligand binding or cell-based, functional radioactive flux and fluorescence (ion- or voltagesensitive dyes) assays. Although these approaches are compatible with the throughput requirements of primary screening and have been useful in supporting the efforts to identify and profile compounds, the high data quality was sacrificed to gain high throughput. Most of these methods have low fidelity, low sensitivity and low temporal resolution. High-throughput techniques often require extensive assay development and are known to have high rates of false-negative and false-positive results. Some techniques are not suitable for measurements on all ion channels since in several cases the readout is coupled to specific ion species, like calcium-sensitive dyes while other methods like the rubidium efflux assay require the use of radioactive compounds. Lacking voltage control over the cell membrane sometimes offer a challenge to investigate the channels activated by the change in transmembrane voltage. On the positive side, these assay techniques allow the screening of up to 100.000 compounds or more in a limited time frame and require less specialized operators [2][3][4][5][7][9][10][11].

\subsubsection{Automated patch-clamp systems}

In recent years, numerous companies have developed and introduced automated patch-clamp platforms suitable for rapid and high quality screening and optimization of ion channel drug candidates. This new technology aims to extract functional data on ion channel active compounds with the throughput capability that is 10 - to 10.000 -fold higher compared to conventional patch-clamp technique, depending on the platform used [1][2][3][4][10][12].

\subsubsection{Automate pipette-based patch-clamping}

Attempts to automate conventional (or manual) electrophysiology started in the late 1990s at Sophion Biosience with the invention of Apatchi-1 [26]. Since that time, a small number of devices have been reported that totally automate manual patch-clamp recordings with glass microelectrodes allowing the pipette control, the production of true gigaseals, and execute compound application and data acquisition. For measurements on mammalian cells, examples 
are the Flyscreen (by Flyion) [4][8][12][27], AutoPatch (Xention) [8][28] and RoboPatch (Wyeth, later acquired by Pfizer) systems [28][29]. All platforms mentioned above are considered as equivalent to manual patch-clamp in terms of quality performance including gigaohm seal formation, small access resistance and stability of recordings. Despite the advantages of these systems most of them are not commercially available, and the attempts for automating conventional glass electrode-based recordings yielded very limited popularity due to the low success rate and throughput of measurements [1][5].

\subsubsection{Planar-array based approaches}

The breakthrough in automated electrophysiology came when planar patch-clamp technology without micromanipulation or visual control was launched and become commercially viable [5][25]. In this method, by the application of negative pressure cells are moved towards the patch-clamp substrate with an array of microapertures for capturing from suspension followed by the formation of the seal with the substrate (Figure 1C). Planar arrays replace glass pipette electrodes with multi-well configurations either in a plate-based or chip-based format to enable higher throughput screening, currently this technology is used in the majority of automated systems. Numerous commercially accessible, successful automated systems exist on the market which are discussed below [1][3][4][5][7].

The IonWorks HT (Essen, later acquired by Molecular Devices) was the first of screening platforms that became widely available. This instrument is an integrated system consisting of computer-controlled fluid handling, recording electronics and processing tools capable of voltage-clamp recordings from up to 384 individual cells per experiment. Cells are positioned to a single hole on the planar chip, where an approximately 100 megaohm seal is created. Electrical access is achieved by applying permeabilizing agent in the intracellular solution to evolve a perforated patch-clamp [1][4][5][7][8][10][12][30]. Next generation systems are the IonWorks Quattro and the IonWorks Barracuda with recording concept called 'population patch-clamp' [4][8][10][12][31][32][33]. In this technique the recorded current is derived from an ensemble of cells in contrast to a single cell, which provides close to $100 \%$ success rate and dramatically reduces well-to-well variability. The IonWorks product family utilize plastic recording substrates. On this surface lipophilic compounds can adsorb nonspecifically and it also does not support gigaseal recordings. As a result of these phenomenon a consistent rightward shift is observed in the compound $\mathrm{IC}_{50}$ values [1][3][4][5][12][34]. Molecular Devices has another automated patch-clamp instrument, the PatchXpress. The PatchXpress 
uses glass substrates for parallel recordings from 16 wells and enables continuous recordings during ligand applications. It supports multiple solution additions and allows the study of both voltage-gated and ligand-gated ion channels. In this system, electrical access is achieved by rupturing the cell membrane underneath the aperture. It was the first planar-array based system which provides gigaohm seal patch-clamp electrophysiology on a chip $[1][3][4][5][7][8][10][12][35][36]$.

The QPatch was released in 2004 by Sophion Biosience, and reached a quite good market acceptance worldwide, due to the properties that compounds affecting both voltage- and ligand-gated ion channels can be screened with true gigaseals and acceptable success rates. QPatch records from 16 cells simultaneously, utilizing silicon oxide-coated silicon nitride structures for high quality recordings. The QPatch was the first planar system designed with microfluidics flow capability for rapid solution exchange, allowing the collection of accurate pharmacological data [1][3][4][8][12][37]. The following devices were the QPatch HT, recording from 48 cells at once and the QPatch HTX using the population patch-clamp principle supports a data throughput of 7.000 data points per day [3][4][10][12][37].

Nanion Technologies introduced the Port-a-Patch, a miniaturized patch-clamp set-up recording from one cell at a time in 2003. The Port-a-Patch makes patch-clamp available to non-experts, and is widely used in academic research owing to its great versatility and userfriendliness [3][4][8][12][38]. The next instrument was the Patchliner (2006), with the capability of recording up to eight cells simultaneously, with versatile experimental features such as temperature control, current-clamp recordings, external and internal solution exchange, fast solution switch times, high success rates with a wide variety of ion channels and different cell lines, as well as with primary cells, stem cell-derived cardiomyocytes and neurons [4][6][8][12][39][40]. In 2010, Nanion launched the SyncroPatch 96, a screening platform recording from 96 cells in parallel. As with all Nanion's appliances, the SyncroPatch 96 supports true gigaseals and utilizes a borosilicate glass chips as recording substrates, where measurements are possible in different modes including whole-cell, cell-attached and perforated-patch configurations. It also has been validated with numerous voltage- and ligandgated channels and various cell types. The design supports a data throughput of 6.000 data points per day [3][6]. In 2013, Nanion released the SyncroPatch 384/786PE, the first truly modular and high-throughput capable automated system with the potential to bridge the gap between primary and secondary ion channel drug screening. It offers 384 or 768 recording wells for simultaneous measurements, and allows the collection of up to 20.000 data points per day, making it the most efficient device on the market for high quality recordings. 
Two further apparatus, the Dynaflow HT platform from Cellectricon and the IonFlux from Fluxion Biosciences utilize a silicone rubber-based (PDMS) microfluidic structure with microchannels used for sealing the cells. These systems are unable to perform high quality recordings, because of the seals are in the megaohm range. The Dynaflow HT records from 96 cells simultaneously. The Fluxion's IonFlux comes in two versions, IonFlux 16 and IonFlux HT. The IonFlux HT has 64 individual recording zones per substrate, and could to achieve 10.000 data points per day. IonFlux systems use the population patch-clamp method. Later the Fluxion introduced a new version of the recording cartridge containing one single aperture per recording place, for single cell application and also gigaseal recordings [3][33][41].

Finally, CytoPatch (from Cytocentrics) is one of the newer robotic platforms, where the quartz-microstructured chip design and perfusion system mimics the manual patch-clamp technique. Unlike other automated systems, the instrument requires neither high calcium buffer to support the sealing process nor fluoride in the intracellular solution to maintain the gigaseal and stable whole-cell recording [3][8][42].

\subsection{Aims}

Aim of the present work was to investigate the role of automated patch-clamp technique in drug research and development and compare it with the conventional cellular electrophysiological techniques. The two main scopes of our studies were:

1. To determine the value of results of screening processes obtained with automated patch-clamp methods using cell lines stably expressing ion channels. During this phase of work the main goals were to evaluate the usability of the studied automated patch-clamp equipment in different screening projects and to analyse the utility of the studied system with comparing the effect of the active compounds in cell lines used for screening and in native targets measured by the conventional electrophysiological methods.

2. To analyze the value of safety pharmacology data obtained with automated patchclamp methods. During this phase of work the main goal was to evaluate the practical usability and the biological significance of the results obtained with the studied automated patch-clamp equipment in stable cell lines. 


\section{MATERIALS AND METHODS}

\subsection{Chemicals}

All chemicals, which are not specifically indicated, were purchased from Sigma-Aldrich. To study the effect of test compounds, a stock solution of test material was prepared in each case. The solubilizing agent was dimethyl sulfoxide (DMSO). Aliquots were stored at $-20^{\circ} \mathrm{C}$. Before experiments, stock solutions were further diluted with external solution to give appropriate concentrations for the measurements. The final DMSO concentrations in the tested samples were $1 \%$ or less.

\subsection{Ethics statement}

All experiments were carried out in compliance with the Guide for the Care and Use of Laboratory Animals (USA NIH publication NO 85-23, revised 1996) and conformed to the Directive 2010/63/EU of the European Parliament. The protocols have been approved by the Ethical Committee for the Protection of Animals in Research of the University of Szeged, Szeged, Hungary (approval number: I-74-5-2012) and by the Department of Animal Health and Food Control of the Ministry of Agriculture and Rural Development (authority approval number XIII/1211/2012).

\subsection{Conventional microelectrode technique}

New Zealand rabbits of either sex weighing 1-2 $\mathrm{kg}$ or adult mongrel dogs (8-14 kg) of either sex were used. Rabbits were sacrificed by cervical dislocation after an intravenous injection of $400 \mathrm{U} / \mathrm{kg}$ heparin, while in case of dogs sedation (xylazine, $1 \mathrm{mg} / \mathrm{kg}, i . v$.) and anaesthesia (thiopental, $30 \mathrm{mg} / \mathrm{kg}$, i.v.) were applied. Then the chest was opened, and the heart was rapidly removed. The heart was immediately rinsed in oxygenated modified Locke's solution containing (in mM): $\mathrm{NaCl} 120, \mathrm{KCl} 4, \mathrm{CaCl}_{2} 1, \mathrm{MgCl}_{2} 1, \mathrm{NaHCO}_{3} 22$ and glucose 11. The $\mathrm{pH}$ of this solution was set between 7.35 and 7.4 when gassed with the mixture of $95 \% \mathrm{O}_{2}$ and $5 \% \mathrm{CO}_{2}$ at $37^{\circ} \mathrm{C}$. Isolated muscle preparations obtained from the right ventricle were individually mounted in a tissue chamber with the volume of $50 \mathrm{ml}$. Each preparation was initially stimulated through a pair of platinum electrodes in contact with the preparation using rectangular current pulses of $2 \mathrm{~ms}$ duration. These stimuli were delivered at a constant cycle 
length of $1000 \mathrm{~ms}$ for at least $60 \mathrm{~min}$ allowing the preparation to equilibrate before the measurements were initiated. Transmembrane potentials were recorded using conventional glass microelectrodes, filled with $3 \mathrm{M} \mathrm{KCl}$ and having tip resistances of 5-20 M $\Omega$, connected to the input of a high impedance electrometer (Experimetria, type 309) which was coupled to a dual beam oscilloscope. The resting potential (RP), action potential amplitude (APA), maximum upstroke velocity $\left(\mathrm{V}_{\max }\right)$ and action potential duration measured at $50 \%$ and $90 \%$ of repolarization $\left(\mathrm{APD}_{50}\right.$ and $\mathrm{APD}_{90}$, respectively) were off-line determined using a home-made software (APES) running on an IBM compatible computer equipped with an ADA 3300 analogue-to-digital data acquisition board (Real Time Devices) having a maximum sampling frequency of $40 \mathrm{kHz}$. The following types of stimulation were applied in the course of the experiments: stimulation with a constant cycle length of $1000 \mathrm{~ms}$; stimulation with different constant cycle lengths ranging from 300 to $5000 \mathrm{~ms}$ [43][44][45][46][47][48].

\subsection{Manual patch-clamp method}

Left ventricular myocytes were enzymatically dissociated from hearts of New Zealand rabbits of either sex weighting 1-2 kg using the retrograde perfusion technique [43]. One drop of cell suspension was placed in a transparent recording chamber mounted on the stage of an inverted microscope. The myocytes were allowed to settle and adhere to the bottom for at least 5 minutes before superfusion was initiated with Tyrode solution containing (in $\mathrm{mM}$ ): $\mathrm{NaCl} 144, \mathrm{NaH}_{2} \mathrm{PO}_{4}$ 0.4, $\mathrm{KCl} 4.0, \mathrm{CaCl}_{2}$ 1.8, $\mathrm{MgSO}_{4}$ 0.53, glucose 5.5 and HEPES 5.0 $(\mathrm{pH} 7.4, \mathrm{NaOH})$. Temperature was set to $37^{\circ} \mathrm{C}$. Only rod shaped cells with clear crossstriations were used. Patch-clamp micropipettes were fabricated from borosilicate glass capillaries (Harvard Apparatus) using a micropipette puller (Flaming/Brown, type P-97). These electrodes had resistances between 1.5 and 2.5 $\mathrm{M} \Omega$ when filled with pipette solution containing (in mM): K-aspartate 100, $\mathrm{KCl} 40, \mathrm{ATP} 5, \mathrm{MgCl}_{2}$ 5, EGTA 4, $\mathrm{CaCl}_{2} 1.5$ and HEPES $10(\mathrm{pH} 7.2, \mathrm{KOH})$. When measuring rapid delayed rectifier potassium currents $\left(\mathrm{I}_{\mathrm{Kr}}\right)$, $1 \mu \mathrm{M}$ nisoldipine (Bayer $\mathrm{AG}$ ) was added to the external solution to eliminate L-type $\mathrm{Ca}^{2+}$ current $\left(\mathrm{I}_{\mathrm{Ca}, \mathrm{L}}\right)$. The slow component of the delayed rectifier potassium current $\left(\mathrm{I}_{\mathrm{Ks}}\right)$ was inhibited by using the selective $\mathrm{I}_{\mathrm{Ks}}$ blocker HMR $1556(0.5 \mu \mathrm{M})$.

Membrane currents were recorded with Axopatch 200B patch-clamp amplifiers (Molecular Devices) using the whole-cell configuration of the patch-clamp technique. After establishing a high resistance (1-10 G $\Omega$ ) seal by gentle suction, the cell membrane beneath the tip of the electrode was disrupted by suction or application of short electrical pulses. The series 
resistance typically ranged from 4 to $8 \mathrm{M} \Omega$ before compensation (50-80\%). When the series resistance was high or substantially increased during the measurement, experiments were discarded. Membrane currents were digitized after low-pass filtering at $1 \mathrm{kHz}$ using analogto-digital converters (Digidata 1322A and 1440A, Molecular Devices) under software control (pClamp 8 and 10, Molecular Devices). The same software was used for off-line analysis [45]. $\mathrm{I}_{\mathrm{Kr}}$ was measured using $1000 \mathrm{~ms}$ long test pulses between $-30 \mathrm{mV}$ and $+50 \mathrm{mV}$. The holding potential was $-80 \mathrm{mV}$ and during measurements $500 \mathrm{~ms}$ long prepulse to $-40 \mathrm{mV}$ was applied in order to ensure the baseline region. The pulse frequency was $0.05 \mathrm{~Hz}$. The tail current at $-40 \mathrm{mV}$ after the test pulse was assessed as $\mathrm{I}_{\mathrm{Kr}}$. The amplitudes of the $\mathrm{I}_{\mathrm{Kr}}$ tail currents were determined as the difference between the peak tail current and the baseline.

\subsection{Automated patch-clamp experiments}

\subsubsection{Automated patch-clamp system Patchliner}

The automated patch-clamp experiments were executed by using planar patch-clamp technology in the whole-cell configuration with a four channel medium throughput fully automated patch-clamp platform (Patchliner Quattro, Nanion) with integrated temperature control [49]. The software controlling the actions of the Patchliner is the PatchControlHT (Nanion) package. Data acquisition and online analysis were performed with an EPC-10 Quadro patch-clamp amplifier (HEKA), using PatchMaster software (HEKA).

\subsubsection{Cells and electrophysiology used for automated patch-clamp measurements}

\subsubsection{Native cells}

\subsection{Native activated human lymphocytes}

Native human lymphocytes were provided by the Department of Biophysics and Cell Biology, University of Debrecen. Cells were cultured at $37^{\circ} \mathrm{C}$ in a humidified atmosphere containing $5 \% \mathrm{CO}_{2}$ in RPMI 1640, supplemented with $10 \% \mathrm{FBS}, 100 \mathrm{mg} / \mathrm{l}$ penicillin, $100 \mathrm{mg} / \mathrm{l}$ streptomycin and $2 \mathrm{mM}$ L-glutamine at $5 * 10^{5}-1 * 10^{6} / \mathrm{ml}$ density for $2-5$ days. The culture medium also contained $2.5-10 \mathrm{mg} / \mathrm{l}$ of phytohemagglutinin A to stimulate proliferation and to increase $\mathrm{K}^{+}$channel expression. Before the experiments cultured cells were suspended and 
centrifuged at $100 \mathrm{~g}$ for $2 \mathrm{~min}$, next they were digested with trypsin-EDTA (PAA) for $2 \mathrm{~min}$. Trypsin was blocked with the complete culture medium, then cells were centrifuged at $100 \mathrm{~g}$ for 2 min and washed in PBS (Life Technologies) and centrifuged again. Finally, cells were resuspended in 1-1.5 ml extracellular solution for patch-clamp measurements.

The extracellular solution consisted of (in $\mathrm{mM}$ ): $\mathrm{NaCl} 145, \mathrm{KCl} 5, \mathrm{MgCl}_{2} 1, \mathrm{CaCl}_{2} 2.5$, glucose 5.5 and HEPES $10(\mathrm{pH} 7.35, \mathrm{NaOH})$. The internal solution consisted of (in $\mathrm{mM}$ ) KF 112, $\mathrm{MgCl}_{2} 2, \mathrm{CaCl}_{2}$ 1, HEPES 8 and EGTA 11 (pH 7.22, KOH). Kv1.3 currents were measured in human peripheral $\mathrm{T}$ lymphocytes at room temperature. The currents were evoked by $15 \mathrm{~ms}$ long pulses to $50 \mathrm{mV}$ from a resting potential of $-120 \mathrm{mV}$ in every $15 \mathrm{~s}$. [50]. Experiments started in extracellular solution. After the control phase, the increasing concentrations of the test compound were added, each for approximately 5 minutes, then a wash-out step terminated the measurements.

\subsubsection{Stable transfected cell lines}

Automated patch-clamp experiments were carried out on suspension of stable transfected cell lines. Suspension of cells for measurements was derived from running cell culture. Cells were maintained in incubator at $37^{\circ} \mathrm{C}$, in $5 \% \mathrm{CO}_{2}$. Before experiments, cells were washed twice with PBS (Life Technologies) and then detached with trypsin-EDTA (PAA) for 30-180 s depending on cell line. Trypsin was blocked with serum containing complete culture medium. The cell suspension was next centrifuged ( $2 \mathrm{~min}, 100 \mathrm{~g}$ ), resuspended in serum free base medium at a final density of $1 * 10^{6}-5 * 10^{6}$ cells $/ \mathrm{ml}$, and kept in the cell hotel of the Patchliner. Cells were recovered after $15-30 \mathrm{~min}$ and remained suitable for automated patch-clamp recordings for up to 4 hours.

Stock of extra- and intracellular solutions were made for automated patch-clamp recordings on stable transfected cell lines. All solutions were sterile filtered. Aliquots were stored at $-20^{\circ} \mathrm{C}$ and warmed up to room temperature before use.

\subsection{HEK-GABA cell line}

Experiments were carried out at room temperature, on HEK293 cells stably expressing the $\mathrm{GABA}_{\mathrm{A}}$ receptor ( $\alpha 5 \beta 2 \gamma 2$ subunit composition). The $\mathrm{GABA}_{\mathrm{A}}$ cell line was provided by EGIS and all results related to this cell line in this thesis are shown with the permission of EGIS. Cells were cultured in DMEM (Life Technologies) medium supplemented with $10 \%$ FBS, 
$3 \mathrm{mg} / \mathrm{l}$ puromycin, $600 \mathrm{mg} / \mathrm{l} \mathrm{G} 418$ (Life Technologies), $200 \mu \mathrm{g} / \mathrm{ml}$ zeocin (Life Technologies) and $10 \mathrm{mM} \mathrm{KCl}$.

The following solutions were used for automated patch-clamp recordings (compositions in $\mathrm{mM}$ ): external solution: $\mathrm{NaCl} 140, \mathrm{KCl} 4$, glucose-monohydrate 5, $\mathrm{MgCl}_{2} 1, \mathrm{CaCl}_{2} 3$ and HEPES 10 (pH 7.4, NaOH); internal solution: $\mathrm{KCl}$ 50, $\mathrm{NaCl}$ 10, KF 60, EGTA 20 and HEPES 10 (pH 7.2, KOH). During measurements cells were clamped to a holding potential of $-50 \mathrm{mV}$. For GABA ion channel assay, the stacked application was used. In this method, the extracellular solution was aspirated to the pipette, directly followed by a plug of compound. In this way, the cell was exposed to GABA for accurately $5 \mathrm{~s}$, and then 3 minutes long washout step occurred. To investigate test compounds, cells were stimulated with control applications of GABA. Control applications were followed by $3 \mathrm{~min}$ pre-incubation of test compound. Then the co-applications of compound and GABA were established for $5 \mathrm{~s}$, and the washout step terminated the protocol cycle. This cycle was repeated with the increasing concentrations of the investigated drug.

\subsection{HEK-HCN1 and HEK-HCN4 cell lines}

Experiments were performed at room temperature, on HEK293 cell line stably expressing the $\mathrm{HCN} 1$ or the $\mathrm{HCN} 4 \mathrm{~K}^{+}$channels. Cell lines were provided by the University of Florence. Cells were maintained in DMEM (Life Technologies) medium contained 10\% FBS, $200 \mu \mathrm{g} / \mathrm{ml} \mathrm{G} 418$ (Life Technologies), $100 \mathrm{U} / \mathrm{ml}$ penicillin and $100 \mu \mathrm{g} / \mathrm{ml}$ streptomycin.

The following solutions were used for patch-clamp measurements (compositions in $\mathrm{mM}$ ): external solution: $\mathrm{NaCl} 140, \mathrm{KCl} 4$, glucose-monohydrate 5, $\mathrm{MgCl}_{2} 1, \mathrm{CaCl}_{2} 3$ and HEPES 10 (pH 7.4, $\mathrm{NaOH}$ ); high $\mathrm{K}^{+}$external solution: $\mathrm{NaCl} 135, \mathrm{KCl} 25, \mathrm{MgCl}_{2} 1, \mathrm{CaCl}_{2} 3$ and HEPES 10 (pH 7.4, NaOH); $\mathrm{K}^{+}$-free external solution: $\mathrm{NaCl} 160, \mathrm{MgCl}_{2} 1, \mathrm{CaCl}_{2} 3$ and HEPES 10 (pH 7.4, NaOH); internal solution: $\mathrm{KCl}$ 50, $\mathrm{NaCl}$ 10, KF 60, EGTA 20 and

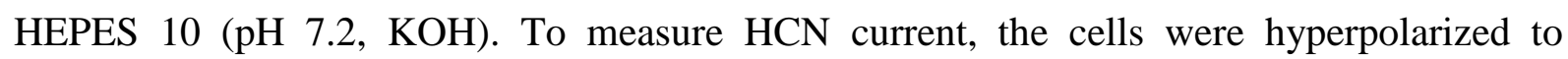
$-100 \mathrm{mV}$ for $4 \mathrm{~s}$, then they were repolarized to $5 \mathrm{mV}$ for $500 \mathrm{~ms}$. The resting potential was $-35 \mathrm{mV}$, the pulse frequency was $0.1 \mathrm{~Hz}$. Gigaseal and whole-cell created in the normal external solution $\left(4 \mathrm{mM} \mathrm{K}^{+}\right)$. Then high $\mathrm{K}^{+}$external solution was used to amplify the current. After the control period, $\mathrm{K}^{+}$-free external solution was applied. Finally the test compounds dissolved in high $\mathrm{K}^{+}$external solution were added to the cells for $5 \mathrm{~min}$. The data were corrected with the current values measured in the $\mathrm{K}^{+}$-free external solution, which served as the baseline. 


\subsection{HEK-GIRK1/4 cell line}

Experiments were executed at room or physiological $\left(37^{\circ} \mathrm{C}\right)$ temperature, on HEK293 cells stably expressing the GIRK1/4 (Kir3.1/3.4) $\mathrm{K}^{+}$channels. The cell line derived from UCL Business PLC. Cells were breeded in MEM medium (PAA) supplemented with 10\% FBS (PAA) and $182 \mu \mathrm{g} / \mathrm{ml}$ zeocin (Life Technologies).

The undermentioned solutions were used during patch-clamp recordings (compositions in $\mathrm{mM}$ ): external solution: $\mathrm{NaCl} 140, \mathrm{KCl} 4$, glucose-monohydrate 5, $\mathrm{MgCl}_{2} 1, \mathrm{CaCl}_{2} 3$ and HEPES 10 (pH 7.4, NaOH); high $\mathrm{K}^{+}$external solution: $\mathrm{NaCl} 135, \mathrm{KCl} 25, \mathrm{MgCl}_{2} 1, \mathrm{CaCl}_{2} 3$ and HEPES 10 (pH 7.4, NaOH); $\mathrm{K}^{+}$-free external solution: $\mathrm{NaCl} 160, \mathrm{MgCl}_{2} 1, \mathrm{CaCl}_{2} 3$ and HEPES 10 (pH 7.4, NaOH); internal solution: K-gluconate 40, $\mathrm{NaCl}$ 20, KF 60, EGTA 20 and HEPES $10(\mathrm{pH} 7.2, \mathrm{KOH})$, supplemented with $0.9 \mathrm{mM} \mathrm{GTP} \gamma \mathrm{S}$ before the experiments to induce channel activation. The voltage protocol for GIRK ion channel assays started with a depolarizing voltage step to $60 \mathrm{mV}$ for $100 \mathrm{~ms}$ before a $500 \mathrm{~ms}$ hyperpolarizing ramp to $-140 \mathrm{mV}$ was applied. The membrane potential then remained at $-140 \mathrm{mV}$ for $100 \mathrm{~ms}$ before returning to the holding potential of $-40 \mathrm{mV}$. The inward currents were calculated from the $-140 \mathrm{mV}$ segment. The pulse frequency was $0.1 \mathrm{~Hz}$. Recording started in the normal external solution $\left(4 \mathrm{mM} \mathrm{K}^{+}\right)$. High $\mathrm{K}^{+}$external solution was then applied to increase the current amplitude. After a 3 minutes control period, the test compounds were added to the cells in increasing concentrations, each for approximately 3 minutes and then $\mathrm{K}^{+}$-free external solution was applied. The data were corrected with the current values measured in the $\mathrm{K}^{+}$-free external solution, which served as the baseline [51][52].

\subsection{CHO-Kv1.4 cell line}

Experiments were carried out at room temperature, on CHO-K1 cell line stably expressing the Kv1.4 $\mathrm{K}^{+}$channel. The cells were purchased from UCL Business PLC. Cells were cultured in F12 (Life Technologies) medium contained 10\% FBS (PAA) and $500 \mu \mathrm{g} / \mathrm{ml}$ hygromycin (PAA).

The following solutions were used for patch-clamp recordings (compositions in $\mathrm{mM}$ ): external solution: $\mathrm{NaCl} 140, \mathrm{KCl} 4$, glucose-monohydrate 5, $\mathrm{MgCl}_{2} 1, \mathrm{CaCl}_{2} 3$ and HEPES 10 (pH 7.4, $\mathrm{NaOH}$ ); internal solution: $\mathrm{KCl} 50, \mathrm{NaCl} 10, \mathrm{KF}$ 60, EGTA 20 and HEPES 10 (pH 7.2, KOH). To study the Kv1.4 channels, we applied $1 \mathrm{~s}$ long $50 \mathrm{mV}$ voltage steps. The resting potential was $-80 \mathrm{mV}$; the time between depolarizing pulses was approximately 
10 seconds. Peak current was corrected the current value of the steady state phase of the voltage step. After the control phase of measurements, the increasing concentrations of the test compound were added, each for approximately 3 minutes, and a wash-out step terminated the protocol.

\subsection{HEK-hERG cell line}

Measurements were performed at room or physiological $\left(37^{\circ} \mathrm{C}\right)$ temperature, on HEK293 cells stably expressing the hERG $(\mathrm{Kv} 11.1) \mathrm{K}^{+}$channel. The cell line originated from Cell Culture Service. Cells were maintained in IMDM (PAA) medium supplemented with 10\% FBS (PAA), 2 mM L-glutamine (Life Technologies), $1 \mathrm{mM}$ Na-piruvate (PAA) and $500 \mu \mathrm{g} / \mathrm{ml} \mathrm{G} 418$ (PAA).

The following solutions were used during patch-clamp experiments (compositions in $\mathrm{mM}$ ): external solution: $\mathrm{NaCl} 140, \mathrm{KCl}$, glucose-monohydrate 5, $\mathrm{MgCl}_{2} 1, \mathrm{CaCl}_{2} 3$ and HEPES 10 (pH 7.4, $\mathrm{NaOH}$ ); internal solution: $\mathrm{KCl}$ 50, $\mathrm{NaCl}$ 10, KF 60, EGTA 20 and HEPES 10 ( $\mathrm{pH} 7.2, \mathrm{KOH})$. The voltage protocol for hERG ion channel started with a short $(100 \mathrm{~ms})$ $-40 \mathrm{mV}$ step, as a reference. A $20 \mathrm{mV}$ depolarizing step was applied for 3 seconds, and then the test potential was $-40 \mathrm{mV}$ for $1 \mathrm{~s}$ to evoke outward tail current. Holding potential was $-80 \mathrm{mV}$; pulse frequency was $0.1 \mathrm{~Hz}$. The peak tail current was corrected the leak current defined during the first period to $-40 \mathrm{mV}$. Experiment started in external solution. After the control period, the increasing concentrations of the test compound were applied, each for approximately 3 minutes, then a wash-out step completed the protocol [44][51].

\subsection{Statistics}

Data are expressed as arithmetic mean \pm SEM values. Results were compared using Student's t-tests for paired data. Differences were considered significant when P value was less than 0.05 . 


\section{RESULTS}

\subsection{Evaluation and characterization of different cell lines with Patchliner}

\subsubsection{Evaluation and characterization of $\mathrm{Kv1.3} \mathrm{K}^{+}$channel in native activated human lymphocytes}

$\mathrm{Kv} 1.3$ is a voltage-gated $\mathrm{K}^{+}$channel, which is the main ion channel of human T lymphocytes and plays a crucial role in antigen-dependent activation and proliferation. Characterization of Kv1.3 channel was performed using the non-selective $\mathrm{K}^{+}$channel blocker tetraethylammonium (TEA) and two selective blockers of the channel, anuroctoxin (AnTx) and margatoxin (MgTx). TEA reduced the Kv1.3 current in dose-dependent manner showing a $28.14 \pm 3.11 \mathrm{mM} \mathrm{IC}_{50}$ value (Figure 2).

A

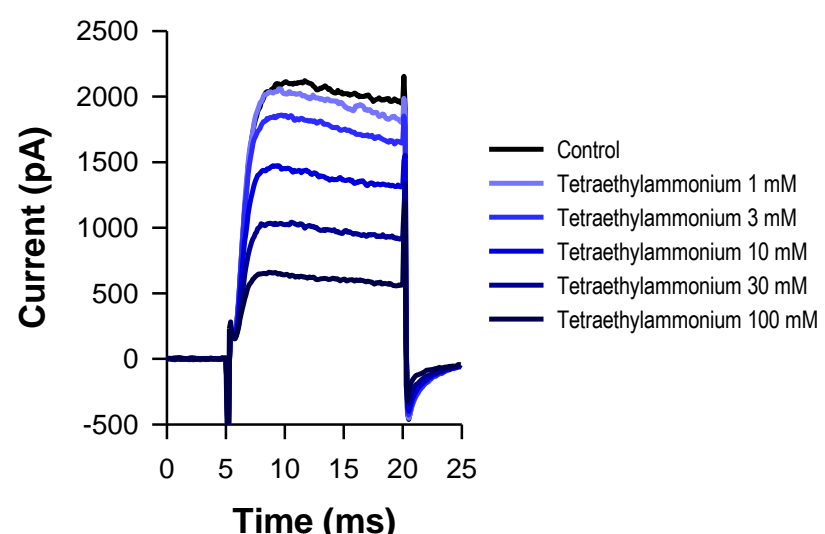

B

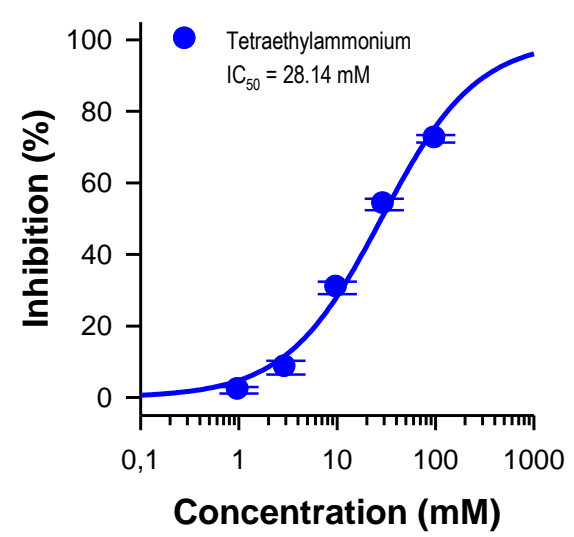

Figure 2. Concentration-dependent inhibitory effect of TEA on Kv1.3 current. Panel $\mathbf{A}$ shows representative Kv1.3 current curves obtained from lymphocyte treated with different concentrations of TEA. Panel $\mathbf{B}$ shows the dose-response curves of TEA. IC 50 was $28.14 \pm 3.11 \mathrm{mM}(n=6)$.

Two selective Kv1.3 blocker peptid toxins originated from scorpion poison were also investigated. Both anuroctoxin and margatoxin inhibited the current in concentrationdependent manner. The $\mathrm{IC}_{50}$ values of both toxins found to be very low: $25.35 \pm 1.64 \mathrm{nM}$ (AnTx) and 68.59 $\pm 16.68 \mathrm{pM}(\mathrm{MgTx})$ (Figure 3). 
A

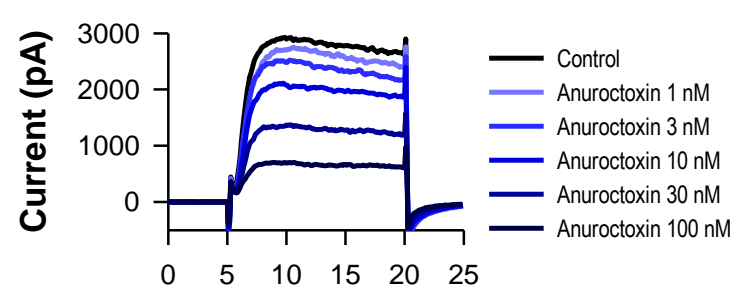

B Time (ms)

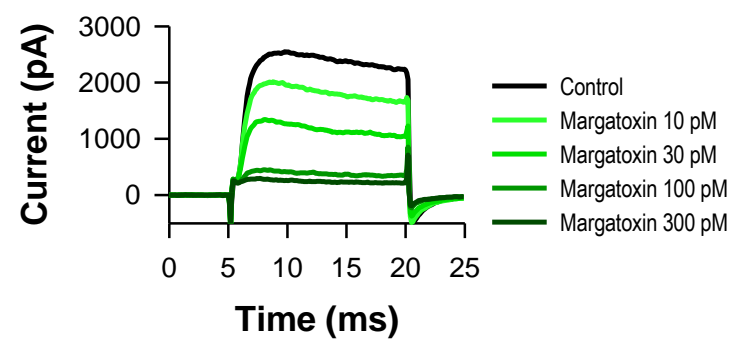

C

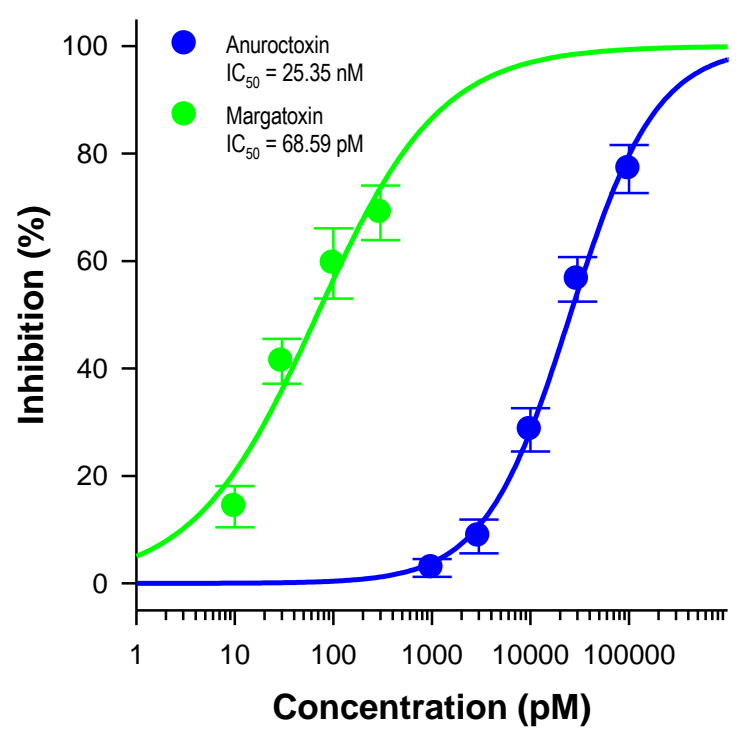

Figure 3. Concentration-dependent blocking effects of scorpion toxins on Kv1.3 current. Panel A and B present typical current curves recorded during application of increasing concentrations of AnTx and MgTx. Panel C shows the dose-response curves of the examined toxins. AnTx and MgTx were extremely effective with $I C_{50}=25.35 \pm 1.64 \mathrm{nM}(\mathrm{n}=5)$ and $\mathrm{IC}_{50}=68.59 \pm 16.68 \mathrm{pM}(\mathrm{n}=5)$, respectively.

\subsubsection{Evaluation of GABA receptors}

The GABA receptor family is the major class of inhibitory chloride ion channels in central nervous system. This channel is known as a ligand-gated ion channel on which gammaaminobutyric acid (GABA) acts as the activator ligand of the channel. $\mathrm{GABA}_{\mathrm{A}}$ channels were investigated by using a stacked application for rapid administration of agonists to cells, in order to study concentration response relations. Figure 4 shows the dose-response curve obtained with the application of 1, 3, 10, 30, 100 and $300 \mu \mathrm{M}$ of GABA. Peak current amplitudes were normalized to the current activated by the maximum concentration of GABA (300 $\mu \mathrm{M}$ is the saturating concentration based on preliminary experiments, data are not shown). The $\mathrm{EC}_{50}$ was determined to $32.20 \pm 1.85 \mu \mathrm{M}$ from the Hill plot.

Potential desensitization of the channel by GABA was also tested. GABA in $10 \mu \mathrm{M}$ concentration was applied 10-15 times on the investigated cells during these experiments. Desensitization was not observed under these circumstances. 
A

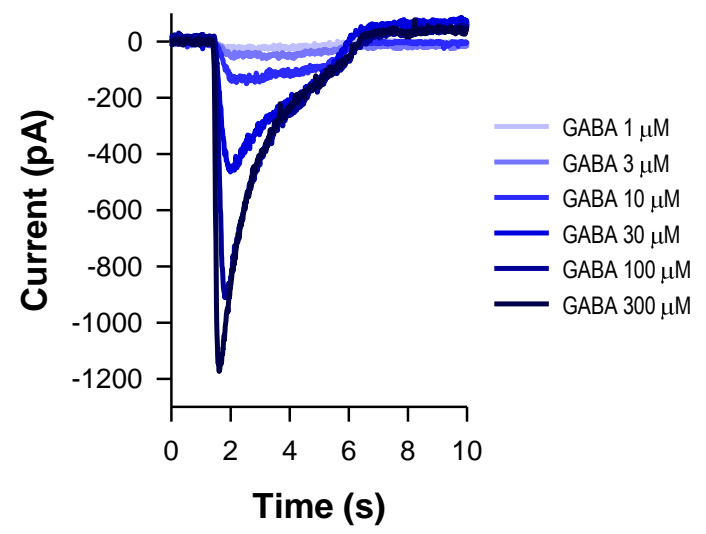

B

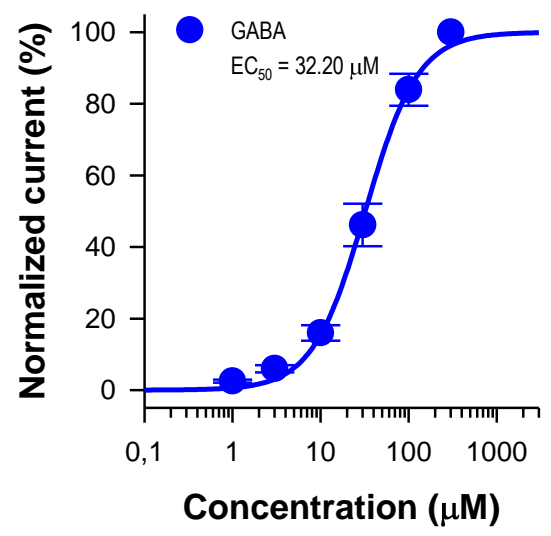

Figure 4. Effect of GABA on whole-cell current. Panel $\mathbf{A}$ depicted sample current curves evoked by different concentrations of GABA. Panel $B$ shows the dose-response relationship of GABA. The $\mathrm{EC}_{50}$ value was determined to $32.20 \pm 1.85 \mu \mathrm{M}(\mathrm{n}=5)$ by plotting the normalized peak current amplitudes against concentration.

The effect of the $\mathrm{GABA}_{\mathrm{A}}$ channel antagonist bicuculline was investigated on $\mathrm{GABA}_{\mathrm{A}}$ current. In these experiments, shown in Figure 5, cells were stimulated with control applications of $10 \mu \mathrm{M}$ GABA. Control applications were followed by the increasing concentrations of bicuculline $(100 \mathrm{nM}, 1 \mu \mathrm{M}, 10 \mu \mathrm{M})$ co-applied with GABA $(10 \mu \mathrm{M})$. The values for the peak amplitudes were normalized against the control. The estimated $\mathrm{IC}_{50}$ value was $371.06 \pm 3.43 \mathrm{nM}$.

A

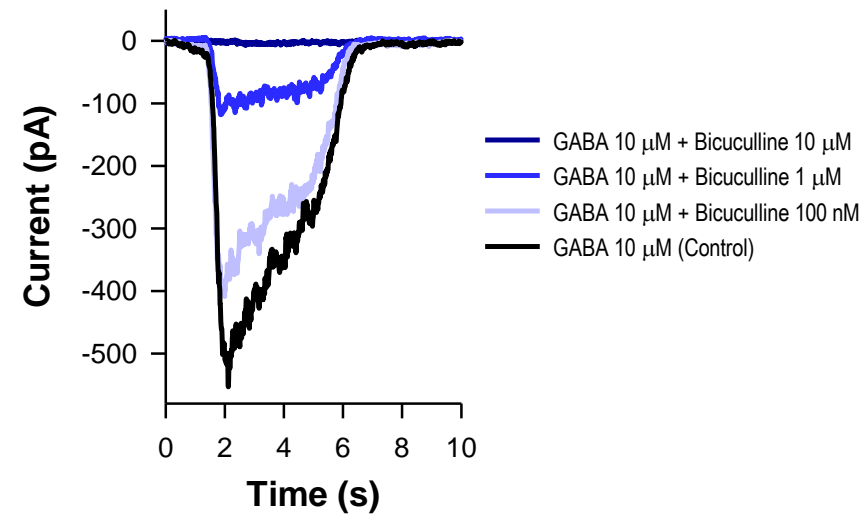

B

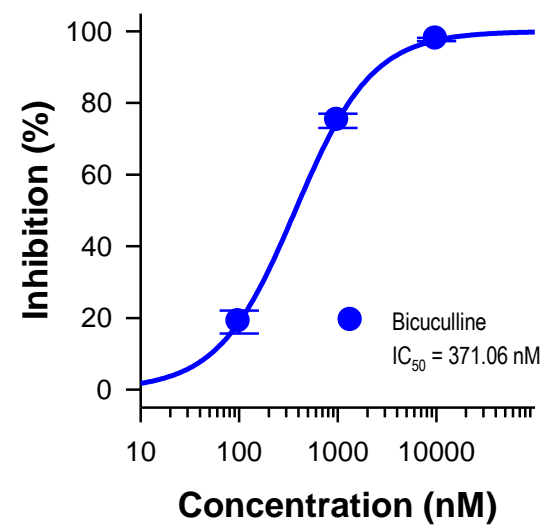

Figure 5. Investigation of bicuculline block on $\mathrm{GABA}_{\mathrm{A}}$ current. Panel $\mathbf{A}$ shows the application of control $(10 \mu \mathrm{M}$ GABA) followed by co-application of $10 \mu \mathrm{M}$ GABA with increasing concentrations of bicuculline. Panel $\mathbf{B}$ shows the concentration-response curve of bicuculline. IC $C_{50}$ was estimated at $371.06 \pm 3.43 \mathrm{nM}(n=3)$. 


\subsubsection{Evaluation of $\mathrm{HCN}$ ion channels}

HCN channels are the molecular determinants of the pacemaker or funny current $\left(\mathrm{I}_{\mathrm{f}}\right)$ in the heart. Cells of the investigated cell lines (HCN1 and HCN4) showed very small HCN currents under physiological circumstances (e.g. $4 \mathrm{mM} \mathrm{K}^{+}$). These weak currents did not allow to perform trustable experiments with automated systems, therefore the effect of higher extracellular $\mathrm{K}^{+}$concentrations on the currents was investigated (Figure 6).

A

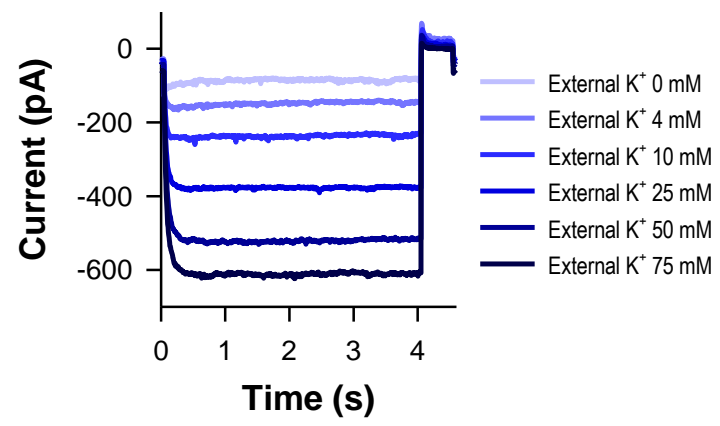

B

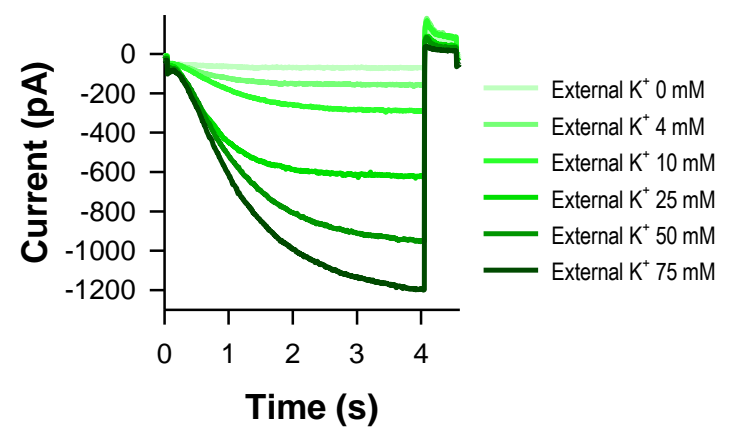

Figure 6. Effects of extracellular $\mathrm{K}^{+}$concentrations on $\mathrm{HCN}$ current. Panel A presents representative $\mathrm{HCN1}$, panel $B$ shows typical HCN4 current sweeps evoked by $0,4,10,25,50$ and $75 \mathrm{mM}$ of external $\mathrm{K}^{+}$.

A

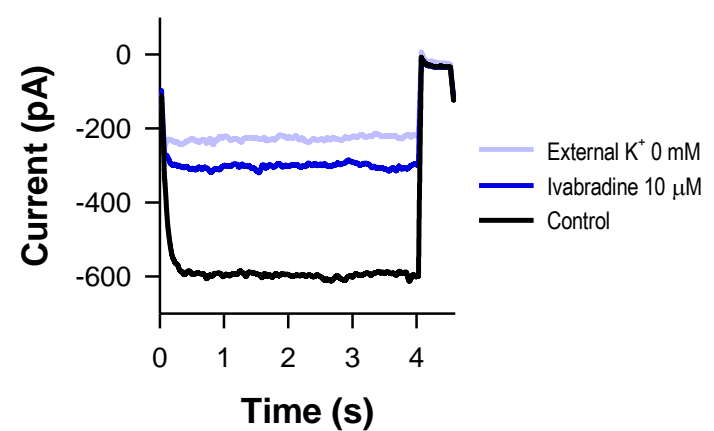

B

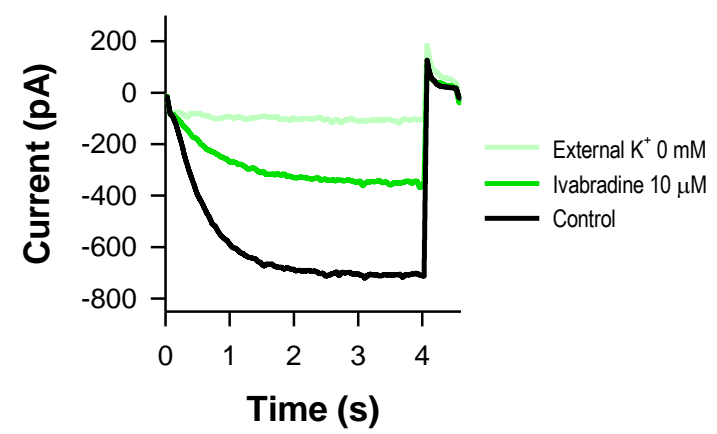

Figure 7. Inhibitory effects of $10 \mu \mathrm{M}$ ivabradine on $\mathrm{HCN}$ channels. Panel A shows representative HCN1, panel B shows typical HCN4 current curves obtained from cells treated with $10 \mu \mathrm{M}$ ivabradine. $\mathrm{K}^{+}$-free external solution served as baseline. Ivabradine $(10 \mu \mathrm{M})$ reduced HCN1 and HCN4 currents by $64.52 \pm 5.36 \%(n=5)$ and $63.79 \pm 1.07 \%(n=6)$, respectively.

Both $\mathrm{HCN} 1$ and $\mathrm{HCN} 4$ currents have shown an obvious dependency on external $\mathrm{K}^{+}$ concentration in the $0-75 \mathrm{mM}$ range, although there was a remarkable difference in their activation kinetics. Since the elevated $\mathrm{K}^{+}$levels increased $\mathrm{HCN}$ currents widely, external 
solution containing $25 \mathrm{mM} \mathrm{K}^{+}$was chosen for use in our experiments. This level of $\mathrm{K}^{+}$was found to be the lowest one providing a current on which changes can be safely detected.

The blocking action of ivabradine on HCN1 and HCN4 channels expressed in HEK cells was also investigated. Ivabradine reduced both currents in $10 \mu \mathrm{M}$ concentration by $64.52 \pm 5.36 \%$ $(\mathrm{n}=5)$ and $63.79 \pm 1.07 \%(\mathrm{n}=6)$, respectively (Figure 7).

\subsubsection{Evaluation of GIRK potassium channels}

GIRK1/4 potassium channels are selectively expressed in the cardiac atrium, and responsible for $\mathrm{K}^{+}$-fluxes and membrane repolarisation and/or hyperpolarisation. To find the ideal formulation of extracellular solution, different external $\mathrm{K}^{+}$concentrations were tested. GIRK current obtained in HEK-GIRK cells showed a definite potassium dependency in the investigated concentration range $\left(0-75 \mathrm{mM} \mathrm{K}^{+}\right)$(Figure 8).

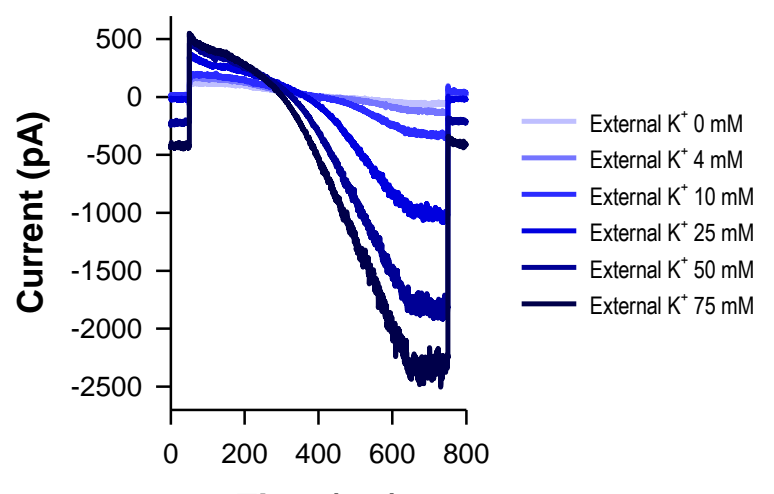

Time (ms)

Figure 8. Effects of extracellular $\mathrm{K}^{+}$concentrations on GIRK current. Illustration depicted sample whole-cell currents evoked by $0,4,10,25,50$ and $75 \mathrm{mM}$ of external $\mathrm{K}^{+}$on the GIRK channel.

External solution containing $25 \mathrm{mM} \mathrm{K}^{+}$was chosen for use in our GIRK experiments, since this was found to be the lowest $\mathrm{K}^{+}$level providing a current on which changes can be safely detected.

Six compounds were studied on HEK-GIRK cells. These experiments were performed at room temperature and results grounded for the screening project performed (see Section 3.2.) on the same cell line also at room temperature. The $\mathrm{IC}_{50}$ of chloroquine, desipramine, JTV-519, NIP-142, propafenone and quinidine were $463.70 \pm 34.61 \mathrm{nM}, 1.47 \pm 0.17 \mu \mathrm{M}$, $814.24 \pm 109.34 \mathrm{nM}, 175.75 \pm 8.59 \mathrm{nM}, 372.99 \pm 27.69 \mathrm{nM}$ and $5.04 \pm 0.62 \mu \mathrm{M}$, respectively (Figure 9). 


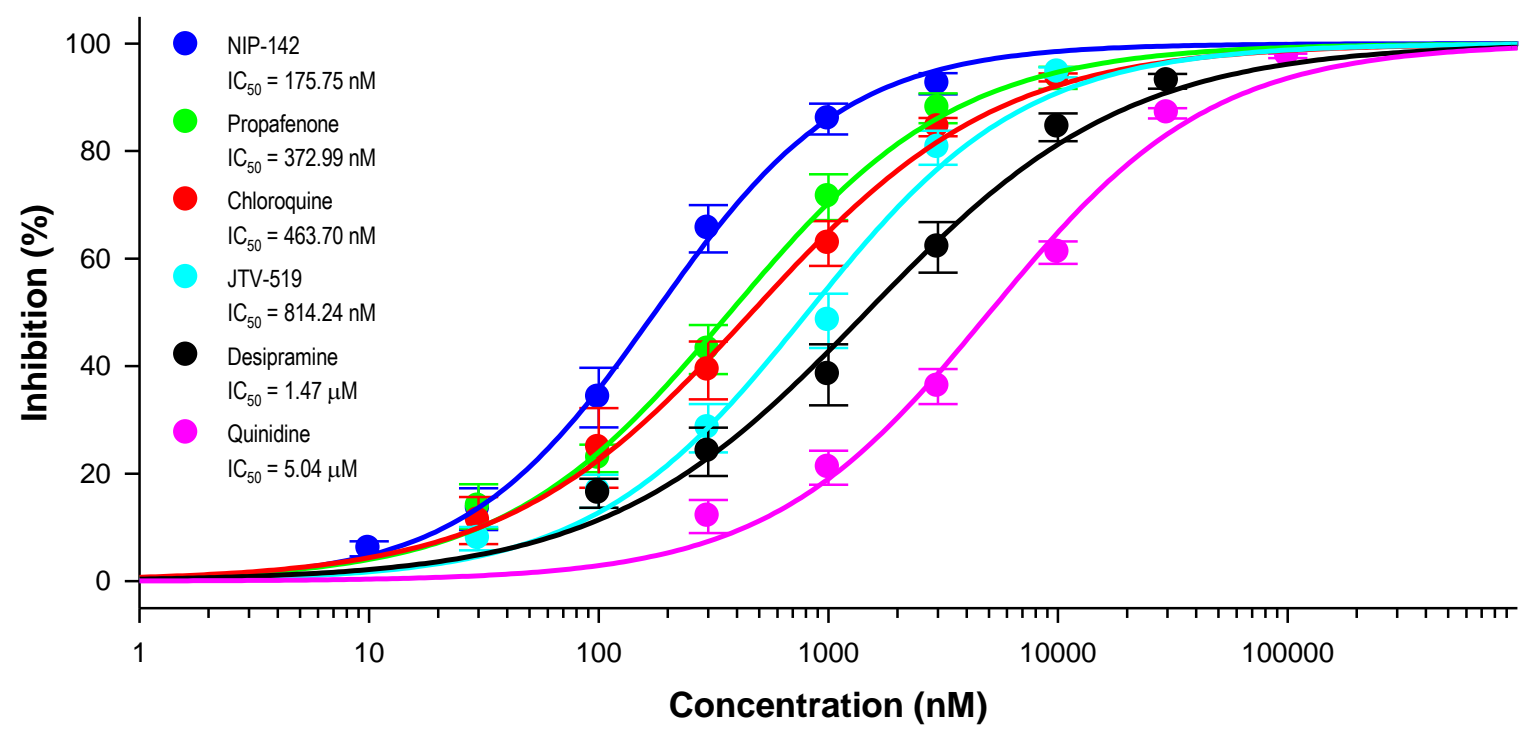

Figure 9. Dose-response curves of six reference agents on GIRK current at room temperature. The $\mathrm{IC}_{50}$ of chloroquine, desipramine, JTV-519, NIP-142, propafenone and quinidine were $463.70 \pm 34.61 \mathrm{nM}, 1.47 \pm 0.17$ $\mu \mathrm{M}, 814.24 \pm 109.34 \mathrm{nM}, 175.75 \pm 8.59 \mathrm{nM}, 372.99 \pm 27.69 \mathrm{nM}$ and $5.04 \pm 0.62 \mu \mathrm{M}$, respectively $(n=5-8)$.

A

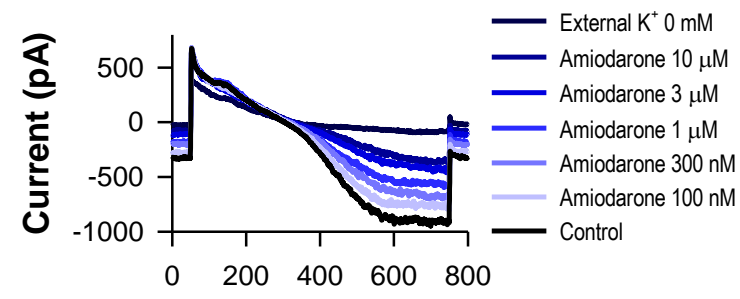

B

Time (ms)

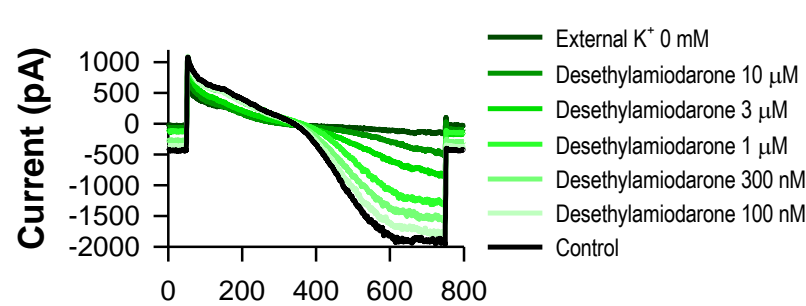

Time (ms)
C

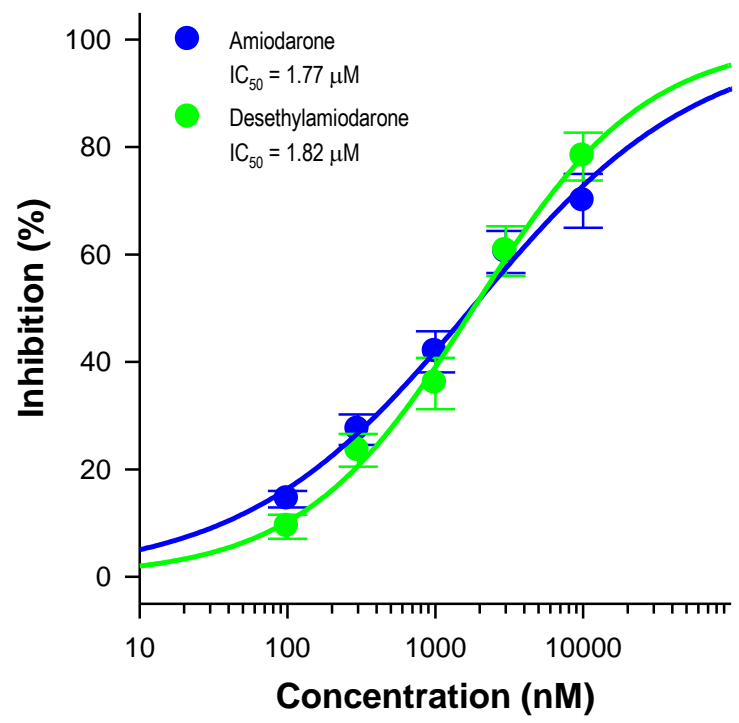

Figure 10. Concentration-dependent inhibitory effects of amiodarone and desethylamiodarone on GIRK current at $37^{\circ} \mathrm{C}$. Panels $\mathbf{A}$ and $\mathbf{B}$ shows representative GIRK current sweeps obtained from cells treated with increasing concentrations of amiodarone and DEA. $\mathrm{K}^{+}-$free external solution served as baseline. Panel $\mathbf{C}$ presents the doseresponse curves of amiodarone $\left(I C_{50}=1.77 \pm 0.18 \mu \mathrm{M}, n=5\right)$ and DEA $\left(I C_{50}=1.82 \pm 0.15 \mu \mathrm{M}, n=5\right)$.

Effect of the antiarrhythmic drug amiodarone and its main metabolite formed during chronic treatment (desethylamiodarone, DEA) was also investigated on HEK-GIRK cells. These studies were performed as parts of the cardiac electrophysiological investigation of these 
compounds and were performed at $37^{\circ} \mathrm{C}$. The $\mathrm{IC}_{50}$ values determined by the Patchliner were nearly identical $(1.77 \pm 0.18$ and $1.82 \pm 0.15 \mu \mathrm{M}$, respectively, see on Figure 10).

\subsubsection{Evaluation of Kv1.4 potassium channels}

Kv1.4 is a voltage-gated potassium channel, which opens on membrane depolarization and inactivate rapidly. Kv1.4 channel underlie the cardiac transient outward potassium current $\left(\mathrm{I}_{\mathrm{to}}\right)$ in cardiac muscle. The blocking effects of chromanol 293B and 4-aminopyridine on $\mathrm{Kv1.4}$ ion channel were investigated at room temperature. Estimated $\mathrm{IC}_{50}$ values of these compounds found to be $85.69 \pm 8.38 \mu \mathrm{M}$ and $791.33 \pm 26.84 \mu \mathrm{M}$, respectively (Figure 11).
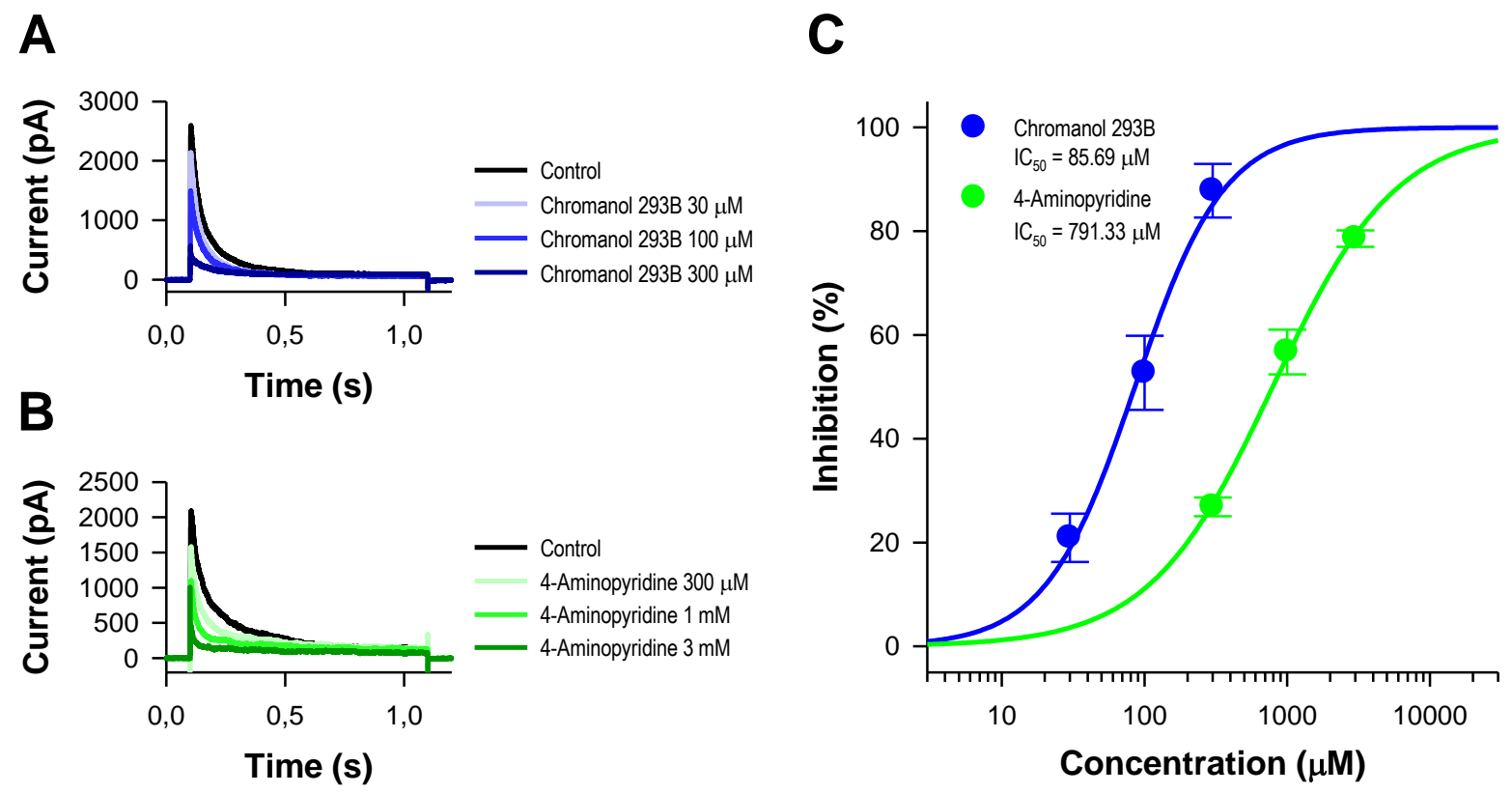

Figure 11. Concentration-dependent blocking effects of chromanol 293B and 4-aminopyridine on Kv1.4 currents. Panel $\mathbf{A}$ and $\mathbf{B}$ present representative current curves recorded during application of increasing concentrations of chromanol 293B and 4-aminopyridine. Panel $\mathbf{C}$ shows the dose-response curves of the reference compounds. The estimated IC $\mathrm{C}_{50}$ values were $85.69 \pm 8.38 \mu \mathrm{M}(\mathrm{n}=4)$ and $791.33 \pm 26.84 \mu \mathrm{M}(\mathrm{n}=4)$, respectively.

\subsubsection{Evaluation of hERG potassium channels}

hERG channel is a $\mathrm{K}^{+}$selective voltage-gated ion channel, belonging to the $\mathrm{Kv}$ channel family, also referred to as Kv11.1. hERG channels mediate the rapid delayed rectifier $\mathrm{K}^{+}$ current $\left(\mathrm{I}_{\mathrm{Kr}}\right)$ in ventricular myocytes. Two compounds, dofetilide and sotalol were tested in hERG assay with automated patch-clamp system. Results are shown in details in Section 3.3.1. 


\subsection{Screening projects: Investigation of ion channel modulator capability of compounds with automated patch-clamp equipment}

The characterized cell lines were used in screening and safety pharmacology projects performed with the Patchliner. Screening projects involved Kv1.3, GABA, GIRK, Kv1.4 and hERG cell lines. All screening projects were carried out at room temperature. Screen results obtained with Kv1.3 and GABA cell lines are not shown in this section due to the intellectual property policy of our industrial research partners.

\subsubsection{Screening of preselected chemical libraries on GIRK channel}

In order to find agents for the treatment of atrial fibrillation, screening of preselected chemical libraries was performed on GIRK channel expressing cell line. Selective GIRK blocking agents found to be effective against atrial fibrillation in previous studies. During our screening project a set of 868 compounds originated from the Department of Organic Chemistry, Semmelweis University, Budapest, and the Institute of Pharmaceutical Chemistry, University of Szeged was tested. All screened compounds were chosen for GIRK studies during a selection process where the chemical structure of the compounds was compared to the known antagonists of GIRK channel. Approximately the $10 \%$ of the revised chemical libraries were selected as possible potent structures and were investigated in automated patch-clamp studies. Compounds were screened in two concentrations ( 1 and $10 \mu \mathrm{M})$ on at least 2 cells.

Approximately $13 \%$ of the investigated compounds showed a notable (i.e. at least $50 \%$ decrease in the GIRK current at $10 \mu \mathrm{M}$ concentration) blocking effect. Compounds were ranked according to their GIRK inhibitory effect. Eleven compounds were chosen from the group of most effective molecules upon their blocking effect and chemical structure. The dose-response curves of these compounds were determined in detailed experiments where effect of the chosen compounds was tested in 6 concentrations on at least 6 cells. Doseresponse curves and $\mathrm{IC}_{50}$ values of these compounds are shown in Figure 12.

Substrates were chosen for selectivity studies by the more precise results of these later studies: hERG inhibitory properties of 4 compounds with the most intense GIRK blocking effect (Ryt-143, Ryt-144, Ryt-230 and Ryt-243 - all having $\mathrm{IC}_{50}$ values under $0.5 \mu \mathrm{M}$ ) were investigated on HEK-hERG cells in 6 concentrations. These dose-response curves were derived from experimental results obtained from at least 5 cells. GIRK and hERG doseresponse curves of these listed compounds are shown in Figure 13. 


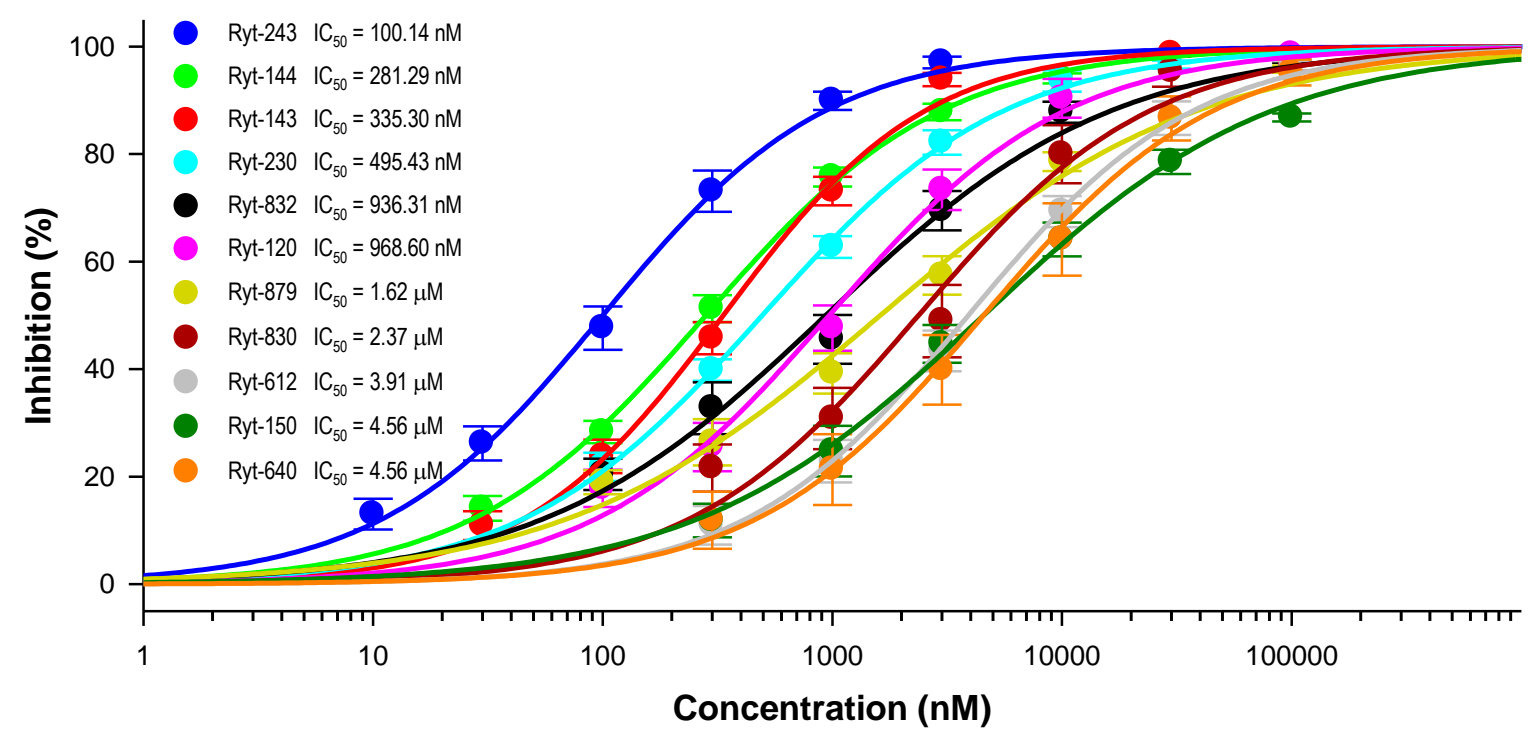

Figure 12. Dose-response curves of eleven compounds which were selected after GIRK screening project of chemical libraries upon their blocking effect and chemical structure. $\mathrm{IC}_{50}$ values were $100.14 \pm 5.10 \mathrm{nM}$ for Ryt-243, $281.29 \pm 9.48 \mathrm{nM}$ for Ryt-144, $335.30 \pm 23.81 \mathrm{nM}$ for Ryt-143, $495.43 \pm 15.90 \mathrm{nM}$ for Ryt-230, $936.31 \pm 118.30 \mathrm{nM}$ for Ryt-832, $968.60 \pm 94.44 \mathrm{nM}$ for Ryt-120, $1.62 \pm 0.20 \mu \mathrm{M}$ for Ryt-879, $2.37 \pm 0.38 \mu \mathrm{M}$ for Ryt-830, $3.91 \pm 0.12 \mu \mathrm{M}$ for Ryt-612, $4.56 \pm 0.28 \mu \mathrm{M}$ for Ryt-150 and $4.56 \pm 0.34 \mu \mathrm{M}$ for Ryt- $640(n=6-9)$.

One out of the 4 chosen compounds showed similar blocking activity on both GIRK and hERG channels: $\mathrm{IC}_{50}$ values of Ryt-243 were $100.14 \pm 5.10 \mathrm{nM}$ and $47.56 \pm 5.31 \mathrm{nM}$, respectively. The other 3 compounds (Ryt-143, Ryt-144 and Ryt-230) showed an at least 10 times higher blocking activity on GIRK channels compared to the results obtained on hERG channel. As hERG blocking effect can be even useful in antiarrhythmic treatment Ryt-243 was subjected to further investigation: despite of its hERG blocking effect the compound lengthened the action potential in rabbit ventricular muscle neither in $5 \mu \mathrm{M}$ nor in $10 \mu \mathrm{M}$ concentrations (Figure 14). This discrepancy needs further examinations. Ryt-243 was also studied in dog model of chronic atrial fibrillation. The compound had a strong antiarrhythmic effect in this investigational set-up: the incidence of atrial fibrillation was reduced by $65-70 \%$ by both $0.3 \mathrm{mg} / \mathrm{kg}$ and $1 \mathrm{mg} / \mathrm{kg}$ doses. Based on these antiarrhythmic results a patent was filed in which anti-atrial fibrillation effects of Ryt-243 are chartered. Compounds showing GIRK-selectivity (Ryt-143, Ryt-144 and Ryt-230) are also subjected to further investigation including antiarrhythmic effect evaluation and structure-effect analysis. 
A

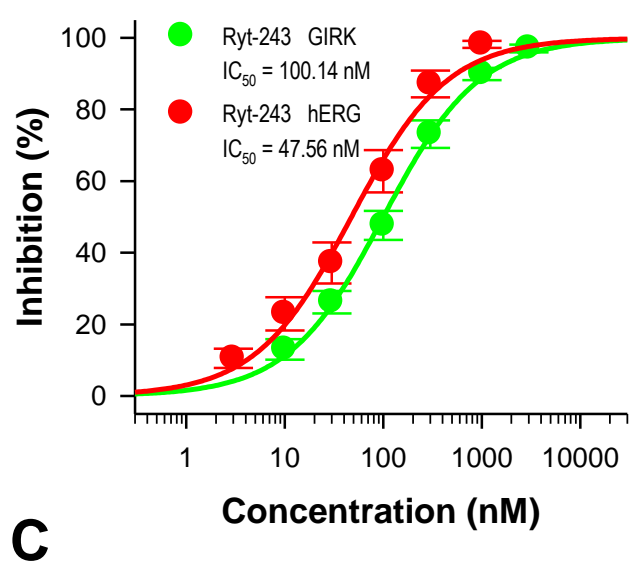

C

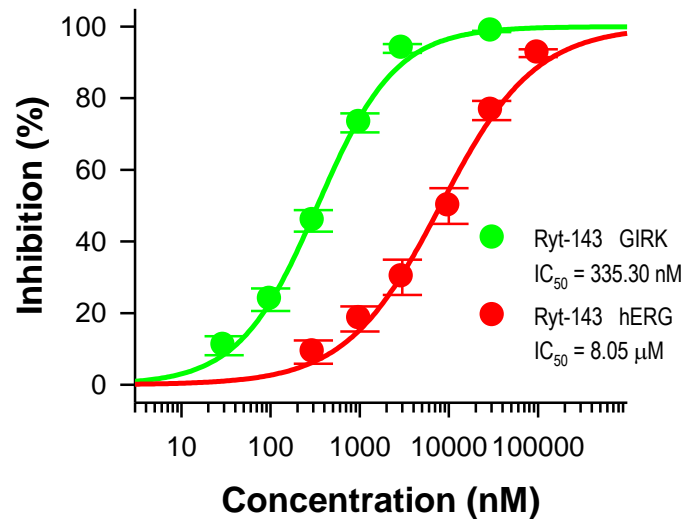

B
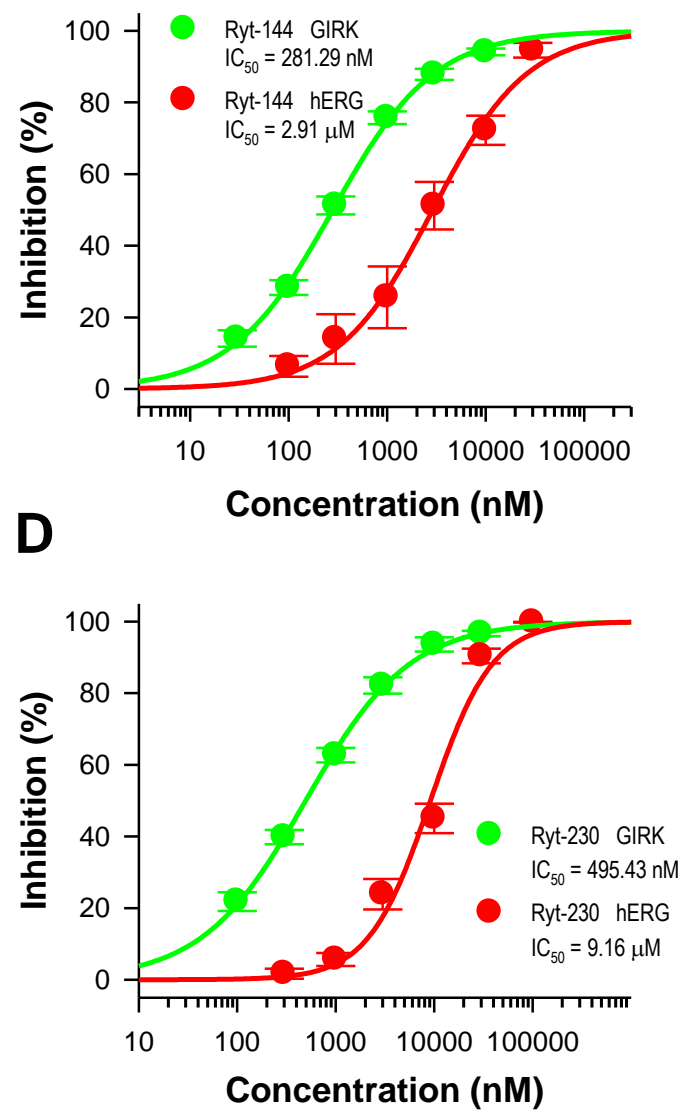

Figure 13. GIRK and hERG dose-response curves of 4 compounds with the most intense GIRK blocking effect. Panel A shows the blocking activity of Ryt-243 on GIRK and hERG channels. The inhibitory properties were similar with $\mathrm{IC}_{50}$ values $100.14 \pm 5.10 \mathrm{nM}$ and $47.56 \pm 5.31 \mathrm{nM}$, respectively. Panel $\mathbf{B}, \mathbf{C}$ and $\mathbf{D}$ depicted the concentration-response relationship of Ryt-144, Ryt-143 and Ryt-230, respectively, on GIRK and hERG channels. These three compounds show severe GIRK-selectivity. I $\mathrm{C}_{50}$ values on GIRK and hERG channels were $281.29 \pm 9.48 \mathrm{nM}$ and $2.91 \pm 0.29 \mu \mathrm{M}$ for Ryt-144, $335.30 \pm 23.81 \mathrm{nM}$ and $8.05 \pm 0.89 \mu \mathrm{M}$ for Ryt-143, $495.43 \pm 15.90 \mathrm{nM}$ and $9.16 \pm 1.30 \mu \mathrm{M}$ for Ryt-230 ( $=5-7)$.

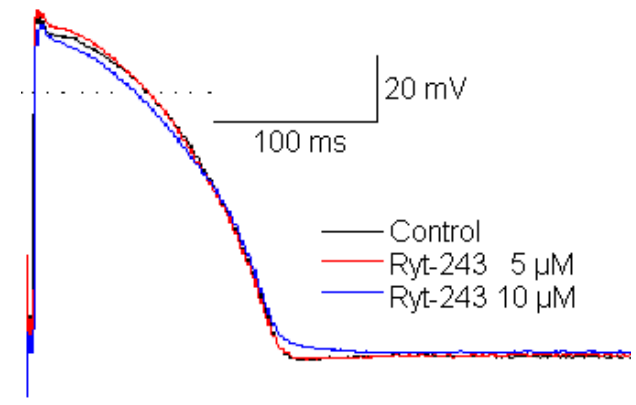

Figure 14. Effects of Ryt-243 on action potential waveform of rabbit ventricular muscle at stimulation cycle length of $1000 \mathrm{~ms}$. Ryt-243 prolonged the action potential neither in $5 \mu \mathrm{M}$ nor in $10 \mu \mathrm{M}$ concentrations. 


\subsubsection{Screening of different substrates originated from plants on GIRK channel}

\subsubsection{Screening of natural plant compounds on GIRK channel}

Compounds originated from natural sources were also investigated in our GIRK screen project. During this phase of screening project a set of 281 natural plant compounds originated from the Department of Pharmacognosy, University of Szeged was tested [51]. These molecules were chosen randomly and were not selected as the expected high hit rate of the natural compounds. Compounds were screened also in two concentrations ( 1 and $10 \mu \mathrm{M})$ on at least 2 cells.

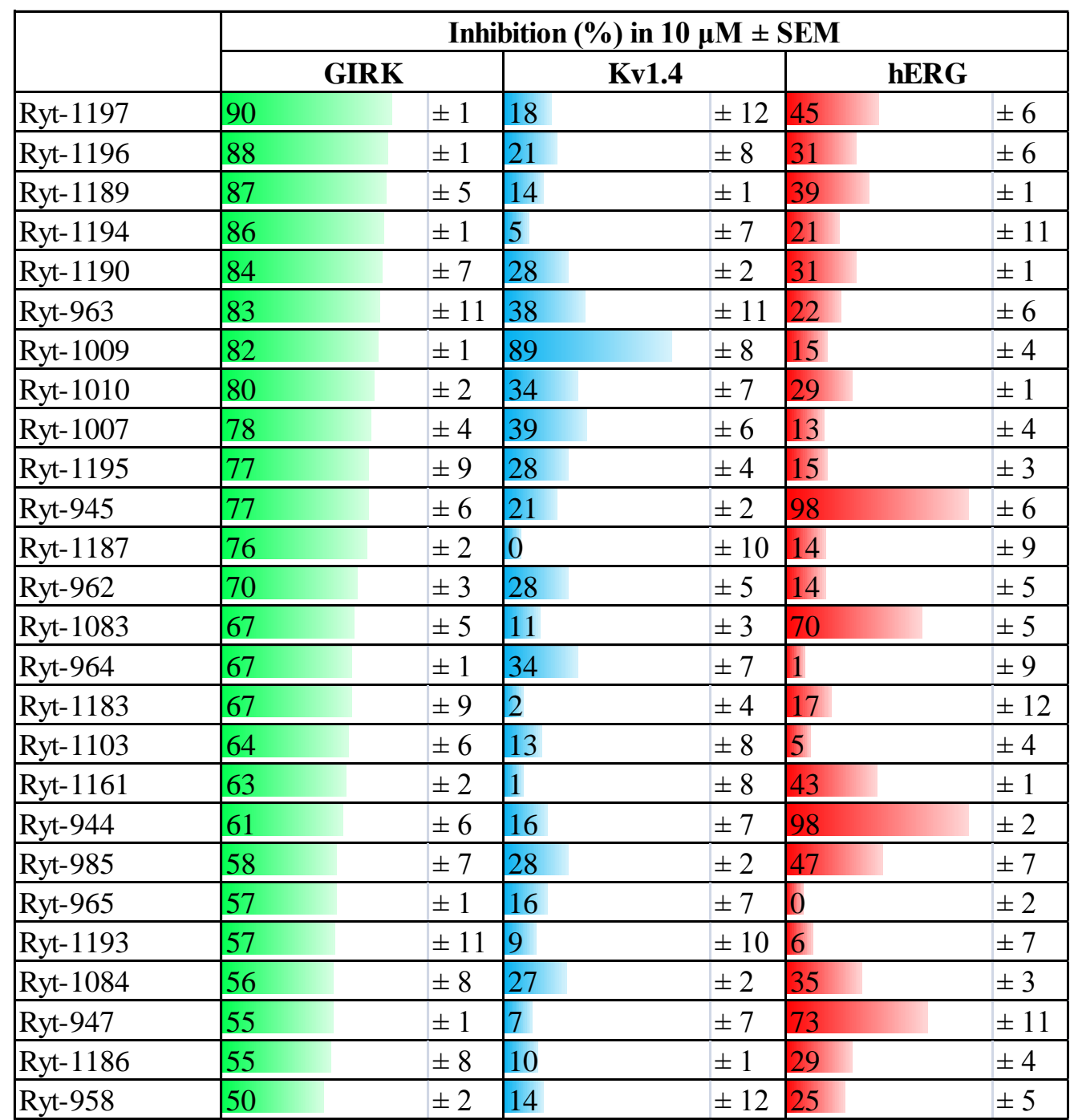

Table 1. Blocking effects of the 26 most effective natural compounds in $10 \mu \mathrm{M}$ concentration on GIRK (green), Kv1.4 (blue) and hERG (red) ion channels $(n=2-3)$. 
Approximately $9 \%$ of the investigated natural compounds showed a notable (i.e. at least $50 \%$ decrease in the GIRK current at $10 \mu \mathrm{M}$ concentration) blocking effect.

The 26 most effective molecules were selected for further evaluation following the primary screen. These compounds were also tested on Kv1.4 and hERG cell lines and selectivity of their GIRK blocking effect was evaluated with these experiments. Blocking effects of these agents in $10 \mu \mathrm{M}$ concentration on the investigated 3 different ion channels are shown in Table 1.

Six natural plant compounds (Ryt-963, Ryt-964, Ryt-1009, Ryt-1103, Ryt-1187 and Ryt-1194) were chosen from the group of most effective ones upon their blocking effects and chemical structure. The dose-response curves of these 6 molecules were determined in detailed experiments where effect of the chosen compounds on GIRK current was tested in 4-5 concentrations on at least 5 cells. Dose-response curves and $\mathrm{IC}_{50}$ values of these compounds are shown in Figure 15.

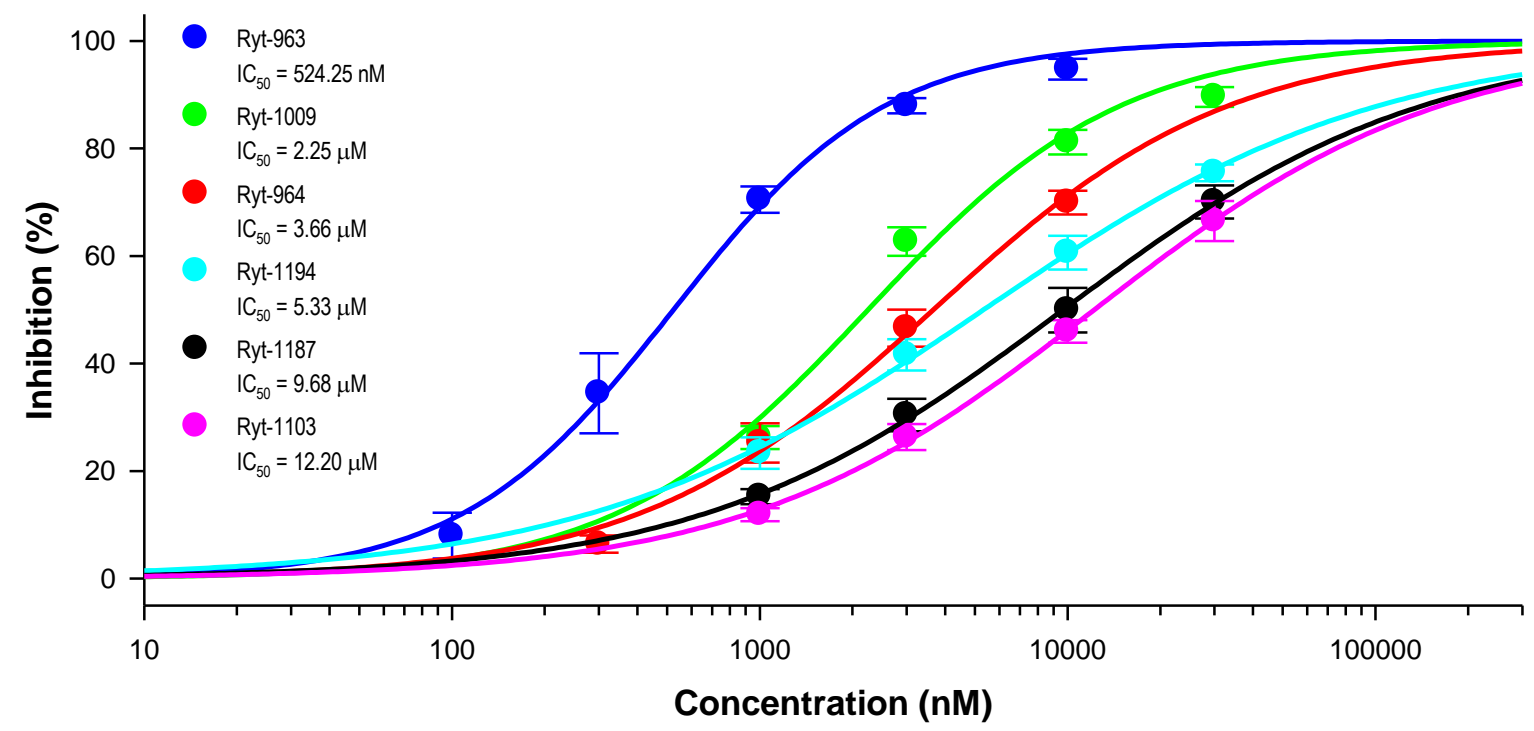

Figure 15. Dose-response curves of six agents which were selected after GIRK screening project of natural plant compounds upon their blocking effect, chemical structure and selectivity. $I_{50}$ values were $524.25 \pm 35.87 \mathrm{nM}$ for Ryt-963, $2.25 \pm 0.33 \mu \mathrm{M}$ for Ryt-1009, $3.66 \pm 0.30 \mu \mathrm{M}$ for Ryt-964, $5.33 \pm 0.23 \mu \mathrm{M}$ for Ryt-1194, $9.68 \pm 0.27 \mu \mathrm{M}$ for Ryt-1187 and $12.20 \pm 0.31 \mu \mathrm{M}$ for Ryt-1103 $(n=5-7)$.

\subsubsection{Screening of plant extracts on GIRK channel}

Testing a new way of tracing biologically active compounds extracts of Polygonum persicaria were also investigated in our GIRK screen system, with the aim to identify natural sources of promising ion channel blocking compounds [52]. For this purpose hexane, chloroform, 
methanol and aqueous extracts were prepared from the dried whole plant. Extracts of different polarity were investigated at two concentrations $(0.01 \mathrm{mg} / \mathrm{l}$ and $0.1 \mathrm{mg} / \mathrm{l})$. The chloroform extract exhibited considerable GIRK channel inhibitory activity. This extract was fractionated by vacuum liquid chromatography on RP-silica gel resulting six fractions (fractions 1-6), which were also evaluated for GIRK modulation activity. The most active fractions (fraction 4 and 5) were subjected then to RP-HPLC, affording the isolation of the main compounds 1-4 in pure form. The eluates containing the mixture of other (minor) compounds were also collected during the HPLC chromatography. Both the isolated compounds (at 1 and $10 \mu \mathrm{M}$ concentration) and the HPLC eluates of the highly active fractions of the chloroform extract - presumably containing unidentified minor compounds - were involved in the GIRK channel inhibitory assay. Table 2 shows GIRK channel blocking effects of Polygonum persicaria extracts, fractions and isolated compounds.

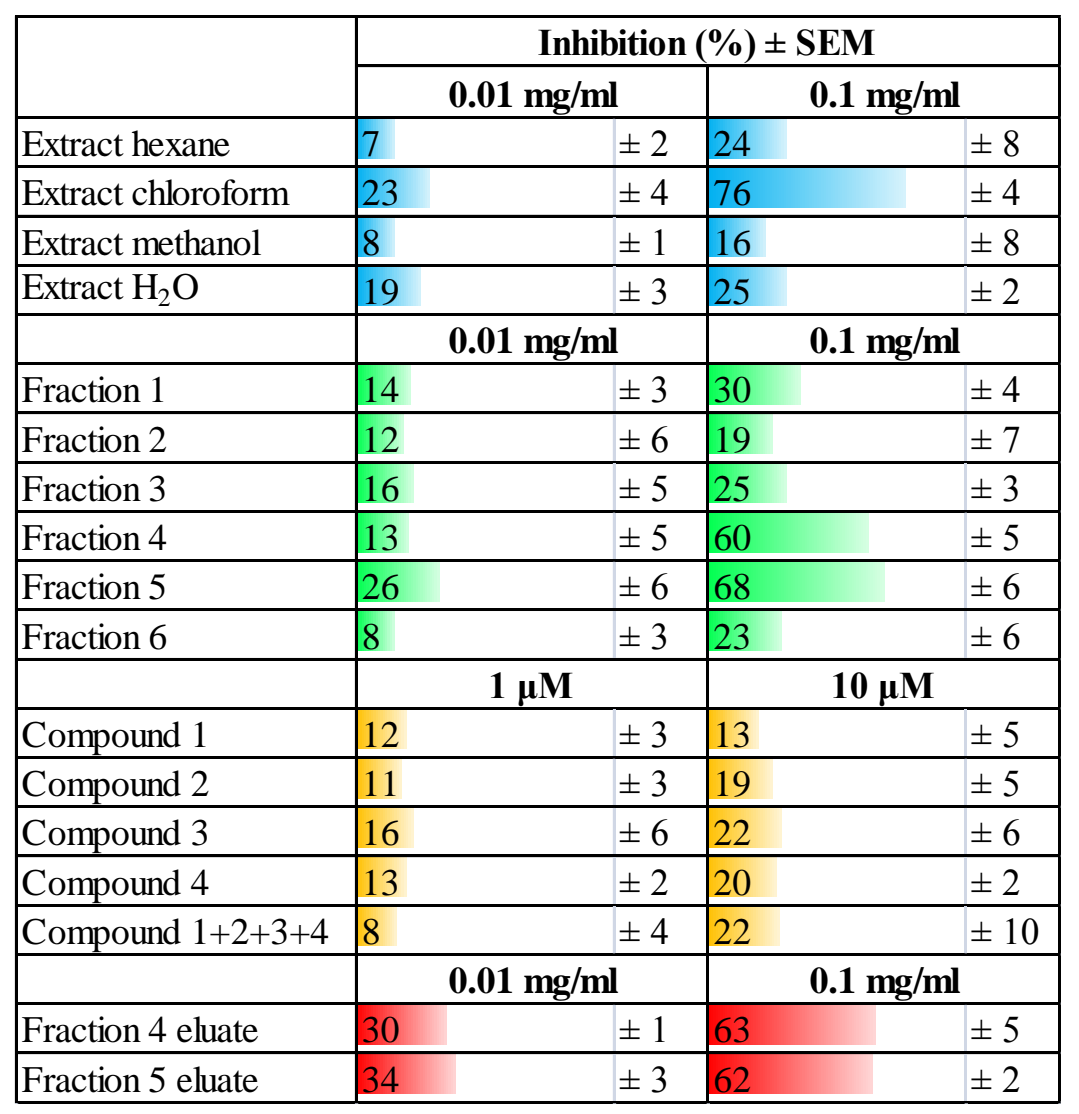

Table 2. GIRK channel inhibitory activity of Polygonum persicaria extracts (blue), fractions of chloroform extract (green), isolated compounds of fraction 4-5 (orange) and fraction 4-5 eluate (red) $(n=3-5)$.

Interestingly, either separated or combined application of the isolated main compounds of the active fractions (compound 1-4) possess only very moderate activity on GIRK channel, while the HPLC eluates of fraction 4 and 5 containing a mixture of minor compounds revealed to be 
active, indicating the presence of electrophysiologically active agents among the minor compounds. Further studies are on the way in order to identify the minor compounds responsible for the GIRK channel blocking effect. Nevertheless our studies confirm the usability of the applied method of tracing active compounds upon their biological activity.

\subsection{Safety pharmacology studies}

\subsubsection{Assessment of hERG assay performed with automated patch-clamp system in the} safety evaluation of investigational compounds

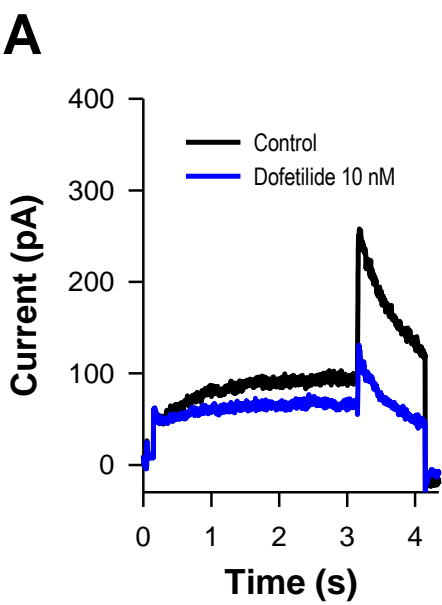

D

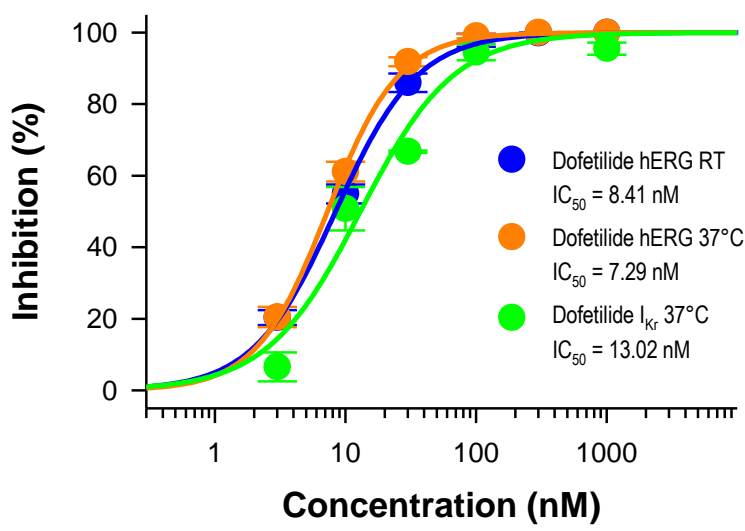

B

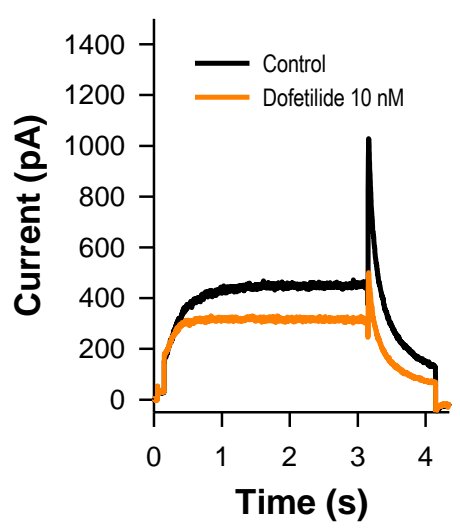

E
C

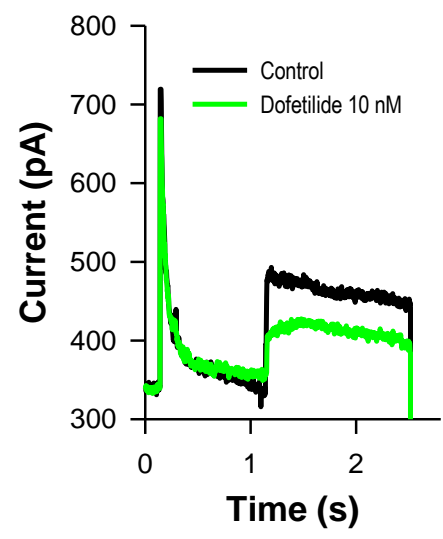

Figure 16. Effect of dofetilide on $\mathrm{hERG}$ and $\mathrm{I}_{\mathrm{kr}}$ current and on action potential waveform. Panel $\mathrm{A}$ shows example traces for hERG mediated currents obtained from HEK-hERG cell treated with $10 \mathrm{nM}$ dofetilide at room temperature. Panel $\mathbf{B}$ depicted the effect of $10 \mathrm{nM}$ dofetilide on $\mathrm{hERG}$ current at $37^{\circ} \mathrm{C}$. Dofetilide inhibited the peak tail currents on these temperatures in similar rate but with different kinetics. Panel $\mathbf{C}$ shows sample $\mathrm{I}_{\mathrm{kr}}$ current sweeps obtained from rabbit ventricular muscle cells treated with $10 \mathrm{nM}$ dofetilide. Panel $\mathbf{D}$ shows the dose-response curves of dofetilide derived from $h E R G$ on room temperature and on $37^{\circ} \mathrm{C}(n=5)$ and $\mathrm{I}_{\mathrm{kr}}(n=2-6)$ experiments. The $\mathrm{IC}_{50}$ values were in good correlation with a value of $8.41 \pm 0.19 \mathrm{nM}, 7.29 \pm 0.16 \mathrm{nM}$ and $13.02 \pm 2.56 \mathrm{nM}$, respectively. Panel $\mathrm{E}$ presented the effects of $13 \mathrm{nM}$ dofetilide on action potential waveform of rabbit ventricular muscle at stimulation cycle length of $1000 \mathrm{~ms}$. 
Two compounds (dofetilide and sotalol) were tested in hERG assay both at room temperature and at $37^{\circ} \mathrm{C}$ with automated patch-clamp system. The $\mathrm{IC}_{50}$ values of dofetilide were very similar $\left(8.41 \pm 0.19 \mathrm{nM}\right.$ at room temperature and $7.29 \pm 0.16 \mathrm{nM}$ at $\left.37^{\circ} \mathrm{C}\right)$. Sotalol displayed different properties at room temperature versus physiological temperature $\left(37^{\circ} \mathrm{C}\right)$. Sotalol blocked hERG channels at room temperature with an $\mathrm{IC}_{50}$ of $773.74 \pm 9.28 \mu \mathrm{M}$. However, at $37^{\circ} \mathrm{C}$ sotalol was more potent $\left(\mathrm{IC}_{50}=342.84 \pm 24.82 \mu \mathrm{M}\right)$.

A

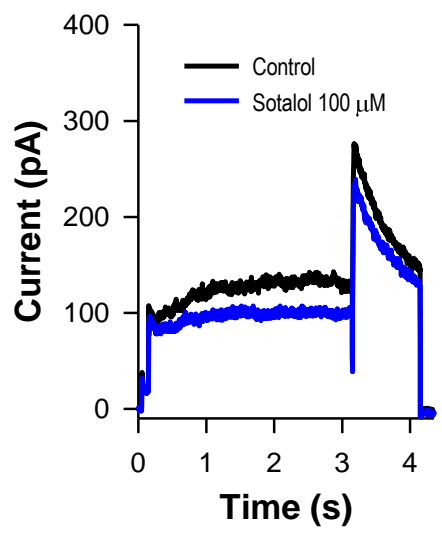

D
B

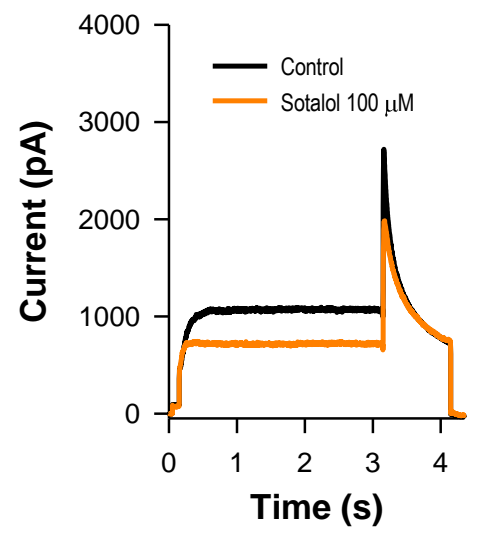

C

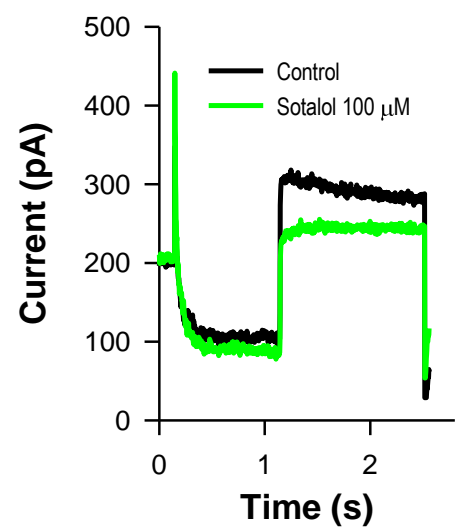

$\mathbf{E}$

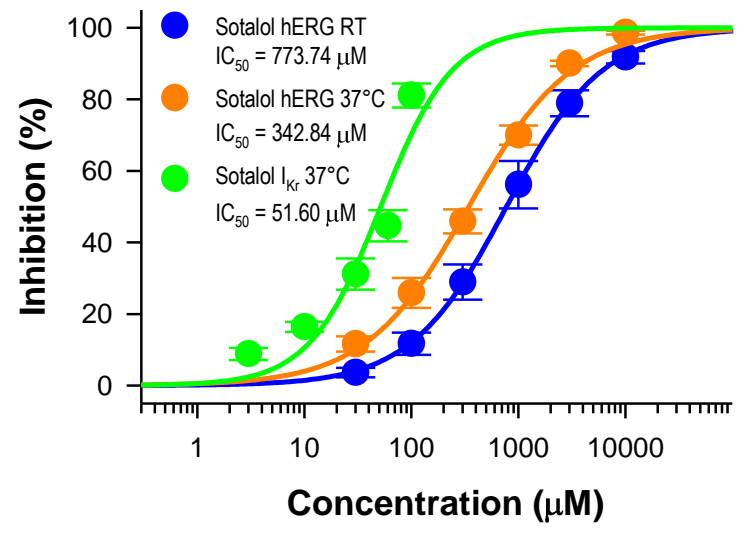

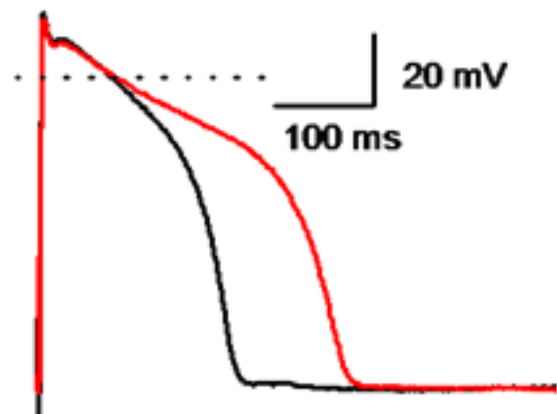

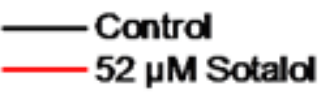

Figure 17. Effect of sotalol on $h E R G$ and $\mathrm{I}_{\mathrm{kr}}$ current and on action potential waveform. Panel $\mathbf{A}$ shows representative hERG current curves obtained from HEK-hERG cell treated with $100 \mu \mathrm{M}$ sotalol at room temperature. Panel B displays the effect of $100 \mu \mathrm{M}$ sotalol on $\mathrm{hERG}$ current at $37^{\circ} \mathrm{C}$. Sotalol had little effect on room temperature, and also mild but somewhat stronger blocking effect on $37^{\circ} \mathrm{C}$. Panel $\mathbf{C}$ shows representative $\mathrm{I}_{\mathrm{Kr}}$ current curves obtained from rabbit ventricular muscle cells treated with $100 \mu \mathrm{M}$ sotalol. The effect was more remarkable than $h E R G$ current. Panel $\boldsymbol{D}$ shows the concentration-response curves of sotalol obtained from $h E R G$ at room temperature and at $37^{\circ} \mathrm{C}(n=5-6)$ and $\mathrm{I}_{\mathrm{Kr}}(\mathrm{n}=2-6)$ measurements. The $\mathrm{IC}_{50}$ values are drastically different with a value of $773.74 \pm 9.28 \mu \mathrm{M}, 342.84 \pm 24.82 \mu \mathrm{M}$ and $51.60 \pm 9.82 \mu \mathrm{M}$, respectively. Panel E shows the effects of $52 \mu \mathrm{M}$ sotalol on action potential waveform of rabbit ventricular muscle at stimulation cycle length of $1000 \mathrm{~ms}$.

To evaluate the prognostic value of hERG assay these compounds were subjected for further investigations. The $\mathrm{I}_{\mathrm{Kr}}$ current blocking capability of the compounds was tested on rabbit 
ventricular muscle with manual patch-clamp method. The $\mathrm{IC}_{50}$ values of dofetilide and sotalol were $13.02 \pm 2.56 \mathrm{nM}$ and $51.60 \pm 9.82 \mu \mathrm{M}$, respectively. $\mathrm{IC}_{50}$ values obtained in $\mathrm{hERG}$ and $\mathrm{I}_{\mathrm{Kr}}$ assays showed a good correlation in case of dofetilide while $\mathrm{IC}_{50}$ value obtained from $\mathrm{I}_{\mathrm{Kr}}$ measurements was approximately 7 times lower in case of sotalol. The results of both automated and manual patch-clamp experiments are shown in Figure 16 and Figure 17.

To study the safety pharmacology consequences of the hERG and $\mathrm{I}_{\mathrm{Kr}}$ inhibitory effect of dofetilide and sotalol the effect of these compounds on action potential configuration were studied in rabbit right ventricular muscle preparations. In these investigations, the $\mathrm{IC}_{50}$ values obtained from $\mathrm{I}_{\mathrm{Kr}}$ experiments were applied. Both agents significantly lenghtened the action potential duration at stimulation cycle length of $1000 \mathrm{~ms}$. The prolongation of $\mathrm{APD}_{90}$ was $47.8 \pm 12.9 \%(\mathrm{n}=7)$ in case of $13 \mathrm{nM}$ dofetilide while $52 \mu \mathrm{M}$ sotalol extended the action potential duration with $56.0 \pm 4.6 \%(\mathrm{n}=5)$. The results are presented in Figure 16, Figure 17 and Table 3.

\begin{tabular}{|l|c|c|c|c|c|}
\hline & $\mathbf{R P}(\mathbf{m V})$ & $\mathbf{A P A}(\mathbf{m V})$ & $\mathbf{V}_{\mathbf{m a x}}(\mathbf{V} / \mathbf{s})$ & $\mathbf{A P D}_{\mathbf{9 0}}(\mathbf{m s})$ & $\mathbf{A P D}_{\mathbf{5 0}}(\mathbf{m s})$ \\
\hline Control & $-88.3 \pm 0.3$ & $109.0 \pm 2.4$ & $182.1 \pm 12.4$ & $190.5 \pm 14.1$ & $154.7 \pm 15.1$ \\
\hline Dofetilide 13 nM & $-87.6 \pm 0.8$ & $109.3 \pm 3.5$ & $187.0 \pm 15.9$ & $285.9 \pm 40.1$ & $234.4 \pm 38.2$ \\
\hline Control & $-90.1 \pm 0.7$ & $103.4 \pm 1.9$ & $170.5 \pm 15.3$ & $156.9 \pm 10.7$ & $116.6 \pm 13.1$ \\
\hline Sotalol $52 \mu \mathrm{M}$ & $-91.8 \pm 0.6$ & $105.8 \pm 3.1$ & $205.3 \pm 21.6$ & $244.3 \pm 15.9$ & $181.3 \pm 21.5$ \\
\hline
\end{tabular}

Table 3. The electrophysiological effects of $13 \mathrm{nM}$ dofetilide and $52 \mu \mathrm{M}$ sotalol in rabbit ventricular muscle preparations at basic cycle length of $1000 \mathrm{~ms}$. RP, resting potential; APA, action potential amplitude; $V_{\max }$, maximum rate of depolarization; $\mathrm{APD}_{90}$ and $\mathrm{APD}_{50}$, action potential durations at $50 \%$ and $90 \%$ of repolarization. Results are mean \pm SEM, $n=5-7$.

\subsubsection{Effects of Chelidonium majus extracts and major alkaloids on hERG ion channel and on dog cardiac action potential}

Chelidonium majus or greater celandine is spread throughout the world, and it is an important plant of the modern phytotherapy, used not only externally, but also internally. Although C. majus contains alkaloids with remarkable physiological effect, safety pharmacology properties of this plant are not widely clarified. Therefore, effects of $C$. majus herb extracts and alkaloids on hERG $\mathrm{K}^{+}$current as well as on cardiac action potential were studied [44]. 


\subsubsection{Effects of extracts and alkaloids of Chelidonium majus on hERG current}

For the investigations of hERG blocking effects of $C$. majus extracts, $25 \%$ and $45 \%$ ethanol (V/V) extracts were prepared with regard to the Assessment report EMA/HMPC/369801/2009 on C. majus herb [53], which refers these extracts for internal use. Both extracts revealed significant $\mathrm{hERG}$ ion channel inhibitory activity at room temperature with estimated $\mathrm{IC}_{50}$ values of $8.31 \pm 0.79 \mu \mathrm{g} / \mathrm{ml}$ and $5.09 \pm 0.49 \mu \mathrm{g} / \mathrm{ml}$ (Figure 18).

A

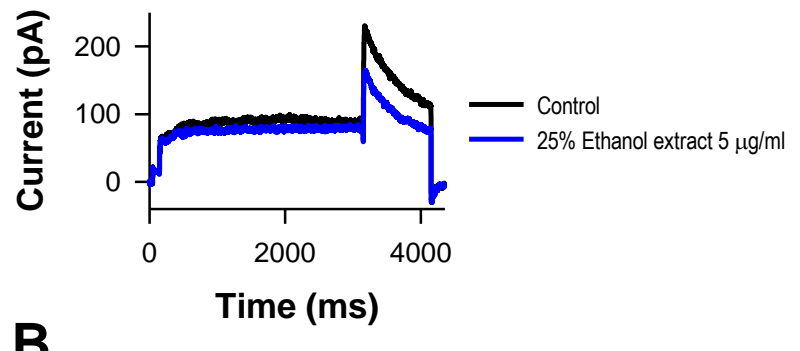

B

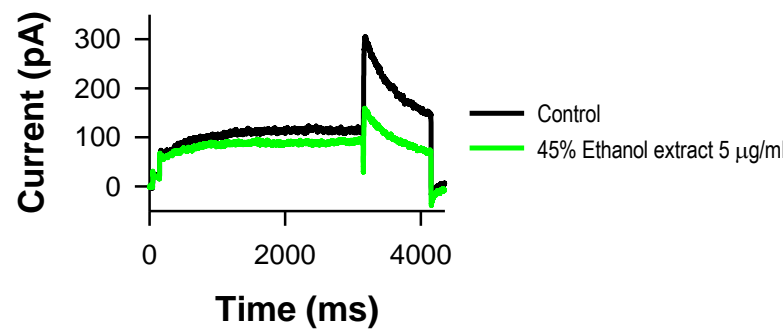

C

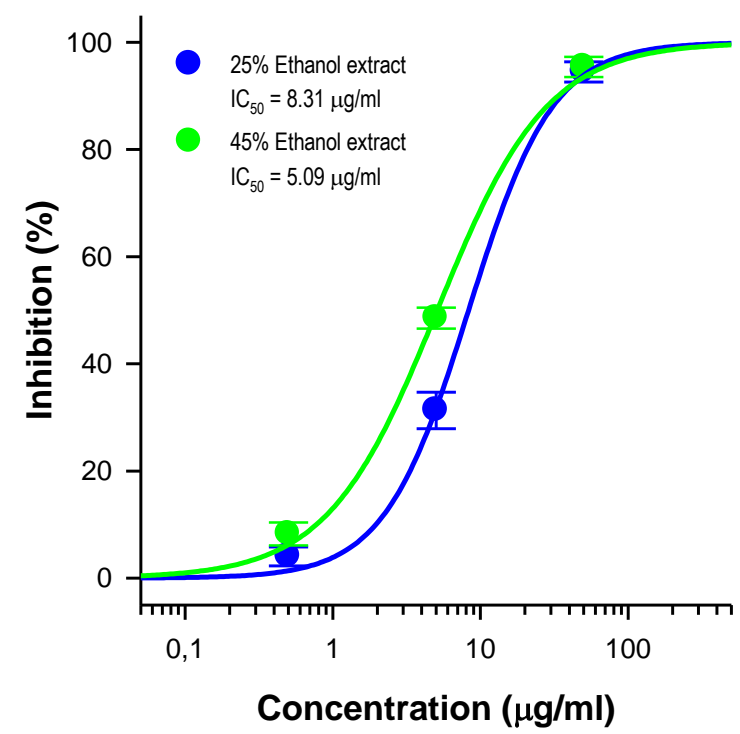

Figure 18. Concentration-dependent effects of Chelidonium majus extracts on hERG current. Panel $\mathbf{A}$ depicted representative hERG current curves obtained from cell treated with $25 \%$ ethanol extract, while panel B shows the effect of $45 \%$ ethanol extract, both at $5 \mu \mathrm{g} / \mathrm{ml}$ concentration. Panel $\mathbf{C}$ shows the dose-response curves of the $25 \%$ ethanol extract and the $45 \%$ ethanol extract on $h E R G$ current. Estimated $I_{50}$ values are $8.31 \pm 0.79 \mu \mathrm{g} / \mathrm{ml}$ and $5.09 \pm 0.49 \mu \mathrm{g} / \mathrm{ml}$, respectively $(n=5)$.

The hERG blocking potencies of the major alkaloids of the plant (sanguinarine, chelidonine, berberine and coptisine) were also evaluated and found that all alkaloids showed considerable inhibitory effect apart from coptisine (Figure 19). Sanguinarine and chelidonine were to have the highest inhibitory effect with the $\mathrm{IC}_{50}$ value of $0.88 \pm 0.08 \mu \mathrm{M}$ and $1.00 \pm 0.10 \mu \mathrm{M}$, respectively. The hERG channel modulatory activity of berberine could be characterized by the $\mathrm{IC}_{50}$ value of $6.46 \pm 0.54 \mu \mathrm{M}$, whereas coptisine exhibited only marginal effect $\left(\mathrm{IC}_{50}=90.08 \pm 2.88 \mu \mathrm{M}\right)$. 
A

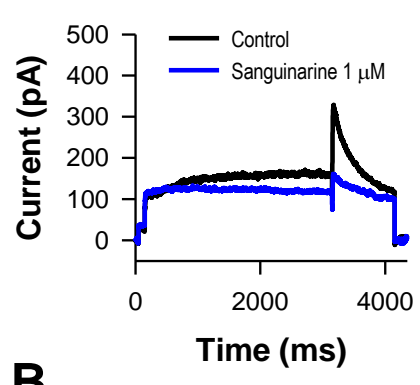

B

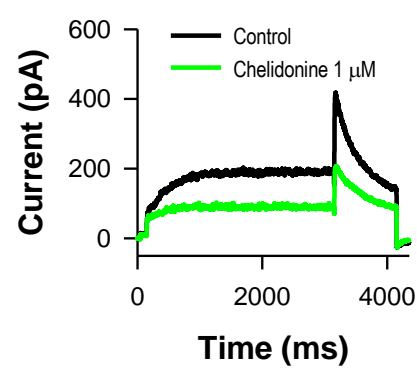

C
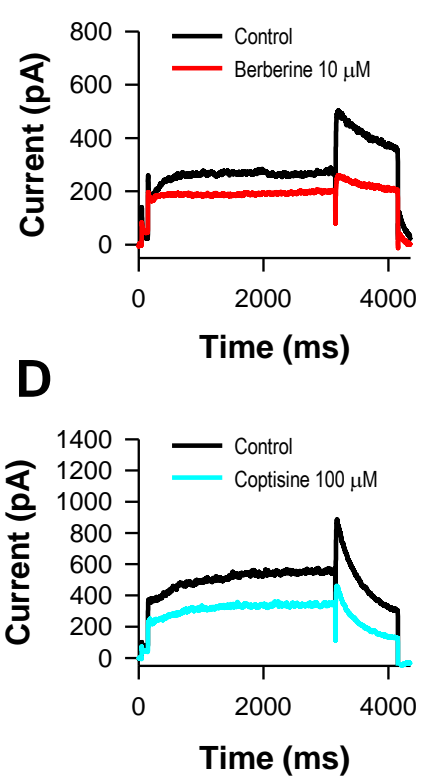

$\mathbf{E}$

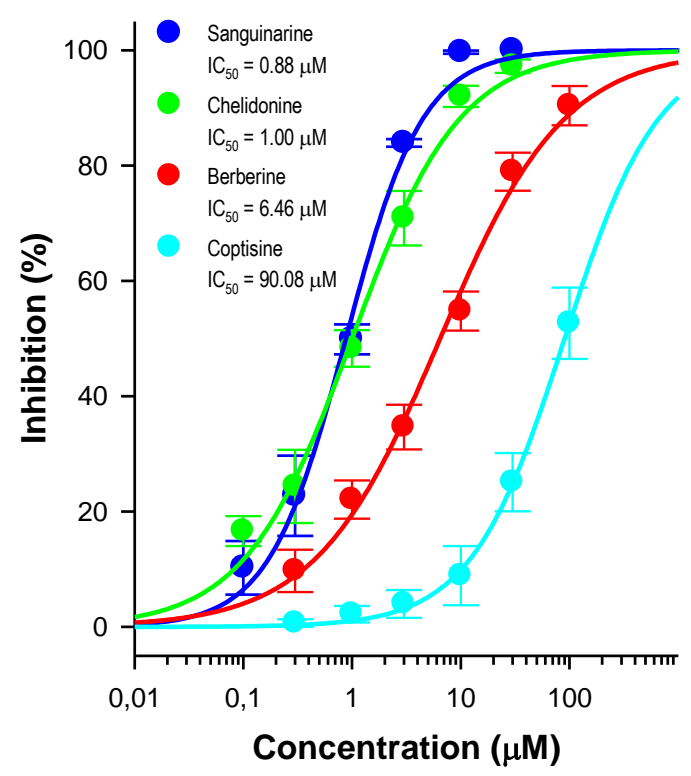

Figure 19. Concentration-dependent inhibitory effects of Chelidonium majus derived alkaloids on $h E R G$ current. Panels A-D show representative hERG current curves obtained from cells treated with $1 \mu \mathrm{M}$ sanguinarine $(\mathbf{A})$, $1 \mu \mathrm{M}$ chelidonine (B), $10 \mu \mathrm{M}$ berberine (C) and $100 \mu \mathrm{M}$ coptisine (D). Panel $\mathbf{E}$ shows the dose-response curves of the examined alkaloids. Sanguinarine and chelidonine were the most effective with $\mathrm{IC}_{50}=0.88 \pm 0.08 \mu \mathrm{M}$ and $1.00 \pm 0.10 \mu \mathrm{M}$, berberine $\mathrm{IC}_{50}$ was $6.46 \pm 0.54 \mu \mathrm{M}$, while coptisine exhibited only marginal effect with $\mathrm{IC}_{50}=90.08 \pm 2.88 \mu \mathrm{M}(\mathrm{n}=4-5)$.

\subsubsection{Effects of extracts and alkaloids of Chelidonium majus on ventricular action potential}

To investigate the safety pharmacology consequences of the hERG blocking effect of C. majus extracts and alkaloids the effect of these agents - with the exception of coptisine - on action potential configuration were studied in canine right ventricular muscle preparations. The results are presented in Table 4.

Both extracts moderately extended the action potential duration at $5 \mu \mathrm{g} / \mathrm{ml}$ concentration in statistically significant manner at basic stimulation cycle length of $1000 \mathrm{~ms}$. The prolongation of $\mathrm{APD}_{90}$ was $10.5 \%$ in case of the $25 \%$ ethanol extract while the $45 \%$ ethanol extract lengthened the action potential duration with $6.7 \%$. The maximum rate of depolarization $\left(\mathrm{V}_{\max }\right)$ was not influenced significantly by the extracts. To study the rate-dependent effect of the extracts on $\mathrm{APD}_{90}$, the preparations were stimulated at cycle lengths ranging from 300 to $5000 \mathrm{~ms}$. Under these circumstances the extracts produced a slight reverse rate-dependent APD prolongation, especially in case of $45 \%$ extract (Figure 20). 


\begin{tabular}{|l|c|c|c|l|l|}
\hline & $\mathbf{R P}(\mathbf{m V})$ & $\mathbf{A P A}(\mathbf{m V})$ & $\mathbf{V}_{\mathbf{m a x}}(\mathbf{V} / \mathbf{s})$ & $\mathbf{A P D}_{\mathbf{9 0}}(\mathbf{m s})$ & $\mathbf{A P D}_{\mathbf{5 0}}(\mathbf{m s})$ \\
\hline Control & $-85.4 \pm 0.5$ & $106.5 \pm 2.3$ & $258.0 \pm 39.2$ & $222.4 \pm 6.4$ & $178.9 \pm 9.2$ \\
\hline $25 \%$ Ethanol extract $5 \mu \mathrm{g} / \mathrm{ml}$ & $-85.0 \pm 0.8$ & $106.0 \pm 2.7$ & $244.1 \pm 39.9$ & $246.5 \pm 13.5$ & $200.8 \pm 14.9$ \\
\hline Control & $-87.3 \pm 0.5$ & $106.3 \pm 1.8$ & $209.3 \pm 25.6$ & $226.0 \pm 5.9$ & $179.8 \pm 7.2$ \\
\hline $45 \%$ Ethanol extract $5 \mu \mathrm{g} / \mathrm{ml}$ & $-85.8 \pm 0.8$ & $104.8 \pm 1.2$ & $245.3 \pm 22.4$ & $241.3 \pm 8.8$ & $186.2 \pm 11.5$ \\
\hline Control & $-86.8 \pm 1.2$ & $105.4 \pm 3.0$ & $250.6 \pm 46.5$ & $219.4 \pm 6.6$ & $181.6 \pm 7.3$ \\
\hline Berberine $1 \mu \mathrm{M}$ & $-86.1 \pm 0.9$ & $107.6 \pm 4.0$ & $226.5 \pm 44.6$ & $233.1 \pm 7.3$ & $196.2 \pm 6.6$ \\
\hline Control & $-86.8 \pm 1.0$ & $107.3 \pm 3.2$ & $247.2 \pm 39.4$ & $223.1 \pm 6.7$ & $183.0 \pm 6.4$ \\
\hline Berberine $10 \mu \mathrm{M}$ & $-86.1 \pm 0.8$ & $107.0 \pm 2.5$ & $247.9 \pm 20.9$ & $258.4 \pm 8.5$ & $215.5 \pm 8.3$ \\
\hline Control & $-88.8 \pm 3.8$ & $106.8 \pm 2.8$ & $174.4 \pm 18.0$ & $230.4 \pm 17.6$ & $180.6 \pm 13.6$ \\
\hline Chelidonine $1 \mu \mathrm{M}$ & $-85.4 \pm 1.4$ & $108.7 \pm 3.3$ & $151.5 \pm 9.0$ & $240.1 \pm 16.2$ & $189.0 \pm 11.4$ \\
\hline Control & $-89.0 \pm 3.7$ & $106.9 \pm 2.7$ & $172.9 \pm 18.7$ & $219.6 \pm 15.9$ & $174.6 \pm 14.0$ \\
\hline Chelidonine $10 \mu \mathrm{M}$ & $-85.9 \pm 1.6$ & $112.9 \pm 3.2$ & $197.8 \pm 36.7$ & $259.7 \pm 17.7$ & $204.8 \pm 14.1$ \\
\hline Control & $-89.0 \pm 2.1$ & $104.0 \pm 2.6$ & $230.1 \pm 43.5$ & $200.4 \pm 9.3$ & $156.4 \pm 8.5$ \\
\hline Sanguinarine $1 \mu \mathrm{M}$ & $-87.6 \pm 2.5$ & $105.5 \pm 4.3$ & $242.8 \pm 59.5$ & $212.9 \pm 11.9$ & $170.9 \pm 11.4$ \\
\hline Control & $-86.8 \pm 0.9$ & $102.1 \pm 3.0$ & $169.2 \pm 23.7$ & $208.0 \pm 12.2$ & $172.2 \pm 13.0$ \\
\hline Sanguinarine $10 \mu \mathrm{M}$ & $-85.8 \pm 1.7$ & $104.3 \pm 1.7$ & $142.3 \pm 24.3$ & $244.2 \pm 6.2$ & $202.5 \pm 5.7$ \\
\hline
\end{tabular}

Table 4. The electrophysiological effects of Chelidonium majus extracts in dog ventricular muscle preparations at basic cycle length of $1000 \mathrm{~ms}$. RP, resting potential; APA, action potential amplitude; $V_{\max }$, maximum rate of depolarization; $A P D_{90}$ and $\mathrm{APD}_{50}$, action potential durations at $50 \%$ and $90 \%$ of repolarization. Results are mean \pm SEM, $n=5-7$.

A

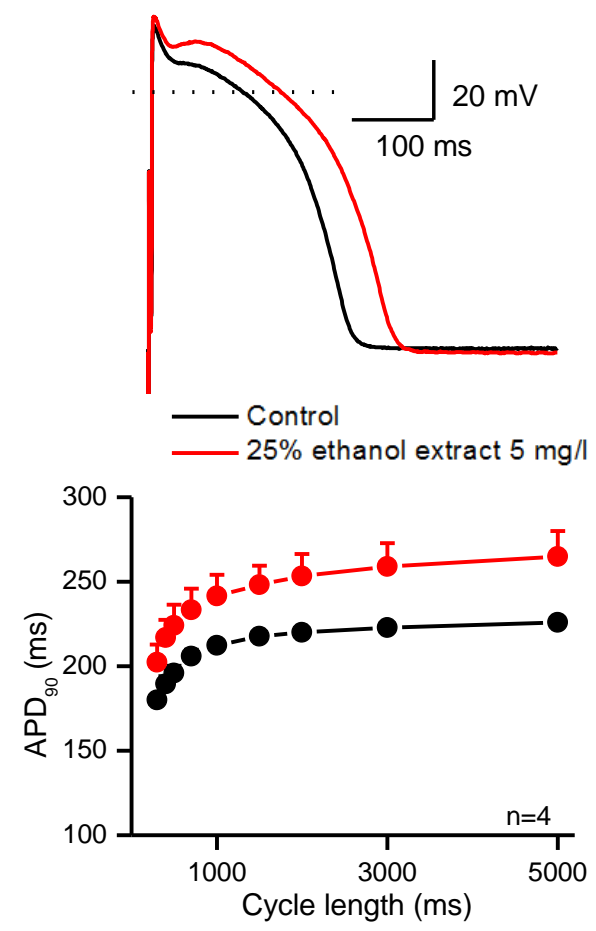

B
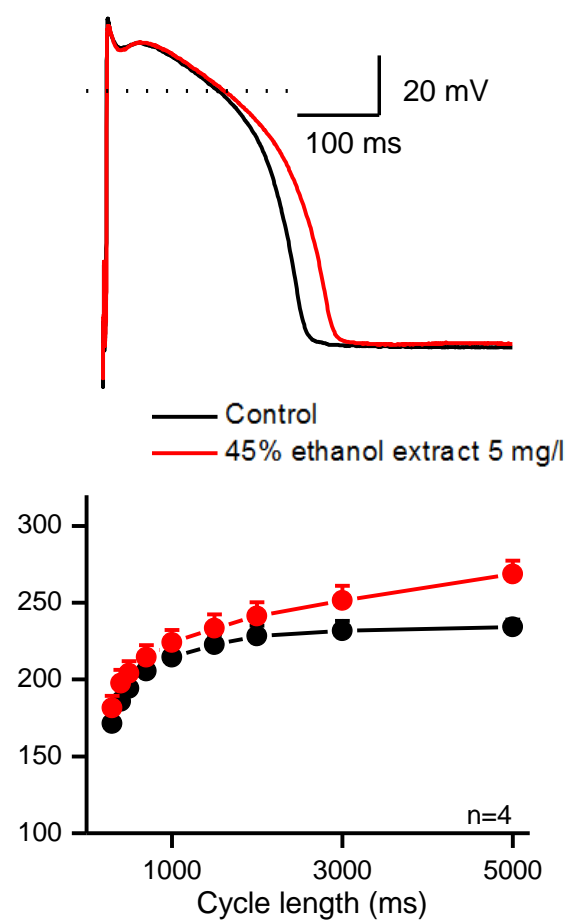

Figure 20. Effects of Chelidonium majus extracts (25\% ethanol extract and $45 \%$ ethanol extract on panel $\mathbf{A}$ and B, respectively) on action potential waveform of dog ventricular muscle at stimulation cycle length of $1000 \mathrm{~ms}$ and rate-dependent effects on action potential duration $\left(\mathrm{APD}_{90}\right)$. 
The effects of berberine, chelidonine and sanguinarine on the action potential parameters at concentrations of $1 \mu \mathrm{M}$ and $10 \mu \mathrm{M}$ were also investigated in dog ventricular muscle at constant cycle length of $1000 \mathrm{~ms}$ (Table 4). All compounds showed mild but statistically significant effect on $\mathrm{APD}_{90}(4.6 \%, 6.1 \%$ and $6.3 \%$ prolongation, respectively) at $1 \mu \mathrm{M}$ concentration. At $10 \mu \mathrm{M}$ concentration the action potential prolongation was more considerable $(18.4 \%, 18.3 \%$ and $16.0 \%)$. The rate-dependent effect of the alkaloids were also studied, where preparations were stimulated with different cycle lengths ranging from 300 to $5000 \mathrm{~ms}$. All examined alkaloids lengthened the action potential duration in reverse-rate dependent manner (Figure 21).

$\mathbf{A}$

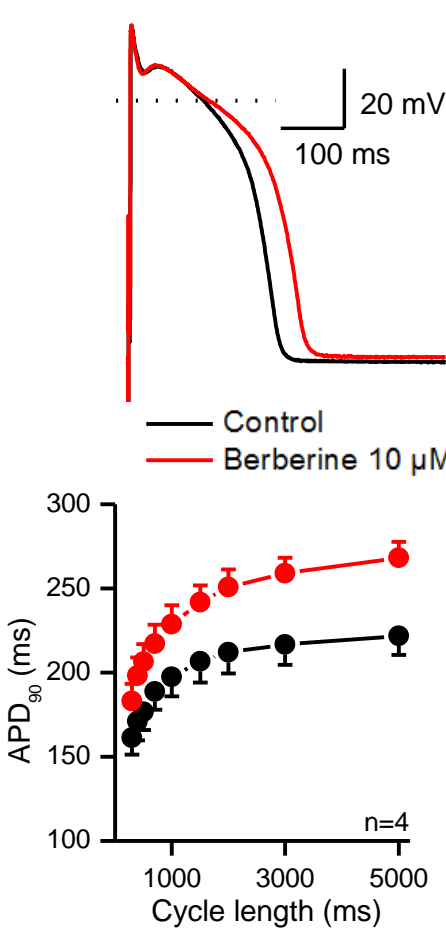

B
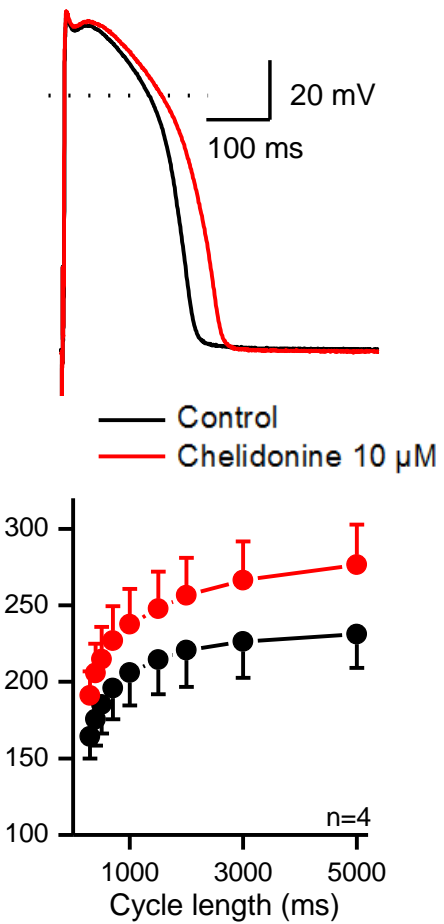

C
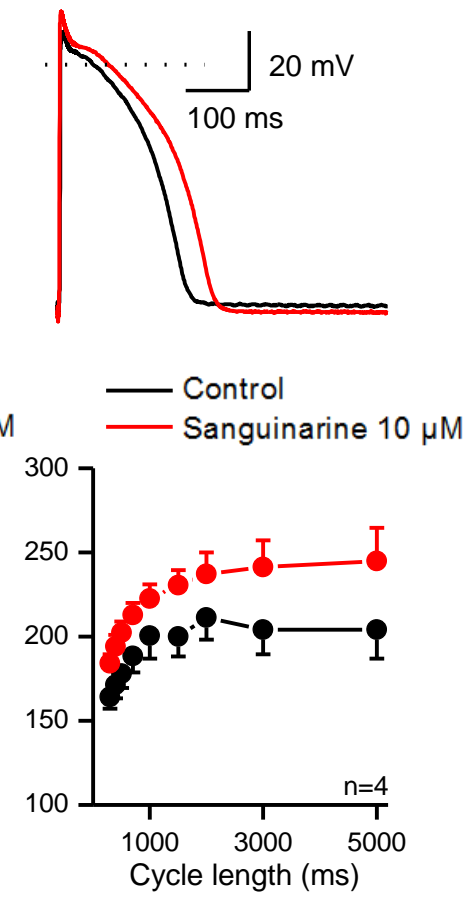

Figure 21. Effects of Chelidonium majus alkaloids on action potential waveform of dog ventricular muscle at stimulation cycle length of $1000 \mathrm{~ms}$ and rate-dependent effects on action potential duration (APD90). Results of treatment with berberine, chelidonine and sanguinarine are shown on panel $\mathbf{A}, \mathbf{B}$ and $\mathbf{C}$, respectively. 


\section{DISCUSSION}

Measurement of the activity of individual ion channels became possible after the pioneering work of Erwin Neher and Bert Sakmann in the late 1970s. The manual patch-clamp method has rapidly become the 'gold standard' in investigating ion channels $[2][3][5][7][9][10][12][25]$. The patch-clamp technique offers a direct, information-rich and real-time technology, and provides excellent dynamic range for voltage control of the cell membrane, extraordinary temporal resolution (submillisecond) and sensitivity (subpicoampere). It also enables characterization of single channels in cell-attached, insideout, and outside-out configurations as well as total cell current in whole-cell configuration. Patch-clamp data can identify many aspects of drug-ion channel interaction, which is highly valuable and desirable during the selection and development of promising drug candidates $[1][2][3][4][7][9][10]$. On the other hand, traditional manual patch-clamp is too slow, technically demanding, and labor intensive, which excludes it as a screening tool in early drug development and optimisation. This does not mean that the conventional patch-clamp method is obsolete. Conventional patch-clamp is applied at the later stages of drug discovery and development and it still represents one of the primarily tools in ion channel research laboratories. In industry, the application of patch-clamp is limited to the end phases of drug research and ion channel screening and mainly used for final compound evaluation. These limitations are the fundamental reasons behind the held back of ion channel drug discovery and why ion channels have remained an unexploited area for the pharmaceutical industry [1][2][3][4][5][7][10][12].

Consequently, high-throughput techniques such as ligand binding, radioactive flux and fluorescence assays are also essential and become pivotal components for primary drug screening and ion channel drug discovery programmes. Although most of these techniques are compatible with the throughput requirements of primary screening, generally these approaches have low fidelity, low sensitivity and low temporal resolution (in the range of seconds to minutes, as compared to patch-clamp that operates in the submillisecond range) $[2][3][4][5][7][9][10][11]$. Due to the limitations of high-throughput techniques a secondary follow-up screening is required using methods that can provide more and detailed information like patch-clamp techniques to confirm 'hits' from the primary screening. Ideally, electrophysiological studies should be performed as early as possible in the drug discovery process, to acquire better information about the compound activity and efficacy, and also about possible safety liability issues [12]. 
In recent years, many companies have developed and introduced automated patch-clamp equipments suitable for rapid and high quality screening and optimisation of ion channel drug candidates. By providing high quality, information rich assays, these appliances have the capability to bridge the gap between primary and secondary ion channel drug screening. Parallelisation of patch-clamp recordings permits higher throughput in characterisation of compounds and ion channels. These systems are able to generate large volumes of functional electrophysiological data in less time for screening and safety profiling, reducing the time to develop ion channel active drugs [1][2][3][4][10][12].

Automated patch-clamp has resided mainly in the pharmaceutical industry with focus on recombinant cell lines induced to overexpress ion channels, while investigations of endogenous ion channels in native cells remain common and important in academic research [39]. Although automated patch-clamp systems are used mainly with recombinant cell lines we have found that Patchliner can produce high quality data from native cells and cells in primary culture, when the evaluation and characterization of the voltage-gated $\mathrm{Kv} 1.3 \mathrm{~K}^{+}$ channel was established in native activated human lymphocytes. Kv1.3 is one of the most important ion channels of human $\mathrm{T}$ lymphocytes and plays a fundamental role in antigen dependent activation and proliferation. Selective inhibition of Kv1.3 offers opportunities to modulate effector memory $\mathrm{T}$ cell responses in chronic inflammation or certain autoimmune diseases such as multiple sclerosis or rheumatoid arthritis, providing a therapeutic potential [50][54][55][56][57]. Three reference compounds were investigated, to test our automated patch-clamp system using these native cells. The $\mathrm{IC}_{50}$ value of tetraethylammonium, the classical small molecule blocker of many $\mathrm{K}^{+}$channel was in the millimolar range $(28.1 \pm 3.1 \mathrm{mM})$. High affinity scorpion toxins anuroctoxin and margatoxin blocked the Kv1.3 channels in the low nano- or the picomolar range, fitting the dose-response relationship resulted in the $\mathrm{IC}_{50}$ values $25.4 \pm 1.6 \mathrm{nM}$ and $68.6 \pm 16.7 \mathrm{pM}$, respectively. For quality assurance of our data, we compared them to manual patch-clamp data from literature. The half-blocking concentrations were described $10 \mathrm{mM}$ for TEA [58], $0.73 \mathrm{nM}$ for AnTx [59] and 10-50 pM for MgTx [50][60]. Our data are slightly elevated, but in good agreement with literature in case of TEA and MgTx. However, $\mathrm{IC}_{50}$ of AnTx was 35-fold higher with automated patch-clamp. Despite this discrepancy, Patchliner seems an appropriate tool for screening native lymphocytes, or even some other primary cells with acceptable success rate. However, automated patch-clamp systems mainly use stably expressing cell lines where the quality of the cell suspensions is fundamental for acceptable success rates. A cell is trapped randomly from the cell suspension; therefore a homogenous expression of ion channels 
among cells is required within the suspension with cells of good quality and health. This blind approach for catching cells is the major reason why most platforms on the market are not practicable to use primary or transiently transfected cells [1][2][11][12]. In addition, some approaches to automate two-electrode voltage-clamp recordings in the Xenopus oocyte expression system have been described like the Roboocyte (Multi Channel Systems) [61] and OpusXpress (Molecular Devices) [62]. These systems provide an option for multiple recordings in parallel towards higher throughput. Nevertheless, pharmacological results created using oocytes were not usually comparable with mammalian data, because of the different membrane components and structure, and therefore the field has focused greatly on automated systems for mammalian cells using planar-array based approaches [1][5].

There are many advantages of the gene-centric approach in which a target protein is overexpressed in recombinant mammalian cell lines. These cell lines are relatively easy to culture and are robust enough to be handled by automated screening platforms. The protein of interest can be overexpressed in these systems, elevating the current level and improving the signal-to-noise ratio. However, host cells with null or very low background conductance can be chosen to enable very sensitive assays of ion channels, and allows to be certain of the molecular identity of the gene accountable for the observed signal [63]. The major disadvantage of using non-native cell lines for electrophysiological measurements is that the cell is not the physiological target and the responses may differ from those that occur in vivo. The evaluation and characterization of cell lines stably expressing GABA, HCN, GIRK, Kv1.4 and hERG channels were performed in our studies. The GABA receptor family is the major class of inhibitory ion channels in central nervous system. $\mathrm{GABA}_{\mathrm{A}}$ chloride channels considered as important therapeutic region for drugs affecting anxiety, influencing sleep processes and treating epilepsy [64][65][66][67][68][69][70][71]. Using the Patchliner platform, HEK-cells expressing $\mathrm{GABA}_{\mathrm{A}}$ ligand-gated ion channel were studied utilizing a stacked solution application for quick and precise administration of compounds to the patchclamped cells. The $\mathrm{EC}_{50}$ value for GABA was determined to $32.20 \pm 1.85 \mu \mathrm{M}$, which is fairly close to manual patch-clamp data on recombinant HEK cell lines (12-53 $\mu \mathrm{M})$ [72][73]. In the further experiments, we applied the $\sim \mathrm{EC}_{20}$ concentration of GABA $(10 \mu \mathrm{M})$, to which the repeated addition does not desensitized the channels, and the effect of the antagonist bicuculline was studied. The estimated $\mathrm{IC}_{50}$ value of this inhibitor $(371.06 \pm 3.43 \mathrm{nM})$ corresponds very well to the literature $(0.1-2.7 \mu \mathrm{M})$ [74][75][76][77][78], reflecting the suitability of Patchliner for $\mathrm{GABA}_{\mathrm{A}}$ investigations. Like most ligand-gated channels, $\mathrm{GABA}_{\mathrm{A}}$ presents receptor desensitization, which is an ordinary phenomenon among ligand-gated ion 
channels. Exposure time, concentration, and application intervals are main factors affecting desensitization and recovery. For rapidly desensitizing channels, quick compound application is also essential, so that the whole ion channel population is exposed to maximum concentration before entering the desensitized state. In our study, within a cycle the cells were exposed to $10 \mu \mathrm{M}$ GABA for $5 \mathrm{~s}$, followed by a 3 minutes wash step. Solution exchange in the environment of the cell was rapid, approximately 50-100 ms for the concentrations. In this way, receptor desensitization can be minimized, and effects of co-applied drugs can be tested. Moreover, this method for stacked solution application, allowing short pulses of compound is convenient for the measurements not only $\mathrm{GABA}_{\mathrm{A}}$-receptor, but for most ligand-gated ion channels.

Among the investigated voltage-gated ion channels, $\mathrm{HCN}$ (hyperpolarization-activated cyclic nucleotide-gated) channels are the molecular determinants of the pacemaker or funny current $\left(\mathrm{I}_{\mathrm{f}}\right)$ in the heart. They are largely expressed in spontaneously active cardiac zones, such as the sinoatrial node, and regulate the activity rate of myocytes. Four isoforms of this channel (HCN1-4) are known; from these we investigated the HCN1 and HCN4 isoforms. Due to the creation of pacemaker activity and the modulation of spontaneous frequency, HCN channels are potential targets of drugs aimed to pharmacologically manage heart rate [79][80][81][82][83][84][85][86][87]. In these cell lines, the detected currents had very small amplitudes under physiological conditions; therefore, $25 \mathrm{mM}$ extracellular $\mathrm{K}^{+}$concentration was chosen for use, which was found to be the lowest one providing a current on which changes can be safely detected. We performed the evaluation of HCN1 and HCN4 cell lines on Patchliner by applying ivabradine, the most specific and selective $\mathrm{I}_{\mathrm{f}}$ inhibitor [88][89]. $10 \mu \mathrm{M}$ ivabradine reduced HCN1 and HCN4 currents by $64.52 \pm 5.36 \%$ and $63.79 \pm 1.07 \%$, respectively, showing almost similar but slightly weaker effects than literature data (the half block concentrations with manual patch-clamp were 0.9 and 2.0-2.1 $\mu \mathrm{M}$ for HCN1 and HCN4 on HEK cell line, and the $\mathrm{IC}_{50}$ for the block of $\mathrm{I}_{\mathrm{f}}$ was $2.2-2.9 \mu \mathrm{M}$ in isolated myocytes) [88][90][91][92].

$\mathrm{G}$ protein-coupled inwardly rectifying potassium channels (GIRK1/4, Kir3.1/3.4), which activated by the release of acetylcholine from the vagus nerve, are selectively expressed in the cardiac atrium and they are not present in the ventricle. Electrical remodelling of atrial heart muscle during chronic atrial fibrillation may result in a constitutively active form of GIRK channel which reflects the main role of this channel in this disease. Therefore, selective inhibition of GIRK channel might be a useful tool in the treatment of atrial fibrillation, devoid of serious ventricular side effects [51][93][94][95]. As with HCN channels, external solution 
containing $25 \mathrm{mM} \mathrm{K}^{+}$was chosen for use in our GIRK experiments, since this was found to be the lowest $\mathrm{K}^{+}$level providing a current on which the current changes can be safely detected. Several reference compounds were investigated on this channel to allow comparison between manual and automated patch-clamp data. Six reference compounds were measured at room temperature, where also the compound screenings were established. Chloroquine, a drug used in the treatment or prevention of malaria described to inhibit the native acetylcholine receptor operated potassium current $\left(\mathrm{I}_{\mathrm{KACh}}\right)$ in isolated guinea pig atrial myocytes with 0.7-0.8 $\mu \mathrm{M} \mathrm{IC}_{50}$ values, which is similar to our result (463.70 $\left.\pm 34.61 \mathrm{nM}\right)$ [96]. Quinidine, which acts as a class I antiarrhythmic agent and also indicated for treatment of malaria, reported to block $\mathrm{I}_{\mathrm{KACh}}$ with $1.8-21 \mu \mathrm{M} \mathrm{IC}_{50}$ values [96]. These are also in good agreement with the $5.04 \pm 0.62 \mu \mathrm{M}$ value defined by Patchliner. Effect of a novel cardioprotective drug, JTV-519, on $\mathrm{I}_{\mathrm{KACh}}$ currents of guinea pig atrial cells was also described [97]. JTV-519 inhibited $\mathrm{I}_{\mathrm{KACh}}$ with the $\mathrm{IC}_{50}$ values of $0.12-2.42 \mu \mathrm{M}$, in conformity with our automated patchclamp data $(814.24 \pm 109.34 \mathrm{nM})$. We examined the effect of NIP-142, a multiple ion channel blocker for the treatment of atrial fibrillation. NIP-142 was described to concentrationdependently blocked the human $G$ protein-coupled inwardly rectifying potassium channel current expressed in $\mathrm{HEK}$ cells with an $\mathrm{IC}_{50}$ value of $0.64 \mu \mathrm{M}$ [98]. This is in the same order of magnitude with our findings $(175.75 \pm 8.59 \mathrm{nM})$. Propafenone is used to treat illnesses associated with rapid heartbeats such as atrial and ventricular arrhythmias. It was reported to block the acetylcholine induced $\mathrm{K}^{+}$current $\left(\mathrm{I}_{\mathrm{KACh}}\right)$ in dissociated guinea pig atrial myocytes under whole-cell voltage-clamp. The values of half-maximal inhibition were 0.2-0.7 $\mu \mathrm{M}$ [99]. Likewise, we measured propafenone exert its effect with $372.99 \pm 27.69 \mathrm{nM} \mathrm{IC} 50$ value on HEK-GIRK cells using Patchliner. Inhibition of GIRK channel by the antidepressant drug desipramine was also concentration-dependent with an $\mathrm{IC}_{50}$ value of $1.47 \pm 0.17 \mu \mathrm{M}$. No literature data are available in native or cultured mammalian cells in this topic. The wellknown class III antiarrhythmic agent amiodarone and its major metabolite desethylamiodarone were investigated at physiological temperature $\left(37^{\circ} \mathrm{C}\right)$. They blocked GIRK current with nearly identical $1.77 \pm 0.18$ and $1.82 \pm 0.15 \mu \mathrm{M} \mathrm{IC}_{50}$ values, in good correlation with literature $\left(\mathrm{IC}_{50}\right.$ for amiodarone was around $2 \mu \mathrm{M}$ in isolated guinea pig atrial myocytes) [100].

Based on these data, which reflect the pharmacology between manual and automated patchclamp platform Patchliner was similar for most reference compounds in case of GIRK cell line, screening of preselected chemical libraries and compounds and extracts originated from natural sources was performed in order to discover new and effective medicaments for the 
treatment of atrial fibrillation. The screening project of chemical libraries resulted in four promising compounds, which dose-response curves and $\mathrm{IC}_{50}$ values were determined in detailed experiments on both GIRK and hERG channels. Ryt-243 showed similar inhibitory effect on GIRK and hERG channels: $\mathrm{IC}_{50}$ values were $100.14 \pm 5.10 \mathrm{nM}$ and $47.56 \pm 5.31 \mathrm{nM}$, respectively. The other 3 compounds (Ryt-143, Ryt-144 and Ryt-230) revealed an at least 10 times higher blocking effect on GIRK channels compared to hERG. As hERG blocking effect can be even useful in antiarrhythmic treatment Ryt-243 was subjected to further investigations. Despite of its hERG blocking activity, Ryt-243 did not prolong the action potential in rabbit ventricular muscle either in $5 \mu \mathrm{M}$ or in $10 \mu \mathrm{M}$ concentrations. A potential explanation to this phenomenon is that this agent has multichannel effect and also blocks other ion channel(s) during cardiac action potential repolarization. Ryt-243 was also investigated in dog model, and the compound had a strong antiarrhythmic effect. Based on these antiarrhythmic results a patent was filed in which anti-atrial fibrillation effects of Ryt-243 are chartered. Compounds showing GIRK-selectivity (Ryt-143, Ryt-144 and Ryt230) are also involved in further ongoing investigations including antiarrhythmic effect evaluation and structure-effect analysis.

Compounds originated from natural sources were also investigated in GIRK screen project. These natural plant compounds were chosen randomly and were not preselected. Approximately $9 \%$ of the investigated natural molecules showed a notable (i.e. at least $50 \%$ decrease in the GIRK current at $10 \mu \mathrm{M}$ concentration) blocking effect. In comparison, in case of chemical libraries, $10 \%$ of the revised chemical libraries were preselected as possible potent structures and were investigated, and $13 \%$ of the selected compounds showed at least $50 \%$ inhibitory effect on GIRK current at $10 \mu \mathrm{M}$ concentration, reflecting the high hit rate of the natural compounds.

Testing a new way of tracing biologically active compounds extracts of Polygonum persicaria were also investigated in our GIRK screen system, with the aim to identify natural sources of promising ion channel blocking compounds [52]. To the best of our knowledge, GIRK inhibitory assay was used for the first time for screening plant extracts for potassium ion channel blockers. In this study the GIRK channel inhibitory activity of the chloroform extract of Polygonum persicaria was demonstrated, and new natural flavonoids were identified from the extract. Unfortunately, the isolated compounds have only moderate activities on GIRK channel; therefore further studies are needed in order to identify minor compounds responsible for the potassium ion channel modulatory activity. 
Kv1.4 is a voltage-gated potassium channel, which open on membrane depolarization and inactivate rapidly. Kv1.4 channel underlie the cardiac transient outward potassium current $\left(\mathrm{I}_{\mathrm{to}}\right)$ in cardiac muscle. It is important in the regulation of the fast repolarizing phase of action potentials in heart and thus may influence the duration of cardiac action potential [101][102][103]. This cell line had relatively high currents in the nanoamper range. Both tested reference compound blocked the current. IC $_{50}$ values for chromanol $293 \mathrm{~B}$ and 4-aminopyridine were $85.69 \pm 8.38 \mu \mathrm{M}$ and $791.33 \pm 26.84 \mu \mathrm{M}$, respectively. According to literature data, chromanol 293B blocked transient outward current $\mathrm{I}_{\text {to }}$ with an $\mathrm{IC}_{50}$ of $38 \mu \mathrm{M}$ in canine left ventricular cells [104]. The $\mathrm{IC}_{50}$ of 4-aminopyridine on $\mathrm{I}_{\mathrm{to}}$ was $0.64-0.67 \mathrm{mM}$ in atrial myocytes isolated from human hearts and $0.28 \mathrm{mM}$ in rabbit sino-atrial node cells [105][106][107]. All these data are in good agreement with our results on Kv1.4 cell line.

Based on our results, several natural plant compounds were selected for further evaluation following the primary screen on GIRK channel. These agents were also tested on Kv1.4 cell line and selectivity of their GIRK blocking effect was evaluated with these experiments.

Besides the ion channel drug screening to discover and develop new and more effective drugs, another important aspect of the application of automated patch-clamp systems is the safety pharmacology. Life threatening cardiac arrhythmias and sudden cardiac death caused by drugs are one of the major safety issues for pharmaceutical industry and regulatory agencies. In recent years, several drugs such as terfenadine, cisapride, grepafloxacin and terodiline have been withdrawn from major markets because of their proarrhythmic effect related to the lengthening of cardiac repolarization manifested as QT interval lengthening on the surface ECG. This cardiac proarrhythmic effect of different compounds is attributed to their ability to block the rapid delayed rectifier $\mathrm{K}^{+}$current $\left(\mathrm{I}_{\mathrm{Kr}}\right)$. Based on this concept investigation of $\mathrm{I}_{\mathrm{Kr}}$ blocking and action potential duration lengthening capabilities became of required item of safety pharmacology profile of new compounds [1][2][4][7][12][13][14]. However those tests are complicated and time consuming. Therefore analysis of $\mathrm{I}_{\mathrm{Kr}}$ current in heart muscle cells was replaced by the examination of its recombinant equivalent hERG current (Kv11.1). Although hERG assay as a high-throughput technique is very powerful but sometimes gives false positive and negative results. The mechanism of the occasional failure of the hERG test is not well understood. Therefore we have compared the effect of dofetilide and sotalol on hERG current (at room temperature and $37^{\circ} \mathrm{C}$ ) and on $\mathrm{I}_{\mathrm{Kr}}$ current $\left(37^{\circ} \mathrm{C}\right)$ and determined the value of hERG current measurements in evaluation of cardiac proarrhytmic risk of 
compounds and helping the understanding of mechanism of proarrhythmic pharmacological safety drug tests.

Current responses of cells expressing the hERG channel at room temperature and physiological temperature were similar in case of dofetilide. The most noticeable effects of raising the temperature to $37^{\circ} \mathrm{C}$ was that the peak amplitude was increased, the rise time was decreased and the time constant of decay phase was faster. Despite that, the dose-response curve generated an $\mathrm{IC}_{50}$ similar to that obtained at room temperature, and similar to that determined in the $\mathrm{I}_{\mathrm{Kr}}$ experiments $(8.41 \pm 0.19 \mathrm{nM}, 7.29 \pm 0.16 \mathrm{nM}$ and $13.02 \pm 2.56 \mathrm{nM}$, respectively). Additionally, these data are in good agreement with our action potential measurements (13 nM dofetilide prolonged the $\mathrm{APD}_{90}$ with $47.8 \pm 12.9 \%$ ) and with literature data [108][109][110][111][112][113][114].

Conversely, sotalol displays not only different kinetics but different potencies at room temperature and $37^{\circ} \mathrm{C}$. Sotalol has been shown to block hERG channels at room temperature with an $\mathrm{IC}_{50}$ of $773.74 \pm 9.28 \mu \mathrm{M}$. However, at physiological temperature sotalol was more potent $\left(\mathrm{IC}_{50}=342.84 \pm 24.82 \mu \mathrm{M}\right)$ and therefore, it is a desirable option to study ion channels at physiological temperature since compounds can exhibit different actions or potencies at $37^{\circ} \mathrm{C}$. For safety screening, it may be particularly critical to test compounds at physiological temperature and this makes the Patchliner an ideal instrument for these experiments. Moreover, in case of sotalol, a significant difference was observed between the hERG $\mathrm{IC}_{50}$ values and the $\mathrm{IC}_{50}$ value on $\mathrm{I}_{\mathrm{Kr}}$ current. The $\mathrm{IC}_{50}$ on $\mathrm{I}_{\mathrm{Kr}}$ on ventricular myocytes was calculated to be $51.60 \pm 9.82 \mu \mathrm{M}$, and accordingly this concentration of sotalol lengthened the action potential with $56.0 \pm 4.6 \%$.

Based on our experiments, results obtained with automated patch-clamp equipment in HEKhERG cells often show a reasonable conformity with outcomes of $\mathrm{I}_{\mathrm{Kr}}$ current measurements. However there are important and not well understood differences between the evaluation of hERG-blocking ability with automated patch-clamp and other techniques such as the $\mathrm{I}_{\mathrm{Kr}}$ or action potential experiments. In manual patch-clamp, test solutions are usually prepared in relatively large quantities directly before the experiments, and are continuously perfused. In automated platforms, compound plates with minor volume are used, and comparatively small volumes of test solutions are applied to the cells. The adverse surface-to-volume ratio in compound plates and microchannels and the increased incubation time can lead to possible reduction of compound concentrations, especially in case of hydrophobic, 'sticky' agents such as astemizole or terfenadine. Adhesion and precipitation have been identified as the major sources of potential right-shifted less accurate dose-response curves [37][109][115]. 
Nevertheless, sotalol is among the least hydrophobic compounds [109], and numerous studies also reported extremely high $\mathrm{IC}_{50}$ values in hERG cell lines utilized for manual patch-clamp (the half-blocking concentrations of sotalol were 137-1200 $\mu \mathrm{M}$ in these experiments) [14][116][117][118][119][120].

Increasing evidence indicates that the composition of native $\mathrm{I}_{\mathrm{Kr}}$ channels is very complex, and the $\alpha$-subunit composition of the channel can affects its blocking sensitivity. The hERG1 gene encodes at least two transcripts: hERG1a, the original isolate, and hERG 1b, an alternate transcript [121][122]. The most of hERG screens have been conducted using recombinant cell lines expressing the hERG 1a subunit, although native ventricular $\mathrm{I}_{\mathrm{Kr}}$ channels are heteromers containing both hERG 1a and 1b subunits [123]. Although the potency of most compounds (including sotalol) was similar for the two targets, some differences were observed. Some drugs was more potent at blocking hERG 1a/1b than 1a channels, others were a more potent blocker of hERG 1a compared with $1 \mathrm{a} / 1 \mathrm{~b}$ channels. Thus the existing hERG 1a assays may underestimate the risk of some drugs and overestimate the risk of others [13][124]. In addition, other studies have identified interacting proteins affecting hERG drug sensitivity. For example, MinK, MiRP1 and KCR1 coassembles with a pore-forming subunit to create stable complexes whose functional attributes resemble those of a native cardiac potassium channel, adding another level of complexity to the control mechanisms affecting cardiac electrophysiology. Their expression and modulation by drugs could play an important role in determining the amount and character of the $\mathrm{I}_{\mathrm{Kr}}$ current in individual cardiac myocytes [114][125][126][127].

Since the results of hERG measurements - in spite of their beneficial time/cost value and popularity - are not as adequate as it previously thought the estimation of proarrhytmic liability by hERG assays can be handled only with precaution. The cellular and molecular base of the techniques applied in these types of safety pharmacology investigations needs further explorative work.

Based on these experiences, safety pharmacology studies of Chelidonium majus were achieved, where the effects of extracts and alkaloids of the plant were investigated on hERG current as well as on ventricular action potential. In our electrophysiological study we investigated $C$. majus herb hydroalcoholic extracts and its four benzylisoquinoline alkaloids, berberine and coptisine from protoberberines subgroup, and chelidonine and sanguinarine from benzophenanthridines subgroup using patch-clamp method and conventional microelectrode technique. Both $25 \%$ and $45 \%$ ethanol extracts were prepared according to the Assessment report EMA/HMPC/369801/2009 on Chelidonium majus herb. These extracts 
which have a long tradition of internal application against a wide scale of different diseases, possess hERG channel inhibition and prolongs the duration of cardiac action potential. In this work, to the best of our knowledge, we report the first experimental evidence of hERG potassium channel blocking and action potential prolonging effect of C. majus herb $25 \%$ and $45 \%$ ethanol extracts. Moreover, the effect of chelidonine and sanguinarine on action potential was investigated for the first time. The examined substances not only inhibit the hERG current, but also extend the duration of the action potential. In certain pathophysiological conditions where repolarization reserve is impaired [128][129] all of these alkaloids may have additive effects further increasing the possibility of proarrhythmic risk and cardiac sudden death. In conclusion, the internal use of $C$. majus extracts or its alkaloids, berberine, chelidonine and especially sanguinarine in some situations where cardiac repolarization reserve is weak may increase the risk of potentially fatal ventricular arrhythmias. These findings are likely to contribute significantly to clear the complex cardiotoxic effects of $C$. majus, and reflect the potential cardiac risk of the usage of this herb. Our results highlight the safety concerns regarding the internal use of $C$. majus: orally applied greater celandine products need cautious evaluation from the view of cardiovascular side effects. 


\section{CONCLUSIONS}

1. The fully automated patch-clamp platform Patchliner provides high data quality and robust recordings. The Patchliner is compatible with many different cell lines, most often showing little discrepancy between the results obtained with automated and manual patch-clamp methods. Because of the elevated throughput and high success rate obtained in our experiments the Patchliner proved to be an excellent tool in cellular electrophysiological experiments and we positively suggest its use both in academic and pharmaceutical industrial research.

2. Several cell lines were characterized and used in screening projects of preselected chemical libraries performed with Patchliner. Based on these screening results a patent was filed in which anti-atrial fibrillation effects of Ryt-243 are chartered.

3. Compounds originated from natural (plant) sources were also involved in GIRK screen project. Our studies reflect the outstandingly high hit rate of compounds originated from natural sources.

4. To the best of our knowledge, GIRK inhibitory assay was used for the first time for screening of plant extracts for inhibitors, with the aim to identify natural sources of promising ion channel blocking compounds.

5. In safety pharmacology studies, we showed important and not well understood differences between the hERG-blocking ability of different compounds evaluated with automated patch-clamp method or other techniques such as $\mathrm{I}_{\mathrm{Kr}}$ experiments with manual patch-clamp or action potential studies. We demonstrated that the estimation of proarrhytmic liability by hERG assays is not as adequate as it was previously thought and can be handled only with precaution.

6. Our electrophysiological studies on extracts and alkaloids of Chelidonium majus herb revealed that the plant possess hERG channel inhibition and prolong the duration of cardiac action potential. These results may contribute to the understanding of the toxic effects of $C$. majus and highlight the potential cardiac risk of the usage of this herb. 


\section{ACKNOWLEDGEMENTS}

First of all I greatly acknowledge to late Prof. Dr. Ádám Vas. He supported my work with all his efforts and without his help the completion of this work would not be possible.

I am deeply indebted to Prof. Dr. András Varró who has guided and supported me on many ways. I am very grateful for his continuous advices.

I am especially grateful to Prof. Dr. Judit Hohmann for her valuable advices and continuous support during my experimental work.

I wish to thank Dr. László Virág for being my tutor and helping me both with advices and technical help since the beginning of my Ph.D. studies.

I am grateful to Dr. László Tálosi for his support and for providing me the technical background and the working facilities.

I am also grateful to Imréné Molnár, Zsófia Kohajda and Amir Geramipour for their help in my experimental work and for their excellent technical assistance.

I pleased to express my thanks to all co-authors of my publications for the valuable cooperation.

Finally, I acknowledge the financial support of the Richter Gedeon Talentum Foundation and the continuous technical assistance of the Nanion Technologies GmbH. 


\section{REFERENCES}

[1] J. Dunlop, M. Bowlby, R. Peri, D. Vasilyev, and R. Arias, "High-throughput electrophysiology: an emerging paradigm for ion-channel screening and physiology," Nat. Rev. Drug Discov., vol. 7, no. 4, pp. 358-368, Apr. 2008.

[2] C. Farre, S. Stoelzle, C. Haarmann, M. George, A. Brüggemann, and N. Fertig, "Automated ion channel screening: patch clamping made easy," Expert Opin. Ther. Targets, vol. 11, no. 4, pp. 557-565, Apr. 2007.

[3] C. Farre and N. Fertig, "HTS techniques for patch clamp-based ion channel screening advances and economy," Expert Opin. Drug Discov., vol. 7, no. 6, pp. 515-524, Jun. 2012.

[4] C. Farre, A. Haythornthwaite, C. Haarmann, S. Stoelzle, M. Kreir, M. George, A. Brüggemann, and N. Fertig, "Port-a-patch and patchliner: high fidelity electrophysiology for secondary screening and safety pharmacology," Comb. Chem. High Throughput Screen., vol. 12, no. 1, pp. 24-37, Jan. 2009.

[5] Q. Lü and W. F. An, "Impact of novel screening technologies on ion channel drug discovery," Comb. Chem. High Throughput Screen., vol. 11, no. 3, pp. 185-194, Mar. 2008.

[6] S. Stoelzle, A. Obergrussberger, A. Brüggemann, C. Haarmann, M. George, R. Kettenhofen, and N. Fertig, "State-of-the-Art Automated Patch Clamp Devices: Heat Activation, Action Potentials, and High Throughput in Ion Channel Screening," Front. Pharmacol., vol. 2, p. 76, 2011.

[7] W. Zheng, R. H. Spencer, and L. Kiss, "High throughput assay technologies for ion channel drug discovery," Assay Drug Dev. Technol., vol. 2, no. 5, pp. 543-552, Oct. 2004.

[8] B. T. Priest, A. M. Swensen, and O. B. McManus, "Automated electrophysiology in drug discovery," Curr. Pharm. Des., vol. 13, no. 23, pp. 2325-2337, 2007.

[9] N. J. Willumsen, M. Bech, S.-P. Olesen, B. S. Jensen, M. P. G. Korsgaard, and P. Christophersen, "High throughput electrophysiology: new perspectives for ion channel drug discovery," Receptors Channels, vol. 9, no. 1, pp. 3-12, 2003.

[10] M. A. Dabrowski, K. Dekermendjian, P.-E. Lund, J. J. Krupp, J. Sinclair, and O. Larsson, "Ion channel screening technology," CNS Neurol. Disord. Drug Targets, vol. 7, no. 2, pp. 122-128, Apr. 2008.

[11] J. M. Treherne, "Exploiting high-throughput ion channel screening technologies in integrated drug discovery," Curr. Pharm. Des., vol. 12, no. 4, pp. 397-406, 2006.

[12] C. Farre, M. George, A. Brüggemann, and N. Fertig, "Ion channel screening - automated patch clamp on the rise," Drug Discov. Today Technol., vol. 5, no. 1, pp. e23-e28, 2008.

[13] N. Abi-Gerges, H. Holkham, E. M. C. Jones, C. E. Pollard, J.-P. Valentin, and G. A. Robertson, "hERG subunit composition determines differential drug sensitivity," Br. J. Pharmacol., vol. 164, no. 2b, pp. 419-432, Sep. 2011.

[14] L. Polonchuk, "Toward a New Gold Standard for Early Safety: Automated TemperatureControlled hERG Test on the PatchLiner," Front. Pharmacol., vol. 3, p. 3, 2012. 
[15] A. L. Hodgkin and A. F. Huxley, "Resting and action potentials in single nerve fibres," $J$. Physiol., vol. 104, no. 2, pp. 176-195, Oct. 1945.

[16] A. L. Hodgkin, A. F. Huxley, and B. Katz, "Measurement of current-voltage relations in the membrane of the giant axon of Loligo," J. Physiol., vol. 116, no. 4, pp. 424-448, Apr. 1952.

[17] A. L. Hodgkin and A. F. Huxley, "Currents carried by sodium and potassium ions through the membrane of the giant axon of Loligo," J. Physiol., vol. 116, no. 4, pp. 449-472, Apr. 1952.

[18] A. L. Hodgkin and A. F. Huxley, "The components of membrane conductance in the giant axon of Loligo," J. Physiol., vol. 116, no. 4, pp. 473-496, Apr. 1952.

[19] A. L. Hodgkin and A. F. Huxley, "The dual effect of membrane potential on sodium conductance in the giant axon of Loligo," J. Physiol., vol. 116, no. 4, pp. 497-506, Apr. 1952.

[20] A. L. Hodgkin and A. F. Huxley, "A quantitative description of membrane current and its application to conduction and excitation in nerve," J. Physiol., vol. 117, no. 4, pp. 500-544, Aug. 1952.

[21] “The Nobel Prize in Physiology or Medicine 1963.” [Online]. Available: http://www.nobelprize.org/nobel_prizes/medicine/laureates/1963/.

[22] E. Neher and B. Sakmann, "Single-channel currents recorded from membrane of denervated frog muscle fibres," Nature, vol. 260, no. 5554, pp. 799-802, Apr. 1976.

[23] E. Neher, B. Sakmann, and J. H. Steinbach, "The extracellular patch clamp: a method for resolving currents through individual open channels in biological membranes," Pflüg. Arch. Eur. J. Physiol., vol. 375, no. 2, pp. 219-228, Jul. 1978.

[24] “The Nobel Prize in Physiology or Medicine 1991." [Online]. Available: http://www.nobelprize.org/nobel_prizes/medicine/laureates/1991/.

[25] N. Fertig, R. H. Blick, and J. C. Behrends, "Whole cell patch clamp recording performed on a planar glass chip," Biophys. J., vol. 82, no. 6, pp. 3056-3062, Jun. 2002.

[26] M. Asmild, N. Oswald, K. M. Krzywkowski, S. Friis, R. B. Jacobsen, D. Reuter, R. Taboryski, J. Kutchinsky, R. K. Vestergaard, R. L. Schrøder, C. B. Sørensen, M. Bech, M. P. G.

Korsgaard, and N. J. Willumsen, "Upscaling and automation of electrophysiology: toward high throughput screening in ion channel drug discovery," Receptors Channels, vol. 9, no. 1, pp. 49$58,2003$.

[27] A. Lepple-Wienhues, K. Ferlinz, A. Seeger, and A. Schäfer, "Flip the tip: an automated, high quality, cost-effective patch clamp screen," Receptors Channels, vol. 9, no. 1, pp. 13-17, 2003.

[28] D. V. Vasilyev, T. L. Merrill, and M. R. Bowlby, "Development of a novel automated ion channel recording method using 'inside-out' whole-cell membranes," J. Biomol. Screen., vol. 10, no. 8, pp. 806-813, Dec. 2005.

[29] D. Vasilyev, T. Merrill, A. Iwanow, J. Dunlop, and M. Bowlby, "A novel method for patchclamp automation,” Pflüg. Arch. Eur. J. Physiol., vol. 452, no. 2, pp. 240-247, May 2006.

[30] K. Schroeder, B. Neagle, D. J. Trezise, and J. Worley, "Ionworks HT: a new high-throughput electrophysiology measurement platform," J. Biomol. Screen., vol. 8, no. 1, pp. 50-64, Feb. 2003. 
[31] A. Finkel, A. Wittel, N. Yang, S. Handran, J. Hughes, and J. Costantin, "Population Patch Clamp Improves Data Consistency and Success Rates in the Measurement of Ionic Currents," J. Biomol. Screen., vol. 11, no. 5, pp. 488-496, Aug. 2006.

[32] V. H. John, T. J. Dale, E. C. Hollands, M. X. Chen, L. Partington, D. L. Downie, H. J. Meadows, and D. J. Trezise, "Novel 384-Well Population Patch Clamp Electrophysiology Assays for Ca2+-Activated K+ Channels," J. Biomol. Screen., vol. 12, no. 1, pp. 50-60, Feb. 2007.

[33] T. J. Dale, C. Townsend, E. C. Hollands, and D. J. Trezise, "Population patch clamp electrophysiology: a breakthrough technology for ion channel screening," Mol. Biosyst., vol. 3, no. 10, pp. 714-722, Oct. 2007.

[34] S. Sorota, X.-S. Zhang, M. Margulis, K. Tucker, and T. Priestley, "Characterization of a hERG screen using the IonWorks HT: comparison to a hERG rubidium efflux screen," Assay Drug Dev. Technol., vol. 3, no. 1, pp. 47-57, Feb. 2005.

[35] H. Tao, D. Santa Ana, A. Guia, M. Huang, J. Ligutti, G. Walker, K. Sithiphong, F. Chan, T. Guoliang, Z. Zozulya, S. Saya, R. Phimmachack, C. Sie, J. Yuan, L. Wu, J. Xu, and A. Ghetti, "Automated tight seal electrophysiology for assessing the potential hERG liability of pharmaceutical compounds," Assay Drug Dev. Technol., vol. 2, no. 5, pp. 497-506, Oct. 2004.

[36] J. Xu, A. Guia, D. Rothwarf, M. Huang, K. Sithiphong, J. Ouang, G. Tao, X. Wang, and L. Wu, "A benchmark study with sealchip planar patch-clamp technology," Assay Drug Dev. Technol., vol. 1, no. 5, pp. 675-684, Oct. 2003.

[37] C. Mathes, "QPatch: the past, present and future of automated patch clamp," Expert Opin. Ther. Targets, vol. 10, no. 2, pp. 319-327, Apr. 2006.

[38] A. Brüggemann, M. George, M. Klau, M. Beckler, J. Steindl, J. C. Behrends, and N. Fertig, "High quality ion channel analysis on a chip with the NPC technology," Assay Drug Dev. Technol., vol. 1, no. 5, pp. 665-673, Oct. 2003.

[39] C. J. Milligan, J. Li, P. Sukumar, Y. Majeed, M. L. Dallas, A. English, P. Emery, K. E. Porter, A. M. Smith, I. McFadzean, D. Beccano-Kelly, Y. Bahnasi, A. Cheong, J. Naylor, F. Zeng, X. Liu, N. Gamper, L.-H. Jiang, H. A. Pearson, C. Peers, B. Robertson, and D. J. Beech, "Robotic multiwell planar patch-clamp for native and primary mammalian cells," Nat. Protoc., vol. 4, no. 2, pp. 244-255, 2009.

[40] S. Stoelzle, A. Haythornthwaite, R. Kettenhofen, E. Kolossov, H. Bohlen, M. George, A. Brüggemann, and N. Fertig, "Automated patch clamp on mESC-derived cardiomyocytes for cardiotoxicity prediction,” J. Biomol. Screen., vol. 16, no. 8, pp. 910-916, Sep. 2011.

[41] A. P. Golden, N. Li, Q. Chen, T. Lee, T. Nevill, X. Cao, J. Johnson, G. Erdemli, C. IonescuZanetti, L. Urban, and M. Holmqvist, "IonFlux: a microfluidic patch clamp system evaluated with human Ether-à-go-go related gene channel physiology and pharmacology," Assay Drug Dev. Technol., vol. 9, no. 6, pp. 608-619, Dec. 2011.

[42] O. Scheel, H. Himmel, G. Rascher-Eggstein, and T. Knott, "Introduction of a modular automated voltage-clamp platform and its correlation with manual human Ether-à-go-go related gene voltage-clamp data," Assay Drug Dev. Technol., vol. 9, no. 6, pp. 600-607, Dec. 2011. 
[43] C. Lengyel, N. Iost, L. Virág, A. Varró, D. A. Lathrop, and J. G. Papp, "Pharmacological block of the slow component of the outward delayed rectifier current $(\mathrm{I}(\mathrm{Ks}))$ fails to lengthen rabbit ventricular muscle QT(c) and action potential duration," Br. J. Pharmacol., vol. 132, no. 1, pp. 101-110, Jan. 2001.

[44] P. Orvos, L. Virág, L. Tálosi, Z. Hajdú, D. Csupor, N. Jedlinszki, T. Szél, A. Varró, and J. Hohmann, "Effects of Chelidonium majus extracts and major alkaloids on hERG potassium channels and on dog cardiac action potential - A safety approach," Fitoterapia, vol. 100, pp. 156-165, Jan. 2015.

[45] A. Kristóf, Z. Husti, I. Koncz, Z. Kohajda, T. Szél, V. Juhász, P. Biliczki, N. Jost, I. Baczkó, J. G. Papp, A. Varró, and L. Virág, "Diclofenac prolongs repolarization in ventricular muscle with impaired repolarization reserve," PloS One, vol. 7, no. 12, p. e53255, 2012.

[46] A. Varro, B. Baláti, N. Iost, J. Takács, L. Virág, D. A. Lathrop, L. Csaba, L. Tálosi, and J. G. Papp, "The role of the delayed rectifier component IKs in dog ventricular muscle and Purkinje fibre repolarization,” J. Physiol., vol. 523 Pt 1, pp. 67-81, Feb. 2000.

[47] P. Biliczki, L. Virág, N. Iost, J. G. Papp, and A. Varró, "Interaction of different potassium channels in cardiac repolarization in dog ventricular preparations: role of repolarization reserve," Br. J. Pharmacol., vol. 137, no. 3, pp. 361-368, Oct. 2002.

[48] N. Jost, L. Virág, M. Bitay, J. Takács, C. Lengyel, P. Biliczki, Z. Nagy, G. Bogáts, D. A. Lathrop, J. G. Papp, and A. Varró, "Restricting excessive cardiac action potential and QT prolongation: a vital role for IKs in human ventricular muscle," Circulation, vol. 112, no. 10, pp. 1392-1399, Sep. 2005.

[49] “The Patchliner.” [Online]. Available: http://nanion.de/images/stories/pdf/patchliner.pdf.

[50] A. Bartok, A. Toth, S. Somodi, T. G. Szanto, P. Hajdu, G. Panyi, and Z. Varga, "Margatoxin is a non-selective inhibitor of human Kv1.3 K+ channels," Toxicon Off. J. Int. Soc. Toxinology, vol. 87, pp. 6-16, Sep. 2014.

[51] T. Kiss, P. Orvos, S. Bánsághi, P. Forgo, N. Jedlinszki, L. Tálosi, J. Hohmann, and D. Csupor, "Identification of diterpene alkaloids from Aconitum napellus subsp. firmum and GIRK channel activities of some Aconitum alkaloids," Fitoterapia, vol. 90, pp. 85-93, Oct. 2013.

[52] I. Lajter, A. Vasas, P. Orvos, S. Bánsághi, L. Tálosi, G. Jakab, Z. Béni, V. Háda, P. Forgo, and J. Hohmann, "Inhibition of $G$ protein-activated inwardly rectifying $\mathrm{K}+$ channels by extracts of Polygonum persicaria and isolation of new flavonoids from the chloroform extract of the herb," Planta Med., vol. 79, no. 18, pp. 1736-1741, Dec. 2013.

[53] European Medicines Agency (EMA) and Committee on Herbal Medicinal Products (HMPC), "Final assessment report on Chelidonium majus L., herba," EMA/HMPC/369801/2009, Sep. 2011.

[54] G. Panyi, "Biophysical and pharmacological aspects of K+ channels in T lymphocytes," Eur. Biophys. J. EBJ, vol. 34, no. 6, pp. 515-529, Aug. 2005.

[55] G. Panyi, L. D. Possani, R. C. Rodríguez de la Vega, R. Gáspár, and Z. Varga, "K+ channel blockers: novel tools to inhibit T cell activation leading to specific immunosuppression," Curr. Pharm. Des., vol. 12, no. 18, pp. 2199-2220, 2006. 
[56] M. D. Cahalan and K. G. Chandy, "The functional network of ion channels in T lymphocytes," Immunol. Rev., vol. 231, no. 1, pp. 59-87, Sep. 2009.

[57] Z. Varga, P. Hajdu, and G. Panyi, "Ion channels in T lymphocytes: an update on facts, mechanisms and therapeutic targeting in autoimmune diseases," Immunol. Lett., vol. 130, no. 1-2, pp. 19-25, May 2010.

[58] S. Grissmer, A. N. Nguyen, J. Aiyar, D. C. Hanson, R. J. Mather, G. A. Gutman, M. J. Karmilowicz, D. D. Auperin, and K. G. Chandy, "Pharmacological characterization of five cloned voltage-gated $\mathrm{K}+$ channels, types Kv1.1, 1.2, 1.3, 1.5, and 3.1, stably expressed in mammalian cell lines," Mol. Pharmacol., vol. 45, no. 6, pp. 1227-1234, Jun. 1994.

[59] M. Bagdány, C. V. F. Batista, N. A. Valdez-Cruz, S. Somodi, R. C. Rodriguez de la Vega, A. F. Licea, Z. Varga, R. Gáspár, L. D. Possani, and G. Panyi, "Anuroctoxin, a new scorpion toxin of the alpha-KTx 6 subfamily, is highly selective for Kv1.3 over IKCa1 ion channels of human T lymphocytes," Mol. Pharmacol., vol. 67, no. 4, pp. 1034-1044, Apr. 2005.

[60] M. Garcia-Calvo, R. J. Leonard, J. Novick, S. P. Stevens, W. Schmalhofer, G. J. Kaczorowski, and M. L. Garcia, "Purification, characterization, and biosynthesis of margatoxin, a component of Centruroides margaritatus venom that selectively inhibits voltage-dependent potassium channels," J. Biol. Chem., vol. 268, no. 25, pp. 18866-18874, Sep. 1993.

[61] K. Schnizler, M. Küster, C. Methfessel, and M. Fejtl, "The roboocyte: automated cDNA/mRNA injection and subsequent TEVC recording on Xenopus oocytes in 96-well microtiter plates," Receptors Channels, vol. 9, no. 1, pp. 41-48, 2003.

[62] R. L. Papke, "Estimation of both the potency and efficacy of alpha7 nAChR agonists from single-concentration responses," Life Sci., vol. 78, no. 24, pp. 2812-2819, May 2006.

[63] R. Numann and P. A. Negulescu, "High-throughput screening strategies for cardiac ion channels," Trends Cardiovasc. Med., vol. 11, no. 2, pp. 54-59, Feb. 2001.

[64] J. A. Armijo, I. de las Cuevas, and J. Adín, “[Ion channels and epilepsy]," Rev. Neurol., vol. 30 Suppl 1, pp. S25-41, Jun. 2000.

[65] S. J. Czuczwar and P. N. Patsalos, "The new generation of GABA enhancers. Potential in the treatment of epilepsy," CNS Drugs, vol. 15, no. 5, pp. 339-350, 2001.

[66] A. C. Foster and J. A. Kemp, "Glutamate- and GABA-based CNS therapeutics," Curr. Opin. Pharmacol., vol. 6, no. 1, pp. 7-17, Feb. 2006.

[67] B. A. Orser, "Extrasynaptic GABAA receptors are critical targets for sedative-hypnotic drugs," J. Clin. Sleep Med. JCSM Off. Publ. Am. Acad. Sleep Med., vol. 2, no. 2, pp. S12-18, Apr. 2006.

[68] C. D'Hulst, J. R. Atack, and R. F. Kooy, "The complexity of the GABAA receptor shapes unique pharmacological profiles," Drug Discov. Today, vol. 14, no. 17-18, pp. 866-875, Sep. 2009.

[69] U. Rudolph and F. Knoflach, "Beyond classical benzodiazepines: novel therapeutic potential of GABAA receptor subtypes," Nat. Rev. Drug Discov., vol. 10, no. 9, pp. 685-697, Sep. 2011. 
[70] M. L. Trincavelli, E. Da Pozzo, S. Daniele, and C. Martini, "The GABAA-BZR complex as target for the development of anxiolytic drugs," Curr. Top. Med. Chem., vol. 12, no. 4, pp. 254-269, 2012.

[71] C. Rundfeldt and W. Löscher, "The pharmacology of imepitoin: the first partial benzodiazepine receptor agonist developed for the treatment of epilepsy," CNS Drugs, vol. 28, no. 1, pp. 2943, Jan. 2014.

[72] K. Jahn, I. Hertle, J. Bufler, H. Adelsberger, E. Pestel, W. Zieglgänsberger, J. Dudel, and C. Franke, "Activation kinetics and single channel properties of recombinant alpha1 beta2gamma2L GABA(A) receptor channels," Neuroreport, vol. 8, no. 16, pp. 34433446, Nov. 1997.

[73] R. Q. Huang and G. H. Dillon, "Effect of extracellular pH on GABA-activated current in rat recombinant receptors and thin hypothalamic slices," J. Neurophysiol., vol. 82, no. 3, pp. 1233 1243, Sep. 1999.

[74] T. Shirasaki, M. R. Klee, T. Nakaye, and N. Akaike, "Differential blockade of bicuculline and strychnine on GABA- and glycine-induced responses in dissociated rat hippocampal pyramidal cells," Brain Res., vol. 561, no. 1, pp. 77-83, Oct. 1991.

[75] Y. Takahashi, T. Shirasaki, H. Yamanaka, H. Ishibashi, and N. Akaike, "Physiological roles of glycine and gamma-aminobutyric acid in dissociated neurons of rat visual cortex," Brain Res., vol. 640, no. 1-2, pp. 229-235, Mar. 1994.

[76] E. Kumamoto and Y. Murata, "Characterization of GABA current in rat septal cholinergic neurons in culture and its modulation by metal cations," J. Neurophysiol., vol. 74, no. 5, pp. 2012-2027, Nov. 1995.

[77] A. Feigenspan and R. Weiler, "Electrophysiological properties of mouse horizontal cell GABAA receptors," J. Neurophysiol., vol. 92, no. 5, pp. 2789-2801, Nov. 2004.

[78] O. T. James, M. R. Livesey, J. Qiu, O. Dando, B. Bilican, G. Haghi, R. Rajan, K. Burr, G. E. Hardingham, S. Chandran, P. C. Kind, and D. J. A. Wyllie, "Ionotropic GABA and glycine receptor subunit composition in human pluripotent stem cell-derived excitatory cortical neurones," J. Physiol., vol. 592, no. Pt 19, pp. 4353-4363, Oct. 2014.

[79] H. F. Brown, D. DiFrancesco, and S. J. Noble, "How does adrenaline accelerate the heart?," Nature, vol. 280, no. 5719, pp. 235-236, Jul. 1979.

[80] D. DiFrancesco and C. Ojeda, "Properties of the current if in the sino-atrial node of the rabbit compared with those of the current iK, in Purkinje fibres," J. Physiol., vol. 308, pp. 353-367, Nov. 1980.

[81] D. DiFrancesco, "Pacemaker mechanisms in cardiac tissue," Annu. Rev. Physiol., vol. 55, pp. 455-472, 1993.

[82] M. Baruscotti, A. Bucchi, and D. Difrancesco, "Physiology and pharmacology of the cardiac pacemaker ('funny') current," Pharmacol. Ther., vol. 107, no. 1, pp. 59-79, Jul. 2005.

[83] A. Ludwig, X. Zong, J. Stieber, R. Hullin, F. Hofmann, and M. Biel, "Two pacemaker channels from human heart with profoundly different activation kinetics," EMBO J., vol. 18, no. 9, pp. 2323-2329, May 1999. 
[84] T. M. Ishii, M. Takano, L. H. Xie, A. Noma, and H. Ohmori, "Molecular characterization of the hyperpolarization-activated cation channel in rabbit heart sinoatrial node," J. Biol. Chem., vol. 274, no. 18, pp. 12835-12839, Apr. 1999.

[85] T. Vaccari, A. Moroni, M. Rocchi, L. Gorza, M. E. Bianchi, M. Beltrame, and D. DiFrancesco, "The human gene coding for HCN2, a pacemaker channel of the heart," Biochim. Biophys. Acta, vol. 1446, no. 3, pp. 419-425, Sep. 1999.

[86] E. A. Accili, C. Proenza, M. Baruscotti, and D. DiFrancesco, "From funny current to HCN channels: 20 years of excitation," News Physiol. Sci. Int. J. Physiol. Prod. Jointly Int. Union Physiol. Sci. Am. Physiol. Soc., vol. 17, pp. 32-37, Feb. 2002.

[87] R. B. Robinson and S. A. Siegelbaum, "Hyperpolarization-activated cation currents: from molecules to physiological function," Annu. Rev. Physiol., vol. 65, pp. 453-480, 2003.

[88] A. Bucchi, A. Tognati, R. Milanesi, M. Baruscotti, and D. DiFrancesco, "Properties of ivabradine-induced block of HCN1 and HCN4 pacemaker channels," J. Physiol., vol. 572, no. Pt 2, pp. 335-346, Apr. 2006.

[89] I. Koncz, T. Szél, M. Bitay, E. Cerbai, K. Jaeger, F. Fülöp, N. Jost, L. Virág, P. Orvos, L. Tálosi, A. Kristóf, I. Baczkó, J. G. Papp, and A. Varró, "Electrophysiological effects of ivabradine in dog and human cardiac preparations: potential antiarrhythmic actions," Eur. J. Pharmacol., vol. 668, no. 3, pp. 419-426, Oct. 2011.

[90] A. Bucchi, M. Baruscotti, M. Nardini, A. Barbuti, S. Micheloni, M. Bolognesi, and D. DiFrancesco, "Identification of the molecular site of ivabradine binding to HCN4 channels," PloS One, vol. 8, no. 1, p. e53132, 2013.

[91] P. Bois, J. Bescond, B. Renaudon, and J. Lenfant, "Mode of action of bradycardic agent, S 16257, on ionic currents of rabbit sinoatrial node cells," Br. J. Pharmacol., vol. 118, no. 4, pp. 1051-1057, Jun. 1996.

[92] A. El Chemaly, C. Magaud, S. Patri, C. Jayle, R. Guinamard, and P. Bois, "The heart ratelowering agent ivabradine inhibits the pacemaker current I(f) in human atrial myocytes," $J$. Cardiovasc. Electrophysiol., vol. 18, no. 11, pp. 1190-1196, Nov. 2007.

[93] D. Dobrev, A. Friedrich, N. Voigt, N. Jost, E. Wettwer, T. Christ, M. Knaut, and U. Ravens, "The G protein-gated potassium current $\mathrm{I}(\mathrm{K}, \mathrm{ACh})$ is constitutively active in patients with chronic atrial fibrillation," Circulation, vol. 112, no. 24, pp. 3697-3706, Dec. 2005.

[94] N. Hashimoto, T. Yamashita, and N. Tsuruzoe, "Tertiapin, a selective IKACh blocker, terminates atrial fibrillation with selective atrial effective refractory period prolongation," Pharmacol. Res. Off. J. Ital. Pharmacol. Soc., vol. 54, no. 2, pp. 136-141, Aug. 2006.

[95] T. Kobayashi and K. Ikeda, "G protein-activated inwardly rectifying potassium channels as potential therapeutic targets," Curr. Pharm. Des., vol. 12, no. 34, pp. 4513-4523, 2006.

[96] Y. Hara and K. Kizaki, "Antimalarial drugs inhibit the acetylcholine-receptor-operated potassium current in atrial myocytes," Heart Lung Circ., vol. 11, no. 2, pp. 112-116, 2002.

[97] H. Nakaya, Y. Furusawa, T. Ogura, M. Tamagawa, and H. Uemura, "Inhibitory effects of JTV519, a novel cardioprotective drug, on potassium currents and experimental atrial fibrillation in guinea-pig hearts," Br. J. Pharmacol., vol. 131, no. 7, pp. 1363-1372, Dec. 2000. 
[98] T. Matsuda, M. Ito, S. Ishimaru, N. Tsuruoka, T. Saito, N. Iida-Tanaka, N. Hashimoto, T. Yamashita, N. Tsuruzoe, H. Tanaka, and K. Shigenobu, "Blockade by NIP-142, an antiarrhythmic agent, of carbachol-induced atrial action potential shortening and GIRK1/4 channel," J. Pharmacol. Sci., vol. 101, no. 4, pp. 303-310, Aug. 2006.

[99] N. Inomata, T. Ohno, T. Ishihara, and N. Akaike, "Antiarrhythmic agents act differently on the activation phase of the ACh-response in guinea-pig atrial myocytes," Br. J. Pharmacol., vol. 108, no. 1, pp. 111-115, Jan. 1993.

[100] Y. Watanabe, Y. Hara, M. Tamagawa, and H. Nakaya, "Inhibitory effect of amiodarone on the muscarinic acetylcholine receptor-operated potassium current in guinea pig atrial cells," $J$. Pharmacol. Exp. Ther., vol. 279, no. 2, pp. 617-624, Nov. 1996.

[101] D. McKinnon, "Molecular identity of Ito: Kv1.4 redux," Circ. Res., vol. 84, no. 5, pp. 620-622, Mar. 1999.

[102] G. Y. Oudit, Z. Kassiri, R. Sah, R. J. Ramirez, C. Zobel, and P. H. Backx, "The molecular physiology of the cardiac transient outward potassium current (I(to)) in normal and diseased myocardium," J. Mol. Cell. Cardiol., vol. 33, no. 5, pp. 851-872, May 2001.

[103] K. Sankaranarayanan, A. Varshney, and M. K. Mathew, "N type rapid inactivation in human Kv1.4 channels: functional role of a putative C-terminal helix," Mol. Membr. Biol., vol. 22, no. 5, pp. 389-400, Oct. 2005.

[104] Z. Q. Sun, G. P. Thomas, and C. Antzelevitch, "Chromanol 293B inhibits slowly activating delayed rectifier and transient outward currents in canine left ventricular myocytes," $J$. Cardiovasc. Electrophysiol., vol. 12, no. 4, pp. 472-478, Apr. 2001.

[105] W. H. Xu, W. Li, H. W. Yue, and X. L. Wang, "Characteristics of transient outward K+ current in human atrial cardiomyocytes," Zhongguo Yao Li Xue Bao, vol. 19, no. 5, pp. 481-485, Sep. 1998.

[106] Y. Liang, X. M. Sun, and X. L. Wang, "Properties of transient outward potassium current and inward rectifier potassium current in immature human atrial myocytes," Zhongguo Yao Li Xue Bao, vol. 20, no. 11, pp. 1005-1010, Nov. 1999.

[107] K. Uese, N. Hagiwara, T. Miyawaki, and H. Kasanuki, "Properties of the transient outward current in rabbit sino-atrial node cells," J. Mol. Cell. Cardiol., vol. 31, no. 11, pp. 1975-1984, Nov. 1999.

[108] J. T. Limberis, Z. Su, B. F. Cox, G. A. Gintant, and R. L. Martin, “Altering extracellular potassium concentration does not modulate drug block of human ether-a-go-go-related gene (hERG) channels," Clin. Exp. Pharmacol. Physiol., vol. 33, no. 11, pp. 1059-1065, Nov. 2006.

[109] Z.-L. Mo, T. Faxel, Y.-S. Yang, R. Gallavan, D. Messing, and A. Bahinski, "Effect of compound plate composition on measurement of hERG current IC(50) using PatchXpress," $J$. Pharmacol. Toxicol. Methods, vol. 60, no. 1, pp. 39-44, Aug. 2009.

[110] L. Guo and H. Guthrie, "Automated electrophysiology in the preclinical evaluation of drugs for potential QT prolongation,” J. Pharmacol. Toxicol. Methods, vol. 52, no. 1, pp. 123-135, Aug. 2005 . 
[111] S. Rezazadeh, J. C. Hesketh, and D. Fedida, "Rb+ flux through hERG channels affects the potency of channel blocking drugs: correlation with data obtained using a high-throughput $\mathrm{Rb}+$ efflux assay," J. Biomol. Screen., vol. 9, no. 7, pp. 588-597, Oct. 2004.

[112] R. A. Pearlstein, R. J. Vaz, J. Kang, X.-L. Chen, M. Preobrazhenskaya, A. E. Shchekotikhin, A. M. Korolev, L. N. Lysenkova, O. V. Miroshnikova, J. Hendrix, and D. Rampe, "Characterization of HERG potassium channel inhibition using CoMSiA 3D QSAR and homology modeling approaches," Bioorg. Med. Chem. Lett., vol. 13, no. 10, pp. 1829-1835, May 2003.

[113] N. K. Jurkiewicz and M. C. Sanguinetti, "Rate-dependent prolongation of cardiac action potentials by a methanesulfonanilide class III antiarrhythmic agent. Specific block of rapidly activating delayed rectifier K+ current by dofetilide," Circ. Res., vol. 72, no. 1, pp. 75-83, Jan. 1993.

[114] M. Weerapura, S. Nattel, D. Chartier, R. Caballero, and T. E. Hébert, “A comparison of currents carried by HERG, with and without coexpression of MiRP1, and the native rapid delayed rectifier current. Is MiRP1 the missing link?," J. Physiol., vol. 540, no. Pt 1, pp. 15-27, Apr. 2002.

[115] C. Möller and H. Witchel, "Automated electrophysiology makes the pace for cardiac ion channel safety screening," Front. Pharmacol., vol. 2, p. 73, 2011.

[116] B. D. Guth, S. Germeyer, W. Kolb, and M. Markert, "Developing a strategy for the nonclinical assessment of proarrhythmic risk of pharmaceuticals due to prolonged ventricular repolarization," J. Pharmacol. Toxicol. Methods, vol. 49, no. 3, pp. 159-169, Jun. 2004.

[117] G. E. Kirsch, E. S. Trepakova, J. C. Brimecombe, S. S. Sidach, H. D. Erickson, M. C. Kochan, L. M. Shyjka, A. E. Lacerda, and A. M. Brown, "Variability in the measurement of hERG potassium channel inhibition: effects of temperature and stimulus pattern," J. Pharmacol. Toxicol. Methods, vol. 50, no. 2, pp. 93-101, Oct. 2004.

[118] C. Wolpert, R. Schimpf, C. Giustetto, C. Antzelevitch, J. Cordeiro, R. Dumaine, R. Brugada, K. Hong, U. Bauersfeld, F. Gaita, and M. Borggrefe, "Further insights into the effect of quinidine in short QT syndrome caused by a mutation in HERG," J. Cardiovasc. Electrophysiol., vol. 16, no. 1, pp. 54-58, Jan. 2005.

[119] T. Vormberge, M. Hoffmann, and H. Himmel, "Safety pharmacology assessment of druginduced QT-prolongation in dogs with reduced repolarization reserve," J. Pharmacol. Toxicol. Methods, vol. 54, no. 2, pp. 130-140, Oct. 2006.

[120] M. J. Perrin, P. W. Kuchel, T. J. Campbell, and J. I. Vandenberg, "Drug binding to the inactivated state is necessary but not sufficient for high-affinity binding to human ether-à-gogo-related gene channels," Mol. Pharmacol., vol. 74, no. 5, pp. 1443-1452, Nov. 2008.

[121] J. P. Lees-Miller, C. Kondo, L. Wang, and H. J. Duff, "Electrophysiological characterization of an alternatively processed ERG K+ channel in mouse and human hearts," Circ. Res., vol. 81, no. 5, pp. 719-726, Nov. 1997.

[122] B. London, M. C. Trudeau, K. P. Newton, A. K. Beyer, N. G. Copeland, D. J. Gilbert, N. A. Jenkins, C. A. Satler, and G. A. Robertson, "Two isoforms of the mouse ether-a-go-go-related gene coassemble to form channels with properties similar to the rapidly activating component of the cardiac delayed rectifier K+ current," Circ. Res., vol. 81, no. 5, pp. 870-878, Nov. 1997. 
[123] E. M. C. Jones, E. C. Roti Roti, J. Wang, S. A. Delfosse, and G. A. Robertson, "Cardiac IKr channels minimally comprise hERG 1a and 1b subunits," J. Biol. Chem., vol. 279, no. 43, pp. 44690-44694, Oct. 2004.

[124] H. Sale, J. Wang, T. J. O’Hara, D. J. Tester, P. Phartiyal, J.-Q. He, Y. Rudy, M. J. Ackerman, and G. A. Robertson, "Physiological properties of hERG $1 \mathrm{a} / 1 \mathrm{~b}$ heteromeric currents and a hERG 1b-specific mutation associated with Long-QT syndrome," Circ. Res., vol. 103, no. 7, pp. e81-95, Sep. 2008.

[125] T. V. McDonald, Z. Yu, Z. Ming, E. Palma, M. B. Meyers, K. W. Wang, S. A. Goldstein, and G. I. Fishman, "A minK-HERG complex regulates the cardiac potassium current I( $\mathrm{Kr})$," Nature, vol. 388, no. 6639, pp. 289-292, Jul. 1997.

[126] G. W. Abbott, F. Sesti, I. Splawski, M. E. Buck, M. H. Lehmann, K. W. Timothy, M. T. Keating, and S. A. Goldstein, "MiRP1 forms IKr potassium channels with HERG and is associated with cardiac arrhythmia," Cell, vol. 97, no. 2, pp. 175-187, Apr. 1999.

[127] S. Kupershmidt, I. C.-H. Yang, K. Hayashi, J. Wei, S. Chanthaphaychith, C. I. Petersen, D. C. Johns, A. L. George, D. M. Roden, and J. R. Balser, "The IKr drug response is modulated by KCR1 in transfected cardiac and noncardiac cell lines," FASEB J. Off. Publ. Fed. Am. Soc. Exp. Biol., vol. 17, no. 15, pp. 2263-2265, Dec. 2003.

[128] A. Varró and I. Baczkó, "Cardiac ventricular repolarization reserve: a principle for understanding drug-related proarrhythmic risk," Br. J. Pharmacol., vol. 164, no. 1, pp. 14-36, Sep. 2011.

[129] A. Varró and I. Baczkó, "Possible mechanisms of sudden cardiac death in top athletes: a basic cardiac electrophysiological point of view," Pflüg. Arch. Eur. J. Physiol., vol. 460, no. 1, pp. 31-40, Jun. 2010. 